\title{
Barriers To Growth In Ontario's VQA Wine Industry
}

\author{
By \\ Rod Story \\ Bachelor of Business Administration (Carleton)
}

\author{
A thesis submitted to the \\ Faculty of Graduate Studies and Research \\ in partial fulfillment \\ of the requirements for the degree of \\ Master of Business Administration \\ Eric Sprott School of Business \\ Carleton University \\ Ottawa, Ontario
}

September 15, 2005

(c) Rod Story 2005 


$\begin{array}{ll}\begin{array}{l}\text { Library and } \\ \text { Archives Canada }\end{array} & \begin{array}{l}\text { Bibliothèque et } \\ \text { Archives Canada }\end{array} \\ \begin{array}{l}\text { Published Heritage } \\ \text { Branch }\end{array} & \begin{array}{l}\text { Direction du } \\ \text { Patrimoine de l'édition }\end{array} \\ \begin{array}{l}\text { 395 Wellington Street } \\ \text { Ottawa ON K1A ON4 }\end{array} & \begin{array}{l}\text { 395, rue Wellington } \\ \text { Ottawa ON K1A ON4 } \\ \text { Canada }\end{array}\end{array}$

Your file Votre référence

ISBN: 0-494-10116-4

Our file Notre référence

ISBN: 0-494-10116-4

NOTICE:

The author has granted a nonexclusive license allowing Library and Archives Canada to reproduce, publish, archive, preserve, conserve, communicate to the public by telecommunication or on the Internet, loan, distribute and sell theses worldwide, for commercial or noncommercial purposes, in microform, paper, electronic and/or any other formats.

The author retains copyright ownership and moral rights in this thesis. Neither the thesis nor substantial extracts from it may be printed or otherwise reproduced without the author's permission.
AVIS:

L'auteur a accordé une licence non exclusive permettant à la Bibliothèque et Archives Canada de reproduire, publier, archiver, sauvegarder, conserver, transmettre au public par télécommunication ou par l'Internet, prêter, distribuer et vendre des thèses partout dans le monde, à des fins commerciales ou autres, sur support microforme, papier, électronique et/ou autres formats.

L'auteur conserve la propriété du droit d'auteur et des droits moraux qui protège cette thèse. $\mathrm{Ni}$ la thèse ni des extraits substantiels de celle-ci ne doivent être imprimés ou autrement reproduits sans son autorisation.
In compliance with the Canadian

Privacy Act some supporting forms may have been removed from this thesis.

While these forms may be included in the document page count, their removal does not represent any loss of content from the thesis.
Conformément à la loi canadienne sur la protection de la vie privée, quelques formulaires secondaires ont été enlevés de cette thèse.

Bien que ces formulaires aient inclus dans la pagination, il n'y aura aucun contenu manquant.

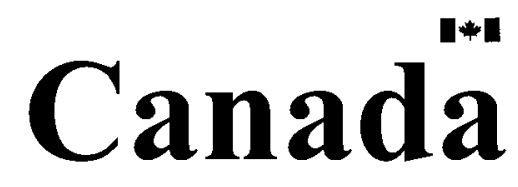




\begin{abstract}
This thesis is the first empirical study of Ontario's VQA wine industry that uses quantitative data. The thesis also proposes and partially tests a conceptual model of growth for small businesses. A literature survey covering the theory of growth and the academic articles on the wine industry in various countries is included. Survey instruments were developed (included in the Appendix) and delivered to the both the wineries and grape growers with a response rate of $79 \%$ for the wineries and $35 \%$ for the grape growers. The significant finding of this research is the projected shortfall of wine grape production in Ontario to meet the VQA wineries' projected growth plans. This shortfall is due to a combination of grape grower and winery acrimony within Ontario's VQA wine industry as well as weak planning and an over estimation of the supply by the winery owners.
\end{abstract}


Table of Contents

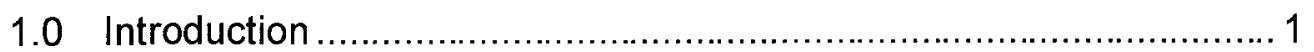

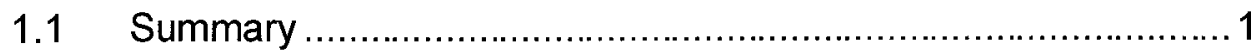

1.2 The Ontario Wine Industry Context..................................... 3

1.3 Importance of Topic........................................................ 10

2.0 Background Literature ..................................................... 12

$2.1 \quad$ Theory of Firm Growth ............................................. 12

2.2 Survey of Empirically Determined Factors Affecting Growth....... 17

2.2.1 Innovation ........................................................18

2.2.2 Intention to Grow...............................................20

2.2.3 Management Competency......................................21

2.2.4 Marketing Competency ...........................................24

2.2.5 Macroeconomic Activity ........................................26

2.2.6 Financial Flexibility.............................................27

2.2.7 Size of the Firm ..................................................29

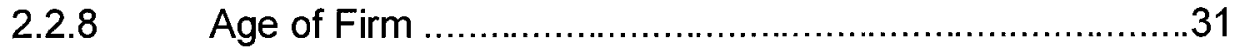

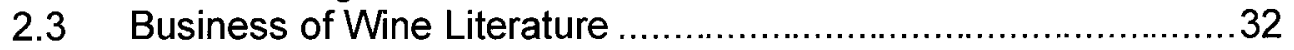

3.0 Research Premise .............................................................. 42

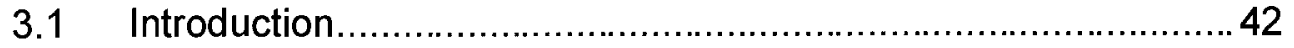

3.2 Conceptual Model for Growth ......................................... 43

3.3 Research Objectives ................................................. 47

$3.4 \quad$ Hypotheses ................................................................ 49

3.4.1 Hypotheses for Wineries ........................................52

3.4.2 Hypotheses for Grape Growers .................................53

3.4.3 Hypotheses for the Conceptual Model ..........................54

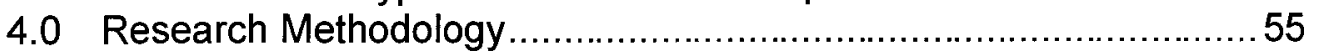

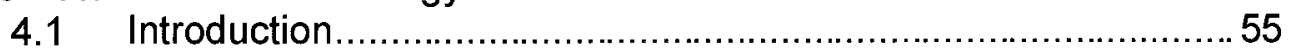

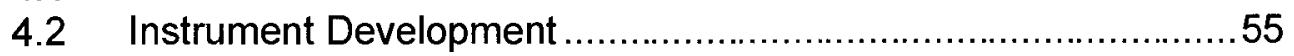

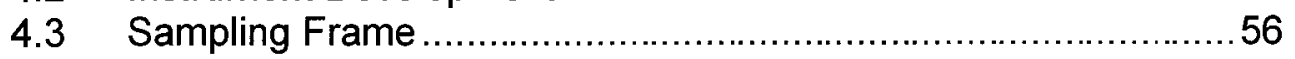

4.4 Sampling Procedure ..................................................... 56

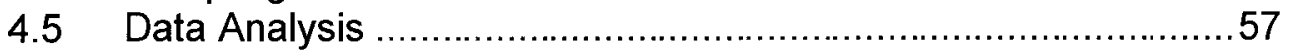

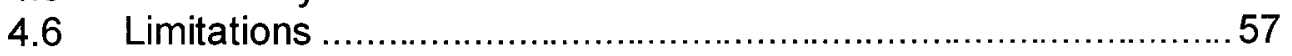

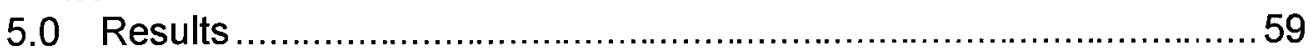

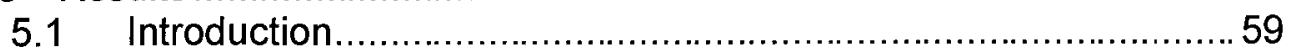

5.2 Bayesian versus Classical Statistic Interpretation ....................60

5.3 Winery Hypotheses ........................................................61 61

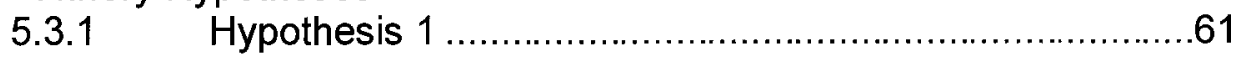

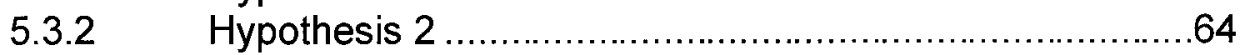

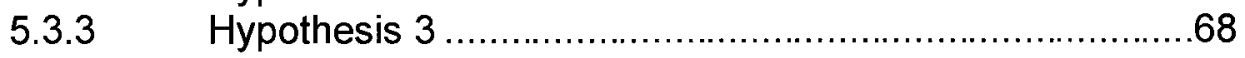

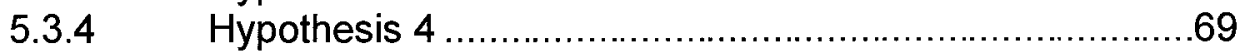

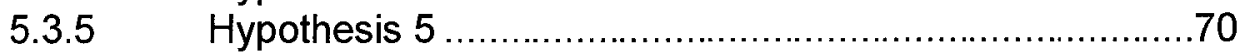

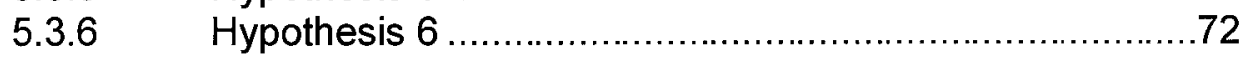

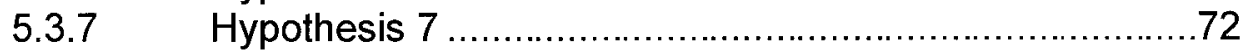

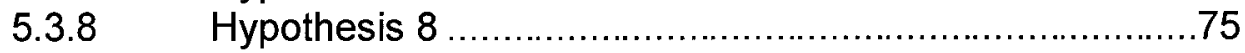

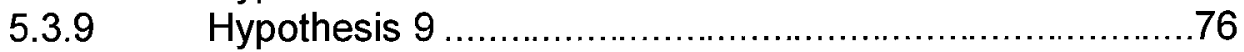


5.3.10 Summary of Winery Hypotheses and Findings .78

$5.4 \quad$ Grape Grower Hypotheses ……............................................. 80

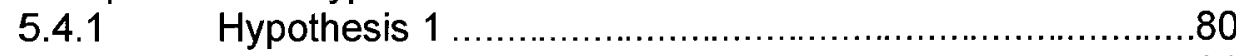

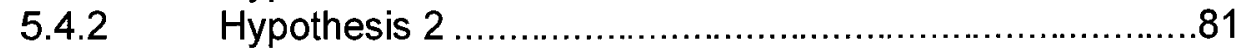

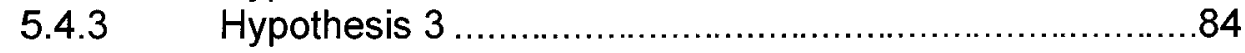

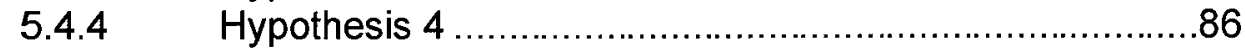

5.4.5 Hypothesis 5 …….............................................. 87

5.4.6 Summary of Grape Grower Hypotheses and Findings.....88

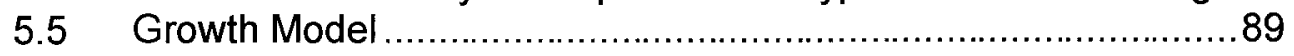

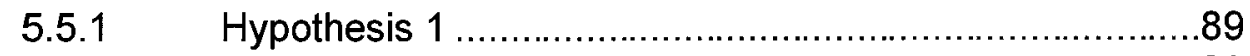

5.5.2 Hypothesis 2 .......................................................93

5.5.3 Summary of Conceptual Model Hypotheses and Findings 94

5.6 The Winery and Grape Grower Dynamic .................................. 95

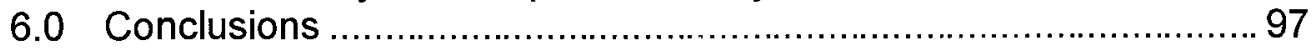

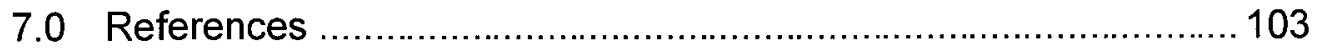

Appendix A Grape Grower Questionnaire ...................................... 108

Appendix B Winery Questionnaire...............................................114 


\section{List of Tables}

Table 1: Summary of research objectives ...............................48 48

Table 2: Summary of winery hypotheses.................................50

Table 3: Summary of grower hypotheses .............................. 51

Table 4: Summary of conceptual model hypotheses..................51

Table 5: Averages based on size of winery ..............................63 63

Table 6: Obstacles differences: new and nearly new wineries.....64

Table 7: Factors affecting growth of craft wineries ....................65

Table 8: Factors affecting growth of small wineries....................66

Table 9: Obstacles for medium-sized wineries ...........................66

Table 10: Obstacles comparison craft vs medium wineries ........66

Table 11: Obstacle comparison small vs medium wineries..........67 67

Table 12: Differences in perceived obstacles based on growing the majority of own grapes ...................................................6 68

Table 13: Comparison of obstacles/reasons between wineries wanting and not wanting to grow ................................................ 71

Table 14: Top four reasons for wineries not wanting to grow.......71

Table 15: Top four obstacle for wineries wanting to grow ............71

Table 16: Price points and volume based on winery size ........... 73

Table 17: Grape contracts and volume price differences ............ 73

Table 18: Marketing competency comparison ........................... 76

Table 19: LCBO as obstacle by winery size ............................. 78

Table 20: Summary of winery hypotheses findings .....................79

Table 21: Comparison of perceived obstacles for those not wanting to grow and wanting to grow................................................. 82

Table 22: Top reasons why growers don't want to grow ............. 82

Table 23: Top obstacles for growers wanting to grow ................ 83

Table 24: Grower contracts and winery relationship scores........ 84

Table 25: Primary income grape grower and contracts...............85

Table 26: Not primary income grape grower and contracts .........85

Table 27: Effects of paying a premium for specific viticulture techniques .................................................................... 86

Table 28: Comparison of grower perception of obstacles based on viticulture specifications in contracts .................................. 88

Table 29: Summary of grower hypotheses findings .................. 89

Table 30: Summary of conceptual model hypotheses findings ... 94

Table 31: Comparing wineries and grape growers..................... 95 


\section{List of Figures}

Figure 1: Conceptual model for growth..............................44 


\subsection{Introduction}

\subsection{Summary}

From a survey of the literature, press and statistics, it becomes obvious that Ontario's as well as the world's wine industry has undergone tremendous growth and change over the past 10 years. The literature survey also shows that Ontario's VQA wine industry has been growing very rapidly and is poised for continued growth. But is this what the wineries and grape growers believe? How many of them actually want to grow? Are there factors that aren't apparent that are or could be barriers to growth for this economically valuable industry? These barriers could be financial, marketing, or regulatory to name but a few. Are there actions which the various levels of government, the Wine Council, the Grape Growers or the LCBO could be taking to enhance the opportunities for growth? These are the questions which this thesis intends to answer.

Growth in the context of this research is defined by Penrose $(1959, \mathrm{p} 1)$ when she states that growth "sometimes denotes merely increase in amount" or it can mean "an increase in size or an improvement in quality as a result of a process development". For the purpose of the research, growth is not limited to an increase in production, staff, quality, price or assets, but can include both forward and backward integration (winery planting more grapes or a grape grower becoming a winery) and diversifying the business by adding a restaurant or accommodation.

Up until now, there have been no published empirical business studies on Ontario's wine industry. Through the use of a survey instrument, this study determines what the winery owners and grape growers of Ontario think are the barriers which hinder their 
growth. Important to this survey was determining which of these stakeholders intend to grow.

This thesis also attempted to extend the empirical theory of growth of a firm. A review of the empirical research literature identified eight factors which affect the growth of the firm, but no models incorporating these factors were found. Given this apparent gap in the literature, a conceptual model for firm growth was developed using these eight factors. A further objective of the survey was to test the validity of this model.

A total of 59 out of a possible 75 VQA wineries responded to the survey which was a $79 \%$ response. The grape grower response rate was $34 \%$ representing $17.5 \%$ of the Ontario wine grape growers.

Highlights of the findings from this study are that $90 \%$ of the wineries surveyed intend on growing, versus $45 \%$ of the grape growers. The wineries' response is much greater than the more typical 50\% number for other types of small businesses. This unequal growth rate between the wineries and grape growers resulted in a projected shortfall in grape supply to match the wineries' wine volume increase projections in two years ( $41 \%$ increase in volume and only $11 \%$ increase in planting). Furthermore, the satisfaction of the grape grower in the winery and grape grower relationship is much lower than that of the wineries making it unlikely that the grape growers are going to increase their production unless their situation improves. The top three obstacles for wineries wanting to grow are taxes, the $\mathrm{LCBO}$ and government regulations. The top three obstacles for grape growers are the Wine Content Act, price of grapes and the cost of land. Lastly, in testing the conceptual model it was found that the size of the winery is positively correlated with its financial flexibility while marketing competency is 
negatively correlated with financial flexibility. Marketing competency being negatively correlated seems contradictory, but it could be a result of the outside capital markets unwillingness to invest in the aggressive growth plans associated with those wineries that have higher levels of market competency. The capital markets may think that there is a maximum rate at which it is possible to grow a winery and it would be foolish to invest beyond this point. Alternatively, the metric for measuring marketing competency could be at fault.

The remainder of this thesis is organized as follows. The next subsection gives background information about Ontario's wine industry and how it fits within the current world market for wine. Following this, the last subsection of the introduction, gives reasons why this research is important to various stakeholders. The next section looks at the research literature of business growth. This section consists of a discussion of the current theories used to explain the growth of a firm, a description of the factors affecting growth as identified by the empirical research literature and lastly a survey of the business research literature that currently exists on the wine industry in general and Canada's wine industry specifically. The third section of this study deals with the research premise, detailing the research objectives, conceptual model of growth, and hypotheses. Next, the research methodology is explained followed by a section detailing the research results with the last section being the conclusions.

\subsection{The Ontario Wine Industry Context}

World wide competition in the selling of wine has never been more intense. The old world producers of Europe are under assault by the new world producers of Australia, California, and Chile (Echikson, 2004). Central to this intense competition is a world 
wide glut of wines: "between 1998 and 2002 Australia produced nearly a billion litres more wine than it sold (para.7, Fickling, 2003)". The current thought is that this excess has to be dumped. The Bordeaux wine producers are experiencing a glut as well. Of the current 10,000 Bordeaux producers, "600 to 1,000 smaller producers may be forced to close over the next few years" because they can't find a market for their wine (para.3, Prial, 2004). In the midst of this fray is Ontario which is a small player by global standards with respect to production, producing less than a quarter of one percent of the world's wine (Madill, Riding and Haines, 2003). Even within its own provincial market, Ontario produced wine (VQA and non-VQA) only has a 39\% market share (LCBO Annual Report 2004, n.d.). By comparison, "US, France, Australia and Italy, each control over $85 \%$ of their home markets" (p. 12, The Canada Wine Industry, n.d.). Ontario and Canada export very little wine. For example, in 2003 Canada's total exports amounted to only $\$ 13.8$ million versus the $\$ 1.1$ billion that it imported (Canada's Exports, n.d.; Canada's Imports, n.d.).

Though Ontario has been making wine for over a century, it has only been since 1975 that vinifera based commercial wines have been made (Mytelka and Goertzen, 2003). This makes Ontario a newcomer to vinifera wine production when compared to countries in Europe whose wine production dates back to the Romans. Even New World regions like Chile and California have been producing vinifera wine for over 100 years due to their climate and Spanish colonial heritage.

Two factors contributed to Ontario's late adoption of vinifera-based wines. One was the belief that Ontario's climate and soil were unsuitable for growing vinifera grapes. The second was the Ontario government's refusal to license more wineries between 1927 and 
1974 (Mytelka and Goertzen, 2004). For example, there were only 6 wineries in Ontario in 1974 (Mytelka and Goertzen, 2003). By June 2004, the number of licensed wineries had grown to 120 . This number includes licenses for the same owners with wineries at different locations, non-grape wineries (apple, plum, raspberries etc.) and non-VQA wineries like Chateau Bourget in Bourget Ontario (Alcohol and Gaming Commission of Ontario). The number of wineries in the Niagara region as of June 2004 was 67 , including the Niagara College teaching winery.

Other than the wineries and grape growers themselves, there are four main players in Ontario's wine industry. One player is the Liquor Control Board of Ontario (LCBO) which is the primary retailer of alcohol in Ontario. In addition to the LCBO stores there is one store permitted at each winery and 288 grandfathered private stores (Mytelka \& Goertzen, 2004). Of these 288 private stores, 270 are owned by Vincor and Andres (Mytelka \& Goertzen, 2004). The second player is the Grape Growers of Ontario (GGO) which was "established in 1947 under the Ontario Farm Products Act" (p.44, Mytelka \& Goertzen, 2004). The GGO represents the grape growers in negotiating the prices that the vintners (and other grape processors - jams, juice, etc) will pay for the different grape varieties each year. These prices are the minimum which the vintners must pay. GGO "is financed by growers, each of whom pays fees to the board for every metric tonne of grapes sold to processors" (p. 51, Mytelka \& Goertzen, 2004). The third major player in Ontario's wine industry is the Wine Council of Ontario (WCO). The WCO is a nonprofit trade organization representing many of the wineries. The primary functions of the WCO are to perform collective marketing activities and represent the wineries in negotiations with the GGO (The Year in Review, n.d.). The WCO is funded by the 
member wineries with membership being optional. The fourth and most influential player in the Ontario's wine industry is the Ontario government through its laws and regulations. The Ontario government creates the rules by which all the others players interact and from time to time these rules change affecting one or more of the players.

Given the current world glut of wine and the fierce competition, one would think that the outlook would be bleak for Ontario's wine producers. This is not necessarily the case. There is evidence that those wineries producing premium and super premium wines are still finding a market for their wines though not necessarily at the prices they would like (Echikson, 2004; Glut sours, 2004). The growth in the number of wineries being created in the Niagara region in the past three and a half years has been significant, most of which produce premium and super premium wines. This appears to support the case that there is a growing market for quality wines. From the time Ontario ended its moratorium on issuing winery licenses in 1975 until the end of 2000, 34 wineries were created (Mytelka and Goertzen, 2003). In the three and a half years since 2000 an additional 30 wineries have been created almost doubling the number created in the previous 26 years! It should be noted that any winery created after June 13, 1993 can only sell wine in Ontario made using 100\% Ontario grapes. The content rules allowing wineries to blend up to $70 \%$ (90\% in certain years) of imported wine or grapes only applies to those wineries licensed before this time ${ }^{1}$.

Given this information, the owners of all these new wineries must believe that it is possible to generate a profit from making VQA wine. The argument can also be made

\footnotetext{
${ }^{1}$ For the sake of accuracy, it is still possible to get a winery license to manufacture wines using foreign content but these establishments can't have a retail store and can't sell their product to the LCBO. They can sell their product out of province or country or (and this is the interesting part) they can sell directly to restaurants in Ontario, but they have to pay the $58 \%$ LCBO mark-up unlike VQA direct delivery.
} 
that these new wineries are focusing on the premium and super premium markets since they don't have the economy of scale or the opportunity to use foreign grapes/wine to compete in the low end of the market. Vincor, Canada's largest winery and North America's fourth largest winery, states in their annual report that "premium branded wines, priced above $\mathrm{CDN} \$ 10 /$ bottle, are the fastest growing and, as a result, the commercially most important price segment of the international wine market" (Vincor Annual Report 2004, n.d.). Further supporting the idea that premium and super premium wines are a growing market is the sales statistics of Ontario VQA and non-VQA wine. According to the GGO's annual report, 2003 VQA wine sales in Ontario by volume increased by $23 \%$ to 10.1 million litres while non VQA sales decreased by $3 \%$ to 34.1 million litres (GGO Annual Report 2004, n.d.).

Even though VQA sales increased at a dramatic rate, it wasn't enough to overcome the $5.4 \%$ increase in imported wine resulting in a volume of 66.7 million litres (GGO Annual Report 2004, n.d.). The end result was that the "market share for Ontario wines decreased from $40.3 \%$ to $39.9 \%$ in 2003 " (p.13, GGO Annual Report 2004, n.d.). Ontario wines include both VQA and blended wines that use imported wine or grapes. It should be noted that an objective of the LCBO in its 2003 annual report is "to build Ontario wines' market share in litres to 50 per cent over the next five years" (p.32, LCBO Annual Report 2003, n.d.). This research is concerned with the growth of the Ontario VQA wine industry (which is growing rapidly) and not the Ontario blended foreign content wine industry (which is shrinking).

From a financial viewpoint, so far very few wineries in Niagara have failed and for those that have, "it has been due to their lack of initial capitalization" (p. 29, Bramble et 
al., 2004). More importantly, Ontario's wine industry has considerable economic impact. "The industry generates approximately $\$ 724,000,000$ in sales and another $\$ 360,000,000$ in induced sales" for a total of over one billion dollars (p. 45, Bramble et al., 2004). Induced sales that are a result of the wine industry (made by tourists visiting the area and employees) that are not direct purchases of wine. The provincial and federal governments receive $\$ 196,500,000$ in taxes and fees from the wine industry (Bramble et al., 2004). Therefore the wine industry contributes considerably to Ontario's economy and its continued well being is in the best interest of the various levels of government.

So in summary, the world market for wine under $\$ 10$ is saturated but the market for wines above this price is growing. Within the Ontario context, the number of VQA wineries are growing rapidly as is the volume of VQA wine being sold. From 2001 to 2003 , the volume of VQA wine sold has increased by $44 \%$ or a $20 \%$ annualized growth rate (GGO Annual Report 2004, n.d.). Given the recent rapid increase in the number of wineries, the additional new volume that these wineries produce will be available to sustain these large annual increases in VQA wine sold.

From the GGO perspective, there was a concern in both 2001 and 2002 that all the wine grapes were not going to be bought but in the end all grapes were purchased (GGO Annual Report 2002\&2003, n.d.; G. Walker of GGO, personal conversation, July 9, 2004). Then the winter of 2002-2003 was quite harsh resulting in vine dieback such that the wine grape production dropped from 43,700 tonnes in 2002 to 26,239 tonnes in 2003 (GGO Annual Report 2004, n.d.). With the reduction in the wine grape harvest, those wineries which can blend in foreign grapes and wine sought and received a temporary reduction in the Ontario grape content required for cellared in Canada designated wines. 
The amount of Ontario grapes which is required has been reduced to $10 \%$ from $30 \%$ until February 1, 2005 (Wine Content and Labelling Act). This temporary change in content rules allows more grapes to be directed to VQA wine production such that the effects of the harsh winter would not decrease the VQA wine production (G. Walker of GGO, personal conversation, July 9, 2004). In addition to lowering the content percentage for those wineries that could blend, the ability to blend foreign content was extended to the post mid-1993 licensed wineries for the 2003 harvest year as well. These wineries could only blend wine to make up for any shortfall caused by the short crop. They could not increase their production above their average growth rate $^{2}$. This was the second time this temporary permission for blending had been allowed. It was done in 1993 as a result of a short crop in that year. With the reduction in grape production in 2003 and the growth in the number of wineries, the concern about there being a surplus of wine grapes has disappeared for the time being (G. Walker of GGO, personal conversation, July 9, 2004). The number of VQA wineries has been growing at a significant rate. The volume of VQA wine that has been sold has increased dramatically as well. Furthermore the premium wine market which these new wineries are targeting is also predicted to grow. Therefore, on the surface the prospect for Ontario's VQA wine industry looks promising so long as the market for premium wine continues to grow as predicted.

\footnotetext{
${ }^{2}$ How many of the VQA only wineries have taken up this option to use foreign content? Given that their existing market is all VQA, to whom are they going to sell this wine? Given that it takes several years to establish a sales channel for a new product and that they only can do this for one year, I wonder if the costs outweigh the benefits. An analysis of this would be an interesting research topic.
} 


\subsection{Importance of Topic}

Investigating the barriers to growth in Ontario's wine industry has value for academia, the various organizations involved in the wine industry, the different levels of government, and the wineries and grape growers themselves.

From an academic perspective, this study has benefits on two different levels. On the more micro-level of business of wine research, it is the first empirical business study on any part of Canada's wine industry. Canada's wine industry, from a VQA perspective, includes British Columbia (BC) and Ontario. Up until now, all the wine research papers have been based on personal interviews with a subset of the winery owners/grape growers. No study has successfully used a survey instrument targeting all owners/growers. On a macro-level, this research attempts to extend the empirical knowledge of business growth by presenting a conceptual model for growth using the eight factors determined by a review of the empirical research literature. This model is then tested using the wine industry. Proving the validity of this conceptual model will contribute to our understanding about firm growth. Independent of the success of the model, the study will further the research into the various factors affecting business growth, as it applies to the wine industry, including the influence of the desire to grow on the part of the winery owner and grape grower. Lastly, this study will provide some insight into how traditional business growth theory applies to the wine industry.

There are numerous wine bodies in Ontario, Canada and around the world. As mentioned earlier the primary ones in Ontario are the Wine Council and the Grape Growers but there is also VQA Ontario. Since a major purpose of all these organizations is to improve the well-being of their constituents, this study will provide valuable 
information that can be used to develop future beneficial strategies for the industry. Even though the study focuses on the Ontario wine industry, there are enough similarities with the wine industry in $\mathrm{BC}$ that this study will have applicability there as well. In BC there is the $\mathrm{BC}$ Wine Institute, Association of $\mathrm{BC}$ Winegrowers as well as several different grape grower associations (Hickton and Padmore, 2004). As of 1999/2000, BC no longer has a grape marketing board. All grape growers are individually responsible for negotiating their own prices and contracts with the wineries. Currently there is no single organization representing the grape growers and many growers don't belong to any organization (J. Sandhu, industry specialist with British Columbia government, personal conversation, September 22, 2004).

This study is important to the various levels of government as well. As stated earlier, Ontario's wine industry is an economically important industry providing both jobs and tax revenues. In addition governments are responsible for various laws, policies, programs, and regulations that can influence the well being of the wine industry. The findings of this study might influence them to make changes.

Last but not least are the benefits to the wineries and grape growers themselves. Up until now, these important players have not had the opportunity to have their opinions about the barriers to growth in the region analyzed in an empirical manner. It is not clear if the subset of stakeholders used in previous studies were representative of the whole. In addition there is nothing in the literature with regards to differences based on size of winery or when it was founded. There could possibly be differences along these dimensions (covariates). This study attempts to give both an accurate collective voice to the players as well as determining if there are differences depending on the covariates 
used for the analysis. No matter the outcome, the wineries and the grape growers will have a much better understanding of what their peers collectively agree are the barriers which may in turn get them to make changes for the better on an individual and/or collective level.

\subsection{Background Literature}

\subsection{Theory of Firm Growth}

The growth of the firm has been studied from both a theoretical and empirical viewpoint. This research has resulted in numerous theories of firm growth. A summary of the current theories is described by Orser and Hogarth-Scott (2002). In their paper they describe six popular theories which are: biological model of small firm growth; macroeconomic activity theory which is also known as ecology theory (Lohmann, 1998); economic theory; disequilibrium theory (dynamic capitalism) of Kirchhoff (1994) which is a refinement of Schumpeter's (1942) creative destruction theory; population ecology theory; and resource exchange theory which is more commonly known as resource-based view (RBV) by Thornhill \& Amit (2003), Rugman \& Verbeke (2002, 2004), Kor \& Mahoney (2004) and others or resource based theory by Lohmann (1998). The relationship between these theories for firm growth will be discussed in more depth after first giving a brief description of each theory.

The biological model has the lifecycle of a small firm follow that of human development from conception through multiple steps finally reaching maturity and decline (Orser \& Hogarth-Scott, 2002). Orser et al. cite considerable empirical evidence showing this theory does not hold up in reality. 
Macro-economic or ecology theory has as its tenet that growth is determined by the economic environment in which the firm is located (Orser \& Hogarth-Scott, 2002, Lohmann, 1998). There is no doubt that the economic environment has an influence as a confounding variable in affecting firm growth but it is not the main factor deciding if a firm will grow, stagnate or fail (Baldwin 1995, Baldwin et. al 2000).

Economic theory is the classical definition of growth which has profit maximization as the impetus driving growth (Orser \& Hogarth-Scott, 2002, Rugman \& Verbeke, 2004). Firms consciously make decisions and tradeoffs based on which path will lead to the greatest profits. If successful, a firm in pursuit of maximum profits grows. Though economic theory is valid in the sense that firms need to make profits in order to remain in existence and that firms make decisions that they will hope will lead to profits, it doesn't adequately explain all the variables which cause one firm to grow and another to stagnate or fail given the vast majority of firms start out with the best intentions of making a profit.

As mentioned above, Kirchhoff's (1994) disequilibrium theory (or dynamic capitalism which is the term Kirchhoff uses in his book) is a refinement of Schumpeter's (1942) creative destruction theory. Schumpeter (p. 83, 1942) defined creative destruction as a process that "incessantly revolutionizes the economic structure from within, incessantly destroying the old one, incessantly creating a new one." The are many examples of this occurring in the world like the Swiss watch industry being overtaken by digital watches and minicomputer manufactures like DEC and Wang being overtaken by PCs. An example of this process in action in the wine industry is the adoption of advanced, quality winemaking by the new world causing dramatic changes in Bordeaux 
as described earlier in this paper. Schumpeter thought that capitalism would eventually fail because innovation would be the exclusive domain of the large firms which would then shut out the entrepreneurs, eliminating creative destruction which in turn would lead to socialism in order to facilitate wealth distribution (Kirchhoff, 1994). Kirchhoff (1994, Kirchhoff \& Greene 1995) suggests that creative destruction as well as capitalism is still alive and well more than 50 years after Schumpeter predicted its demise. Kirchhoff argues that small businesses are the engine of job growth and that their ability to innovate more than the large firms is the reason.

Population ecology theory originates from the work by Hannan and Freeman (1977). They theorized that organizations had inertia based on their structure and processes and that this inertia limits the rate at which the organization can adapt and change. Drawing parallels to the biological world Hannan and Freeman also theorized that unsuccessful organizational forms would either adapt or be selected out. They also empirically proved that small firms had a greater chance of failing which was contrary to pure neoclassical economic thought (Aldrich \& Fiol, 1994). In addition, population ecology borrowed from institutional theory the concept of organization legitimacy based on the need for the people in new organizations to become effective functioning units as well as having the external market accept the legitimacy of the business and how it operates (Aldrich \& Fiol, 1994; Shane, 1998). Population ecology brought sociological thought into business research as was encouraged by Granovetter (1985) and in turn helped in explaining real world situations that economic theory could not (Shane, 1998; Aldrich \& Fiol, 1994). Population ecology theory is extremely useful in explaining organizational forms, survival rates and why industries have clusters of similarly structured firms, but it is not 
in and of itself a growth theory since it doesn't delve into why firms grow in an encompassing way.

Resource based view (RBV) of firm growth originated with Edith Penrose's (1959) seminal book titled "The Theory of the Growth of the Firm". The term RBV will be used to refer to this theory throughout this paper rather than resourced based theory. It is interesting to note that Lohmann (1998) lists RBV and strategic management as separate theories of growth. In papers by Rugman \& Verbeke (2002, 2004), Kor \& Mahoney (2004) and Lockett \& Thompson (2004) they present RBV as a theory for strategic management rather than separate from it. I much prefer this latter definition since RBV is a more encompassing way in which to view firm growth.

Penrose (1959) approaches firm growth using the premise that growth is determined by resources both internal and external to the firm. Her theory takes into account organic growth such as increasing sales of existing products, adding new products, changing product focus all together, forward and backward integration, mergers and acquisitions as well as international expansion. The resources that are included in her theory are not restricted to tangible assets such as building, equipment, land etc. but include the traits of the entrepreneur and/or management, the collective knowledge and skill of the management team and their ability to combine the tangible and intangible resource at their disposal in a manner that will generate profits for the firm. Penrose takes into account the company's strategies, the people and their skills that make up the company and the business environment in which it operates.

It is my belief that Penrose's initial work provides the framework in which the aforementioned growth theories reside. Penrose agreed with Schumpeter's (1942) (and 
therefore Kirchhoff (1994)) process of creative destruction when she stated that firm research is carried out as a "logical response of the individual firm to the challenge inherent in the Schumpeterian 'process of creative destruction' (p. 112, Penrose, 1959). From a macro-economic viewpoint, Penrose acknowledges its influence while at the same time tempering its overall affect. This is best illustrated by her statement:

"Therefore, except within very broad limits, one cannot adequately explain the behaviour of firms or predict the likelihood of success merely by examining the nature of environmental conditions" (p.42, Penrose, 1959).

The viewpoint of classical economic theory that the profit motive drives all business growth doesn't explain why some businesses grow and others fail. Something else must be occurring as well which causes some firms to grow and others not to grow. The following quote best sums it up: "At all times the productive opportunity of a firm is being shaped by......internal and external inducements, and internal and external obstacles. In a certain sense each one is decisive, but nothing can be determined by looking at one of them in isolation" (p. 87, Penrose, 1959).

Lastly, population ecology looks at the organizational structure of the firm and investigates its structure and effectiveness and implicitly its survivability. The basic ideas of population ecology theory, that of inherited structure and effectiveness of an organization and its ability to overcome its own inertia, is covered by Penrose's theory of growth as illustrated by the statement describing "an appropriate form of organization inherited from the past and operated by people, also inherited from the past, who share a common tradition, who are accustomed to the organization and to each other, and who thus form and entity which works with sufficient consistency and efficiency in broad 
areas" (p.18, Penrose, 1959). The structure of an organization is also a resource consistent with RBV.

So in summary, after investigating the various growth theories it is my opinion that they all continue to build upon the foundation created by Edith Penrose (1959) and her concept of how a firm's resources internally and externally, tangible and intangible determine its growth. I view the other theories described above as subtending theories which explain the internal workings of a greater whole. Therefore I have chosen RBV as the theoretical underpinning for this study.

In the next section each of the resources which have been identified by the empirical research literature as a contributing factor to firm growth is described. These factors then form the theoretical basis for the questions contained in this study's survey instrument.

\subsection{Survey of Empirically Determined Factors Affecting Growth}

From a survey of the empirical research on business growth and failure, eight factors were determined to have an effect on the growth of a firm. Factors learned from the study of failure are considered important as well since their presence or absence will certainly affect the prospects for growth even though they don't necessarily predict growth. The eight factors in the order they will be described are innovation, intention to grow, management competency, marketing competency, macroeconomic activity, financial flexibility, size of the firm, and age of the firm.

Before presenting each factor, it is important to note that each factor does not work in isolation. Each factor interacts with the other factors in affecting growth. Therefore, included with the presentation of each factor is a brief description of how it interacts with the other factors. The purpose here is to incrementally develop a model that shows how 
the various factors affecting growth interact. No one factor is sufficient on its own to determine growth. The full growth model is explained in section 3.2 (Conceptual Model for Growth) on page 43.

\subsubsection{Innovation}

The entrepreneur who creates a new product, finds a unique way of combining a service or creates a new selling paradigm is being innovative. It seems intuitively obvious that in order to be successful and grow, a business must do something different than its competitors. What motivates a customer to buy a product or service from one firm over another? There has to be something innovative in one or more of the four PsProduct, Price, Place or Promotion. This intuitive belief that innovation is a factor influencing growth is borne out by the research. Statistics Canada has produced three works (Baldwin 1995, Johnson et al. 1997, Gellatly 1999) which together show the correlation between innovation and small firm growth, as well as differentiating the characteristics of innovative firms.

Baldwin (p. 2, 1995) says it most succinctly in his statement "Innovative activities are the most important determinants of success; that is, for a wide range of industries, they serve to discriminate between the more- and the less-successful firms better than any other variable". The paper (Baldwin, 1995) was based on a survey in 1988 of small firms which had 500 employees and less than $\$ 100$ million assets in 1984 and had grown in the four-year period. The firms were asked questions about their strategies and activities including innovating activities. The response group was divided into two equal groups based on which firms had grown the most in market share and profitability. The research 
found that the group of more successful companies had a $41 \%$ higher mean score $(.0001$ significance) on R\&D innovation than the less successful companies.

In another Statistics Canada study (p. 13, Johnson et al., 1997), it was found that "faster-growing successful entrants are almost twice as likely to innovate as slowgrowing firms". This finding was based on a study of growing firms that were created between 1983 and 1986 and were surveyed in 1996. The surveyed companies were divided into two groups based on their respective growth rates. Innovation for the purpose of the study was considered to be creating or modifying a product or process.

The third paper's (Gellatly, 1999) purpose was to study how innovative and noninnovative firms differ in order to better understand what other characteristics are associated with an innovative firm. While the previous two studies looked at a crosssection of all industries, this paper considered only business service firms. It found that innovative firms placed more importance on financial management, capital acquisition, recruiting skilled labour and incentive-based compensation. These findings are consistent with the papers described in section 2.2.3 on Management Competence. Management competencies and innovation are both found in growing firms. This is also consistent with RBV since these are resources which contribute to business success. The paper did make an additional finding that innovative firms "are more likely to report difficulties related to market success, imitation, and skill restrictions" (p. v, Gellatly, 1999). The paper presents evidence to show that innovators are more aware of these issues than noninnovators. This adds empirical credence to the motto "Only the paranoid survive" of Andrew Grove, former CEO of Intel (Grove, n.d.). 
Even though innovation has been found to be the most important factor affecting growth, it is by no means sufficient in and of itself to determine growth. Without the ability to market the innovation, the capital to productize it or the management acumen to operate the company, the firm will invariably fail.

\subsubsection{Intention to Grow}

The intention to grow on the part of the small business owner is an important determinant of firm growth. This point was made by Penrose $(p .34,1959)$ when she stated that for some people the ambition that would lead others "to expand their operations in an unending search for more profit, and perhaps greater prestige, may be lacking”. Studies by Orser \& Hogarth-Scott (2002) and Orser and Riding (2003) in addition to several citations made by Sara (1998) show that this is indeed the case.

Orser \& Hogarth-Scott (2002) in their study investigated both change in employment and change in revenues over a five-year period. They determined that those small business owners who wanted to grow increased their number of employees at almost twice the rate and their revenues at over twice the rate of those business owners who did not want to grow. These findings "were statistically significant at p-value of less than 0.025” (p. 292, Orser \& Hogarth-Scott, 2002).

Using MANCOVA (Multivariate Analysis of Covariance), Orser and Riding (2003) were able to show that the intention to grow was a significant ( $p$-value $<5 \%$ ) determinant of the variance in revenue growth between those business owners who wanted to grow and those who did not. Furthermore, using multiple regression they determined that intention to grow was a significant positive determinant $(p$-value $=.3 \%$ ) of revenue growth (management diversity and self-fulfillment were determinants as well). 
Based on the empirical findings of the above studies it is imperative that any study on growth must take into account the growth intentions of the business owner. So intention is yet another piece in the growth model. Intention is also likely to affect the level of innovation exhibited by a firm. All firms need some level of innovation in order to differentiate themselves and be successful, but the amount of innovation is likely to be influenced by the desire of the firm to grow.

\subsubsection{Management Competency}

Management competency is another dimension which seems intuitively obvious as a factor influencing firm growth. As expected there are numerous papers in the empirical literature which show the causality between management competency and firm growth as well as papers which show that a lack of management competency is associated with firm failure. Those papers showing the causality between management competency and growth will be discussed first followed by the papers showing that firm failure is often the result of poor management.

Lohmann (1998) studied the management characteristics of high-growth firms in Hawaii, a business environment that he showed to be quite adverse. As a part of his study he compared the responses of CEOs of high-growth firms to that of non-high-growth firms against various management behaviour/competency questions. For every question where there was a significant statistical difference $(p<0.05)$ between the scores, Lohmann (1998) found that the CEOs of the high-growth firms placed more importance on that behaviour/competency than their counterparts in the non-high-growth firms. The behaviours and competencies that were found to be different were internal communications, strong leadership, entrepreneur's personal impact, taking initiative, 
rapid response, managing growth, customer satisfaction focus, attention to detail, and internal locus of control. Lohmann (1998) showed that the CEOs of high-growth firms are distinct in some of their management characteristics with the implication being that these differences are an important contributing factor to firm growth.

Johnson et al. (1997) in their comparison of faster- and slower-growing successful entrants found similar behaviour/competency differences to that of Lohmann (1998). Specifically, Johnson et al. (1997) found $(p<0.05)$ that the faster-growing firms placed more emphasis on customer service, flexibility in responding to customer needs, innovation, the use of information technology, financial flexibility in meeting unforeseen circumstances, recruiting skilled employees, and providing incentive compensation plans.

Orser and Riding (2003) in their multiple regression analysis of firm growth found that management diversity was a significant $(p=0.093)$ determinant. In their study management diversity was a composite variable created by taking the respondents answers to 25 management related questions and converting it to a binary $(0,1)$ scale and then summing them. Originally each question had been answered using a 5 point scale. Answers which scored 4 or 5 were converted to a 1 and the remainder to 0 . The 25 questions came from the following functional areas of management: networking; personal care; general management; planning; marketing; operations management; finance; human resource; and management of technology.

Given that the above three studies all found that growth of firms is related to superior management competency, it should not come as a big surprise that the next two papers to be discussed show that the failure of firms is related to a lack of management competency. 
Thornhill and Amit (2003) in their paper investigated 339 Canadian bankruptcies to determine if new and old firms fail for different reasons and if these reasons can be attributed to a resourced based explanation. Questionnaires were filled out by the bankruptcy trustee assigned to the bankrupt business. Using a linear regression model, they showed that a determinant of new firm failure was a lack of management competency. Management competency in their study was measured by asking three, 5point scale questions. The questions asked were to what extent the failure was caused by deficiencies in breadth of management knowledge, depth of management knowledge and control.

Baldwin et al. (1997) looked at why firms fail using an individual firm resource based approach while not controlling for age as Thornhill and Amit (2003) did. Baldwin et al. (1997) found that inexperienced management was the prime cause of failure and that management's knowledge and vision were critical to its success. The paper found that the number of failures was almost equally split between those due to external and internal causes. One of the internal reasons for failure was found to be weakness in management due to inexperience. The paper states that of all failures, $71 \%$ were attributed to poor financial planning and then goes on to make the connection that poor financial planning is just another indicator of lack of management experience. Furthermore the paper states that even the external reasons can partially be attributed to internal reasons since the companies don't have the management competencies or experience to handle the external shocks which caused their eventual demise. Not surprisingly, the paper states that in order for a young firm to survive it must master basic management skills and as the firm ages and grows it must then learn to manage complexity, to delegate and to consult 
outside advisors. The study found a general reluctance within the failed firms to consult outside advisors whom could have potentially provided the necessary information to prevent the firms' eventual failing.

From the above investigation of the empirical papers that study growth and failure, management competency has been shown to be an important factor leading to firm growth when it is present (dependent on other factors) and firm failure when it is not (independent of other factors). With respect to an encompassing model of growth, it is apparent that management competency is required for a firm to grow but it is not the main factor causing growth. Therefore, management competency appears to be a moderating variable in the growth model. Also following from Thornhill and Amit's (2003) research, management competency is positively correlated with the age of the firm.

\subsubsection{Marketing Competency}

From conversations with business people involved in Ontario's wine industry, the comment has been made numerous times that wineries often suffer from a lack of marketing knowledge or interest. Winery owners, it is thought, are passionate about wine making but treat the business of wine selling as a necessary evil. From a survey of the empirical based literature, this could be a large handicap for Ontario's wine industry if it is true.

Johnson et al. (1997) in their paper analysing the characteristics differentiating faster and slower growing firms found that the faster growing firms were statistically significantly $(p<0.05)$ more likely to follow marketing strategies that target new foreign markets, improve position in existing markets, promote company or product reputation 
and use third-party distributors. It is interesting to note that the paper did not find a statistically significant difference for satisfying existing customers. These findings of Johnson et al. (1997) are consistent with the informal information obtained about Ontario's wine industry.

Baldwin et al. (1997) in their study of firm failures found that lack of marketing skill was the third most important factor for why firms failed with $50 \%$ of the failed firms suffering from this deficiency. They found that bankrupt firms "fail to establish a market niche" and that they fail "to get the basic product strategy correct from the very start" (p. 30, Baldwin et al., 1997). Other factors that they found contributed to the poor product strategy were poor pricing strategies and a poor location for the business.

In their study of growth strategies for small and medium enterprises, Orser and Riding (2003) found (using factor analysis) that a market development factor was the third of three growth factors that contributed to the variance. The market development factor consisted of the responses to the following three questions: seeking new international markets; selling over the internet; and expanding advertising and promotion. When ranking each firms revenue growth based on which factor was dominant, Orser and Riding (2003) found that the market development factor was a close second. The value of marketing and market development cannot be underestimated as major contributing influence to the growth of a firm.

It is important to note that marketing competency is different than marketing innovation. As described earlier, innovation is the most important factor determining growth of a firm. If the innovation is a marketing innovation, within the conceptual model this would be represented as an innovation not marketing competency. 
Nevertheless, there would most likely be a high correlation between someone who has a great marketing innovation and scoring well on a marketing competency measure. Given this separation between marketing innovation and competency, it is felt that like management competency, marketing competency has a moderating effect on the growth of the firm.

\subsubsection{Macroeconomic Activity}

Lohmann (1998) in his comparative study of high- and low-growth firms and industries in Hawaii found that there are distinct environmental differences separating the industries with high- and low-growth firms. The results were consistent across factor, discriminant and regression analysis. Consistently those industries which had a large number of firms, high total sales, high total employees, and a younger average firm age were more likely to contain high-growth firms. This intuitively makes sense because any industry that has undergone some profound innovation that has changed the market stability will have a large number of young firms which are all eagerly trying to satisfy the new market. Only once the market matures does it begin to consolidate into fewer firms with better operational efficiencies.

Thornhill and Amit (2003) in their study of business failures looked at a measure of industry change to explain why older firms fail. There hypothesis was that a firm having survived through infancy had at least managed to obtain some minimal management competencies for survival and that other factors would contribute to its demise as it aged. This thought is very similar to population ecology theory and its concept of inertia and the inability of a company to change course to confront adversity (Hannan and Freeman (1977). Thornhill and Amit's (2003) measure for industry change considered change of 
technology, change in market conditions and change in labour or industrial relations legislation. The study did find that there was a statistically significant coefficient $(p<$ $0.01)$ for the industry change predictor in the regression. Therefore industry change is a macroeconomic factor which contributes to a firm's demise. If industry change can shorten one firm's life expectancy, it most probably will reduce another firm's prospect for growth.

Baldwin et al. (2000) in their analysis of new firm failure rates looked at the effect of increased rates of GDP output on the survival rates of new firms. Their analysis confirmed what one would intuitively expect: that survival does "vary cyclically with the business cycle - a higher growth rate in real output leads to more survival" (p. 12, Baldwin et al., 2000).

So in summary, the empirical research on macroeconomic factors show that the growth stage that an industry is currently undergoing, the amount of change in an industry (regulatory or innovation) and GDP growth rates all affect a firm's ability to grow. Therefore macro factors act as moderating variables in the conceptual model for growth.

\subsubsection{Financial Flexibility}

Financial flexibility is more than just having sufficient capital to operate a firm including unforeseen circumstances. It is also having a firm's capital come from multiple sources. These sources can be classified as internal and external. Internal financing is share equity that can come from the public and/or the founders. External financing is money lent to the firm that has to be repaid (e.g. loans, bonds etc.). The empirical 
research shows that successful firms have a balance between the two types of financing with proportionally more financing being internal.

When Johnson et al. (1997) compared faster-growing firms to slower-growing firms they found that the faster-growing firms placed higher importance on financial flexibility in meeting unforeseen circumstances $(\mathrm{p}<0.05)$, used proportionally less external only financing $(p<0.05)$ and made more use of a mixture of internal and external types of financing $(p<0.10)$. These three pieces of information when put all together make intuitive sense. The more successful firms use a combination of both internal and external financing rather than exclusively external. Not relying solely on external financing buffers the firm from having all its capital called at an inopportune time allowing it to meet unforeseen circumstances.

Baldwin et al. (1997) state that of all failures, $71 \%$ were attributed to poor financial planning. Thornhill and Amit (2003), using a subset of the same data which Baldwin et al. (1997) did, found that the primary cause of failure was undercapitalization and that this was independent of age, industry or size of firm. Undercapitalization as the primary cause of failure is consistent with the previously described findings for the few failures in Ontario's wine industry (Bramble et al., 2004).

Therefore, having sufficient capital and having it come from a mixture of internal and external sources together with adequate financial planning are important factors in firm growth. Within the context of the conceptual model of growth, financial flexibility plays an interesting role. Financial flexibility is a dependent variable of the firm's management and marketing competency and the perceived value of its innovation. A firm is unlikely to raise sufficient capital from diverse sources without these factors in place. While at 
the same time, financial flexibility is an independent variable of growth because without it, a firm is unlikely to grow or at best to grow slowly based only on retained earnings. Besides financial flexibility being both a dependent and independent variable, it also has several moderating variables. Older firms with successful track records are more likely to receive funds than new firms, making age a moderating factor. Size is also a moderating factor since a larger firm has more assets which to collateralize. Lastly macro factors such as the current state of the economy have an effect on the ability of a firm to raise money.

\subsubsection{Size of the Firm}

As opposed to other things in life, when it comes to business growth and survival, size (based on the number of employees) actually does matter. The empirical literature shows that the management skills required to facilitate high growth vary with the size of the firm and that survival rates improve based on a firm's relative size to its peers in the same industry.

Rumball's (2000) paper investigates the management competencies required by high growth firms in Ontario during different stages of growth as defined by the number of employees (size). Only firms with less than 200 employees, a minimum of $\$ 2$ million in gross operating revenue and with revenue having grown by at least $50 \%$ during the 1993 1996 period were considered. The data for the paper was obtained via a detailed questionnaire which the CEOs of the firms in question responded to. The paper divided the firms into six groups based on number of employees. The employee size of each group was $0-9,10-19,20-29,30-49,50-99$, and 100+. As expected the management competencies exhibited by each firm varied depending on its size. For the small-sized 
firms, the CEO is running the whole show, hasn't got time to plan and the biggest concern is access to capital. As the firm grows through the six stages, CEOs progressively delegate more, plan more, and develop themselves and their employees more while building a full, well-rounded management organization. Rumball's (2000) study gives further empirical support to the previously described Baldwin et al. (1997) findings that young firms must master basic management skills and as they grow they must then learn to manage complexity, to delegate and to consult outside advisors.

The Baldwin et al. (p. 52, 2000) study of Canadian firm failures found that firms in an industry increased their survival rate as they became larger "relative to the first-year entrant average within that firm's industry". Therefore new firms (even mature firms for that matter) that are larger than the average new firm have a greater likelihood of surviving. Baldwin et al. (2000) also found that the larger the average entrant size is, relative to the incumbents in an industry, also increases the survival rates. From a wine industry perspective this means that so long as a winery comes into existence close to the same size as the other wineries, size should not be a determining factor for its survival and growth so long as the owner has the management skills and cashflow to operate a business of that size.

In regards to the conceptual model for growth, as described in the previous subsection, larger firms have more assets to collateralize and therefore generally have greater financial flexibility. Also following Schumpeterian logic (Kirchhoff, 1994), larger firms also have more money to dedicate to innovation. Therefore size is a moderating variable of both financial flexibility and innovation. 


\subsubsection{Age of Firm}

As previously described, Thornhill and Amit (2003) found that new firms fail for different reasons than older firms. They found that new firms failed due to a lack of management competencies while older firms failed because they were unable to keep up with the changes within their industry. Therefore age is a factor affecting firm survival but for different reasons depending on the age of the firm.

The findings of Baldwin et al. (2000) showed that new firms were more likely to fail than older firms. This is a well known and documented occurrence and "reflects what Stinchcombe (1965) called the liability of newness" (p. 959, Hannan \& Freeman, 1977). As described earlier, this age effect has been shown to be caused by a lack of management competencies (Baldwin et al., 1997). As a firm ages it gains more experience thereby decreasing the likelihood that it will fail. But as has been pointed out earlier by both Baldwin et al. (1997) and Thornhill and Amit (2003), even though the likelihood of failure decreases with age, it is still present. Older firms have to develop the skills to manage greater complexity (Baldwin et al., 1997) as well as overcome their own internal inertia (Hannan \& Freeman, 1997) to deal with industry change (Thornhill \& Amit, 2003).

Johnson et al. (p.15, 1997) in their study of successful entrant firms found by "the time the firm has reached an established stage, its management and human resources capabilities are typically quite developed, and growth is more closely associated with innovation". As Johnson et al. (1997) point out; their findings are complimentary to the previous findings of Baldwin (1995) and Baldwin et al. (1997 \& 2000). Many competencies are required for a firm to survive and grow but without innovation it will most likely stagnate. In other words, a firm that has managed to survive for a number of 
years has at one time innovated but will not grow unless it continues to innovate.

Therefore, age is not a direct contributor to growth. Since a firm has managed to survive, it has developed some level of management competency which makes age a moderating variable on management competency. In addition, older firms have an established track record that it can use when obtaining capital (assuming the track record is positive). This then makes age a moderating variable of financial flexibility.

\subsection{Business of Wine Literature}

The review of the business of wine literature has been divided into four parts. The first part presents a survey of journal articles that deal with specific topics within the wine business from around the world. In conjunction with this survey, the relevance of the articles with respect to the barriers to growth in Ontario's wine industry is also analysed. The second part of the business of wine literature review looks at the conference proceedings body of literature in the same manner as for the first part. The third part presents the relevant information learned from studying wine clusters focusing specifically on the Okanangan and Niagara wine clusters. The fourth and final part takes a brief look at what the business literature on the Canadian wine market has to say with respect to growth via exports which includes both domestic (other provinces) and foreign markets.

From a survey of the articles in various business journals, the overwhelming majority of the academic work on the wine industry relates to wine marketing. A small indicative sample of marketing article titles from over the years are "Brand value, convictions, flexibility, and New Zealand wine" (Beverland, 2004), "Behavioural Segmentation in the Australian Wine Market Using Conjoint Choice Analysis" (Johnson et al. 1991), and 
"Strategic interactive marketing of wine - a case of evolution" (Quinton \& Harridge March, 2003). There is even a journal dedicated to wine marketing titled "International Journal of Wine Marketing" published by the South Australian Institute of Technology. This body of wine marketing literature, though very important, doesn't have much bearing on the current study. The purpose of this study is to determine the barriers to growth (one of which might be marketing competency as described above); it is not to develop a marketing plan for the industry. With respect to marketing competency, there are some wine marketing journal articles that point out a deficiency in the marketing abilities of some wineries. Though somewhat dated and based on anecdotal evidence, articles by Corkindale (1991) and Spawton (1989) discuss improving marketing for wineries and thereby give further credence to the previously made point that marketing competency is a barrier for some wineries. In the Niagara context, Tefler (p. 26, 2001), who investigated Niagara winery alliances from a tourism perspective, noted that only $30 \%$ percent of the wineries that he surveyed kept "accurate statistics on the number of visitors". He goes on to state that wineries need to "keep more accurate records to better understand their customers" (p. 27, Telfer, 2001). Understanding your customer demographics is a basic marketing function and it doesn't appear that all Niagara wineries were (are they still not?) doing this.

Besides wine marketing, there have been investigations into the hedonic pricing of wine (Angulo et al. 2000, Combris et al 2000), the rate of return of buying wine as an investment (Burton \& Jacobsen, 2001), the effects of who operates a winery professional manager or owner (Frick, 2004), the motivation (utility and/or profit) of winery owners (Morton and Podolny, 2002), the relationship of quality and grape 
growing contracts (Goodhue et al., 2003), the relationship between social order, status and quality amongst wineries (Benjamin \& Podolny, 1999) as well as several studies of wine clusters that will be described in more detail later. Some of these papers do have relevance to the current study.

Frick's (2004) empirical study of the effects of who manages a winery found that wineries managed by professional managers were more profitable and attributed this to management competency. Morton and Podolny (2002) also found that some owner operated wineries were not as profitable as other wineries but found that this was due to the fact that these owners were in the business not purely to make a profit since they also derived enjoyment (utility) from owning a winery and making wine. Morton and Podolny (2002) go on to state that since utility has value as well, these wineries can remain in a market segment when purely profit motivated wineries will have abandoned the market segment. These papers give empirical support to the previously mentioned barriers that certain wineries will not be interested in growing since they are not necessarily motivated purely by profits and also that management competency will influence a winery's profitability and ability to grow.

Over the past three years there have been several wine conferences. There was the "Wine in the World Conference" at the University of Avignon from March 2 to March 4 2004. There was "The International Colloquium in Wine Marketing" held in Adelaide, July 26-27 2003. Lastly there was the "Bacchus to the Future" conference held at Brock University May 23-25, 2002. The proceedings from these conferences were investigated to determine if there were any papers relevant to the current research. The papers of these conferences by and large follow a case study approach rather than some other empirical 
approach and tend to deal with marketing and strategy issues. There are some papers that give historical accounts, others that take a socio-cultural approach and still others that use a cluster analysis approach. The marketing and strategy papers could form a basis for further research once the barriers to growth for Ontario's wine industry have been identified. Two papers from the conferences were found to be useful and will be discussed later. Specifically, Bramble et al.'s (2004) paper on the Niagara cluster from the Avignon conference will be discussed in the following section on wine cluster research and Madill et al.'s (2003) paper on strategic dilemmas for Canada's wine industry from the Adelaide conference will be discussed in the final section which looks at Canadian wine export opportunities both domestic and foreign.

With respect to wine clusters, Harvard MBA students have mapped out the interdependencies of the Californian wine cluster (Porter, 1998) and Mytelka (Mytelka \& Goertzen 2003,2004) has lead a study of wine clusters in various countries in her role as Director of The Institute for New Technologies for the United Nations University (UNUInTech). These papers on wine clusters study the inter-relationships that exist within each wine cluster. These inter-relationships can be of a concrete nature like suppliers and consumers of services and goods (Porter, 1998) or more abstract like tracking how innovations are learned and transferred within a cluster (Hickton \& Padmore, 2004). Three paper's based on Niagara's wine cluster (Mytelka \& Goertzen 2003, 2004; Bramble et al. 2004) and one paper based on Okanagan's wine cluster (Hickton \& Padmore, 2004) were pertinent to the study of the barriers to growth for Ontario's wine industry. 
Mytelka and Goertzen (p. 7, 2003) found that financial services (bank, venture capitalists, etc) don't play as important a role in the Niagara cluster as they do in other clusters even though capital investments for a new winery "can amount to as much as $\$ 1$ million over five years". Since capital is obviously required to start a winery it is assumed that Mytelka and Goertzen don't include informal capital (money from friends, family and private investors) in financial services. This gives the impression that financial flexibility in Canada's wine industry isn't as much of a problem as it is for other types of businesses. Why don't financial services play more of a role? Is it because they feel the business is too risky or that the return on investment isn't sufficient? Lack of financing might be a barrier to growth if the financial services are unwilling to invest and the winery owners don't have capital of their own to expand their wineries. But lack of investment is often a sign of some larger underlying problem like the management competency to develop a sound business plan (Baldwin et al., 1997) or it could be the motivation of many small winery owners is more utility based rather than profit based making them less attractive to the banks.

Mytelka and Goertzen (2003) in their study of the emerging Niagara wine cluster state that innovation is necessary for a cluster to survive and grow, adding further credence to the findings of Baldwin (1995). Their study was based on a series of interviews with various stakeholders in the Niagara wine cluster. They found that the Niagara wine cluster had made many innovations over the years (planting vinifera, establishing VQA, and adopting new viticulture and oenological techniques) but that the cluster was still not an innovation system like the Italian shoe or Swiss watch clusters due to poor information flow. They determined that the current information flow between all 
of the actors within the cluster is not sufficient to "enable producers in the cluster to reconceptualize their products and markets" and to create "new channels of communication through which problems can be identified collectively and a consensus on how to resolve them can be built"' (p. 24, Mytelka \& Goertzen, 2003). So in looking at Ontario's wine industry from a cluster perspective reveals the potential macro-economic barrier of weak communication and information transferral within the cluster. This point has also been mentioned by another actor within Niagara's wine industry. Even though the Niagara cluster may not communicate effectively on the business aspects (products and markets), Telfer (2001) showed that they did work together and collaborate with regards to wine tourism.

In a subsequent article on the Niagara wine cluster, where Mytelka and Goertzen (2004) studied both the Liquor Control Board of Ontario (LCBO) and the Grape Growers of Ontario (GGO), they stated that the current relationship between the GGO and the wineries is adversarial and not conducive to long-term contracts and trusting relationships "that is often a positive factor in the growth of dynamic innovation systems (p. 66, Mytelka \& Goertzen, 2004). Bramble et al. (2004) cited the same issue as a challenge for the cluster. Detailed contracts have been empirically shown to be an indicator of quality in the California winegrape industry (Goodhue et al., 2003). The adversarial relationship between the grape growers and the wineries in Ontario is another environmental condition similar to that of the previously described suboptimal information transferral within the cluster and is potentially an additional macroeconomic barrier to growth. According to Mytelka and Goertzen (2004) and Linda Franklin (president Wine Council of Ontario, personal conversation, July 19,2004) this grape grower and winery acrimony 
causes wineries to invest in creating their own vineyards in order to obtain the quality of grapes that they require. This in turn ties up capital that could otherwise be used to support growth. One of the intents of this study is to determine if and to what extent this is actually the case for Niagara's wine cluster.

Mytelka and Goertzen (2003) make the differentiation between two classes of wineries based on those that can blend foreign content and those that cannot. Given that the ability to blend foreign content is based on when the winery was licensed (pre or post mid-1993), age of winery might also affect a winery's growth potential. Wineries premid-1993 can have an additional product line using blended wines, thereby opening up more product and growth opportunities. Another age related factor is the grandfathering of the additional private retail stores setup by some wineries before the 1989 Canada-US Free Trade Agreement (FTA) (Mytelka \& Goertzen, 2003; Bramble et al. 2004). Wineries created after 1989 don't have this additional retail option and can only sell through the LCBO or their one retail store that is allowed with the establishment of the winery.

Mytelka and Goertzen (2004) found that the LCBO is effectively a private retailer and that it provides nominal help to small wineries in broadening their sales. They arguably classified the WOW program, craft winery program, and Ontario superstars as nominal help for the small estate winery. This last finding is somewhat controversial because of limitations on what the LCBO can do, due to the North American Free Trade Agreement (NAFTA) and General Agreement on Tariffs and Trade (GATT). Some people within Ontario's industry have commented that British Columbia's (BC) liquor distributor does more to help its domestic wineries but according to Hickton and Padmore 
(p. 40, 2004), who have studied the BC wine industry and cursorily compared it to Ontario's, the two systems are "very similar". Further detailed research must be done to confirm if there are real differences in the way the two provinces retail wine from small wineries. Another topic for further research is determining if the LCBO's reluctance to assist Ontario's small wineries further is due to either profit or legitimate trade regulation concerns.

Independent of the root causes for the small wineries' issues with the LCBO, Mytelka and Goertzen $(2003,2004)$ as well as Bramble et al. (2004) do point out a real concern that has been expressed by the small wineries they have interviewed. They found that access to the LCBO and staying listed by the LCBO is a challenge for small wineries. Though the causes for this difficulty are up for debate, it still remains a barrier to growth based on size which is one of the previously determined factors affecting growth.

Another size barrier, as pointed out by both Mytelka and Goertzen (2003) and Kevin Nullmeyer (marketing director for the Wine Council of Ontario, personal conversation, July 14,2004 ), is that a winery can realistically only expect to sell between five and ten thousand cases through their one retail store and licensees. Licensee sales are when the winery sells directly to restaurants. This is a natural limit which these people have observed in their discussions with the wineries. To grow above this point, the winery must develop further sales channels, by either exporting (to other provinces or countries) or working successfully with the LCBO.

The topic of exporting as a way to grow for Ontario and Canada's wineries is an interesting one. Both Bramble et al. (2004) and Madill et al. (2003) state that exporting is a priority for future growth. Madill et al. (p. 1, 2003) in their conference paper "Strategic 
Dilemmas of a Small Market Player: The Canadian Wine Industry" make an impassioned argument for foreign exporting, though they admit that it is radical and that it "would be especially difficult for the large number of small Canadian winery businesses". Madill et al. (2003) discount the low cost and easier access of expanding the domestic market by arguing that Canadian consumers won't take Canadian wine seriously until foreign markets do (citing historical examples of Canadian art and entertainment) and that the small wineries will only be stealing market share from each other in a zero sum game. I don't disagree that exporting is a potential growth strategy but I do disagree with their arguments that growing domestically is a zero sum game for the small wineries and that exporting is the only way to achieve credibility at home. Each of these points will be discussed in turn.

As has been previously shown, VQA wines in Ontario have been growing at an annual rate of $20 \%$ over the past three years such that VQA wines now have $9 \%$ of the Ontario market (GGO Annual Report 2004, n.d.). Admittedly this growth has been at the expense of the blended wines which only 19 of the 66 Niagara based wineries can legally make. In reality, the vast majority of the blended wines are produced by only two companies - Vincor and Andres. So the market share growth in VQA wines is not coming at the expense of the small wineries. Currently BC VQA wines have $17 \%$ of their market and have had an average annualized growth rate of $33 \%$ over the past two years (BC Wine Annual Report 2002-2003, n.d.). According to Hickton and Padmore (2004), BC's VQA market share is expected to grow at $20 \%$ per year until 2006 . Given that Ontario's VQA market share is $9 \%$ versus BC's $17 \%$, one would think that there would be considerable room for growth for the small wineries in Ontario. 
I agree with Madill's et al. argument that Canadians will not take Canadian wine seriously until it has been accepted by foreign markets. But I disagree that this can only be achieved by exporting. In my opinion, winning prestigious international wine awards like Inniskillin's 1991 Vinexpo award for their 1989 Vidal Icewine (Madill et al., 2003) and Mission Hill's winning of the London International Wine \& Spirit Competition trophy for Best Chardonnay in 1994 as well as the only North American gold medal at the 2001 Chardonnay du Monde Competition in France (Mission Hill Winery, n.d.) can have the same effect. Canadians see that their wines are winning meaningful international awards and therefore come to accept them as being okay. Proving that this is actually the case is yet another topic for research. If doing well or winning at international competitions does legitimize Canadian wines for Canadians, then entering international competitions is a much cheaper alternative than trying to export.

In summary, a survey of the business of wine research literature illustrates examples of each of the eight barriers to growth as identified by the theory of growth literature. To recap, even though there are numerous papers on wine marketing it appears that marketing competency for small wineries is still an issue. Due to changes in regulations and grandfathering, newer wineries in Ontario have more restrictive rules than older wineries leading to the possibility of different growth barriers due to age. From previous studies there appear to be size differences as well since smaller wineries in Ontario have greater difficulties in getting and keeping products listed with the LCBO. The literature has also shown that motivation (treated here as intention to grow) and management competency do affect the profitability of wineries. For the Niagara cluster itself, there are macroeconomic conditions of suboptimal communication between the actors and an 
acrimonious relationship between the grape growers and wineries than can also act as barriers to growth. Lastly, financing might be an issue in the Niagara cluster since financial services are apparently not involved as much as they are in other clusters even though wineries do require substantial financing. Winery owner motivation and/or management competency are possible moderating variables for this finding.

\subsection{Research Premise}

\subsection{Introduction}

This study investigates the barriers to growth for Ontario's VQA wine industry using an empirical method. Up until now all the published business research on Ontario's wine industry has been based on interviews of a subset of the wineries. This study attempts to change this by using a short survey instrument and by obtaining a significant (and unusual) response rate in the order of $80 \%$. In the theory of growth literature review, arguments were presented to support the concept that in one way or another all things contributing to or inhibiting growth can be viewed as resources. Using this viewpoint, all growth theories (strategy, population ecology, macroeconomic etc.) then fit under the umbrella of resource theory. Next the empirical research of the growth of the firm was investigated to determine the salient factors (resources) which have been determined to affect the ability of a firm to grow. This section identified the eight factors of age, size, innovation, management competency, marketing competency, intention, financial flexibility, and macroeconomic. Lastly, the business of wine research literature was investigated to determine which barriers of growth had been presented there. Remarkably enough, examples of each of the eight factors identified by the empirical work on the theory of growth were present in the business of wine literature. 
The remainder of this section is divided into three parts. The next part presents a conceptual model that has been developed as a result of the literature survey. This is followed by the research objectives followed by a description of the research hypotheses which concludes this section.

\subsection{Conceptual Model for Growth}

From the review of the empirical business growth literature, eight factors have been determined to affect firm growth. In the literature that was surveyed, no one paper discussed all factors and all the papers were correlational studies that looked at each of the factors on either an individual basis or as part of a factor analysis. In an effort to build upon the previous academic work and further the understanding of growth, a conceptual model of growth was developed and is presented here. This model was created based on the previously reviewed academic literature combined with an intuitive and common sense approach to how these various factors would interact. The model is shown in Figure 1 below. 


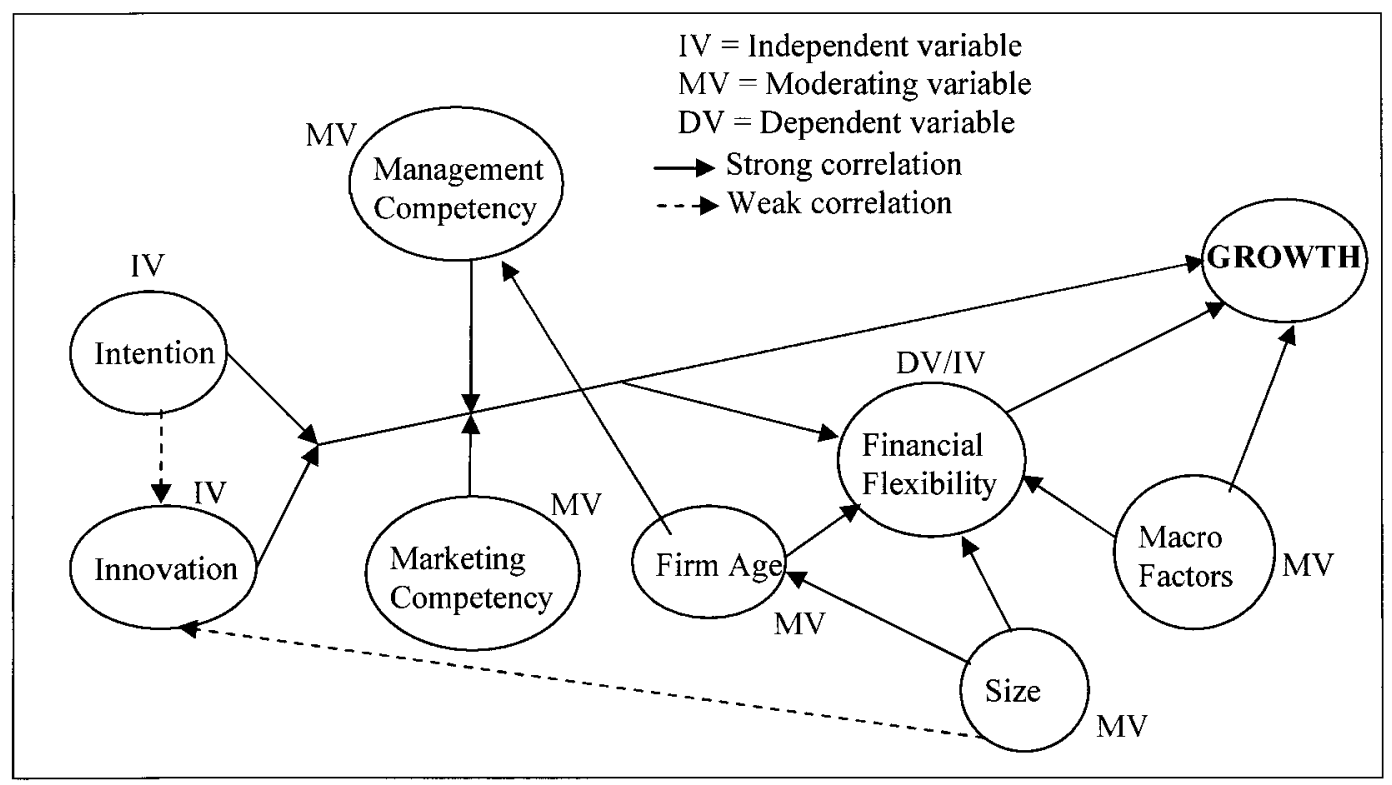

Figure 1: Conceptual model for growth

From the literature survey (Orser \& Hogarth-Scott, 2002; Baldwin, 1995), it has been shown that intention and innovation are the main drivers of growth. Without either of these, growth is unlikely to happen. In creating a conceptual model, this presents the question of whether innovation and intention are dependent on each other or are they independent. If they are dependent, which comes first? The argument can be made that intention to grow spurs innovation as a means of realizing the intention. But to remain in business a firm has to be doing something innovative, otherwise a competitor with a more innovative product or service will displace it. Therefore even a firm that has no intention of growing will exhibit innovative behaviour. Possibly the amount of innovation is a function of intention. It can also be argued that innovation creates the demand for the product or service which gives the business owner the impetus to grow that otherwise may not have been there. Nevertheless, it seems logical to assume that those firms that desire growth will be more innovative than those firms that don't. So for the purposes of 
the model, intention and innovation are independent variables equally driving growth with a weak linkage from intention to innovation. There is also a weak linkage from size of firm to innovation acknowledging that large firms have more resources to dedicate to innovating activities. But as illustrated by Kirchhoff (1994), even though large firms can innovate more than small firms, it is the small firms that are more often able to successfully productize the innovations.

As determined by Johnson et al. (1997) and others, both management and marketing competency are important influencers of whether a company will grow. But without innovation or intention to grow, management and marketing skills won't have much to work with. Given this, management and marketing competency are considered moderating variables on the growth of a firm.

With regards to financial flexibility, it is both an important determinant of growth as well as an outcome of intention, innovation, marketing competency and management competency. As Baldwin et al. (1997) pointed out; poor financial planning is just another indicator of poor management. If a firm comes up with a truly innovative idea (assumes profitable) and has the drive and the requisite management and marketing competencies to go with it, the firm will get the investment capital that they require. If one of these pieces is missing, then the firm will experience difficulty in achieving its financing requirements and therefore its growth expectations. Nevertheless, there are examples where firms have been unable to secure the outside capital they require but have still managed to grow with judicious use of retained earnings and informal capital. In order to represent these two situations, the conceptual model was drawn showing financial flexibility as a dependent variable of intention, innovation, marketing and management 
competency, (just like growth) and as an independent variable affecting growth. Size plays a moderating role with regards to financial flexibility since a larger firm generally has more assets (tangible and intangible) which it can leverage to obtain the capital it requires.

Age like size is a moderating variable on growth. As firms age, they develop more management competencies by experience (Baldwin et al., 1997). Therefore age is a moderating variable on management competencies. In addition, if a business is older and it has a successful track record (which it most likely has since it has survived), potential sources of capital are more likely to invest in it. Therefore age is a moderating variable on financial flexibility. There is also a correlation between size and age. Often as a firm gets older it gets larger, but this is not necessarily the case for all businesses and all industries.

The final factor to be discussed from the model is the macroeconomic factors. Typical factors that can be included here are the state of the economy as well as the social and economic environment in which the firm lives. Baldwin et al. (2000) showed that firms do better (fewer go bankrupt) under good economic times rather than bad. Lohmann (1998) showed that growth was affected by the government and regulation environment which the firm had to deal with. Therefore macroeconomic factors are moderating variables which affect the growth of a firm. These factors can also reduce the financial flexibility of a firm if they create the perception of risk in the minds of the potential sources of capital. Macroeconomic factors can then be a moderating variable on financial flexibility as well. 


\subsection{Research Objectives}

The original research objective was to determine which of the previously described eight factors (innovation, intention, management competency, marketing competency, macroeconomic activity, financial flexibility, size and age of firm) were significant within Ontario's wine industry. In order to achieve this, it would have been necessary to carry out a longitudinal study since there had been no prior research of this type that had involved Ontario's wine industry. Furthermore a longitudinal study was also required in order to validate the conceptual model for growth. Therefore the objectives of this research had to be structured such that they could be realized using a cross-sectional study.

The four primary objectives of this research are summarized in Table 1 below. The first objective was to determine those barriers which the wineries and grape growers perceived to be affecting their ability to grow. These barriers were then analysed using the eight factors which affect growth to determine if perception of barriers were different depending on each of the factors. The second objective was to carry out a preliminary test of the conceptual model of growth. Given that growth itself could not be tested, the remaining factors' interaction with financial flexibility was pursued instead. The third objective was to explore the dynamics of the macro economic factor of the well documented acrimony between grape growers and wineries. The fourth and final objective was to obtain the growth intentions of the wineries and grape growers thereby creating the first data point of a longitudinal study that can be completed at a later date (in 2 years). In addition to the four primary objectives, an informal but important 
objective was to provide value to the wine industry participants such that they too would benefit from this research.

\begin{tabular}{|l|l|}
\hline Objective & Description \\
\hline $\begin{array}{l}\text { Determine the barriers affecting the } \\
\text { growth objectives of the wineries and } \\
\text { grape growers }\end{array}$ & $\begin{array}{l}\text { Using a survey instrument get the } \\
\text { winery owners and grape growers to rate } \\
\text { on a 5-point scale the effect of each } \\
\text { potential barrier. Analyse the data } \\
\text { based on the 8 empirical factors which } \\
\text { affect growth. }\end{array}$ \\
\hline Test the conceptual model of growth & $\begin{array}{l}\text { Since this was not a longitudinal study, } \\
\text { only factors relationship to financial } \\
\text { flexibility plus the interactions between } \\
\text { intention and innovation as well as size, } \\
\text { age and innovation could be tested. }\end{array}$ \\
\hline $\begin{array}{l}\text { Explore determinants, possible } \\
\text { recommendations, and industry outcomes } \\
\text { of grape grower and winery acrimony }\end{array}$ & $\begin{array}{l}\text { Winery and grape grower acrimony is a } \\
\text { major macro factor affecting the wine } \\
\text { industry. The hope is by understanding } \\
\text { it better, that possible solutions might be } \\
\text { realized. }\end{array}$ \\
\hline $\begin{array}{l}\text { Obtain two-year growth intentions of } \\
\text { wineries and grape growers. }\end{array}$ & $\begin{array}{l}\text { By obtaining the future growth } \\
\text { intentions, a follow-up study can be } \\
\text { performed in two years in order to test } \\
\text { out the conceptual model of growth. }\end{array}$ \\
\hline
\end{tabular}

Table 1: Summary of research objectives

In the course of the research in preparation for this study (literature survey and stakeholder interviews), it became apparent that there might be a sizable percentage of the participants in Ontario's wine industry whom do not derive their primary source of income from the either owning the winery or growing grapes. If someone doesn't have to earn a living from the business, this probably changes their perception of the barriers affecting them. So unique to this study, grape growing or winery ownership as a primary source of income was added as a ninth factor that can affect growth and perception of barriers. Due to the uniqueness of this factor to the wine industry, it was not added to the general conceptual model for growth described previously. 


\subsection{Hypotheses}

In conversations with various players within Ontario's wine industry, it was determined that having a short survey instrument was paramount in obtaining a meaningful response rate. This limit on the length of the survey instrument then precluded exploring all eight growth factors at this time. The factor involving management competency was not tested in this study for this reason. Additionally, the only macroeconomic factor explored with this study is the adversarial relationship between the wineries and grape growers. The other macroeconomic factor of information flow in the cluster is not covered due to survey length considerations. A summary of the hypotheses for the wineries is shown in Table 2 below. A summary of the hypotheses for the grape growers is shown in Table 3 below. A summary of the conceptual model hypotheses are shown in Table 4 below. 


\begin{tabular}{|c|c|}
\hline Hypothesis & Area being tested \\
\hline $\begin{array}{l}\text { 1. Barriers perceived by old and new wineries } \\
\text { will be different. }\end{array}$ & Investigates age growth factor \\
\hline $\begin{array}{l}\text { 2. Barriers will be different based on the size of } \\
\text { winery. }\end{array}$ & Investigates size growth factor \\
\hline $\begin{array}{l}\text { 3. Barriers are different for those wineries that } \\
\text { grow most of their own grapes than for those } \\
\text { wineries that purchase the majority of their } \\
\text { grapes. }\end{array}$ & $\begin{array}{l}\text { Investigates macro factor of grape } \\
\text { grower/winery acrimony }\end{array}$ \\
\hline $\begin{array}{l}\text { 4. Those wineries which express a higher } \\
\text { satisfaction score for their grape grower } \\
\text { relationships will show statistically less interest } \\
\text { in growing via backward integration. }\end{array}$ & $\begin{array}{l}\text { Investigates macro factor of grape } \\
\text { grower/winery acrimony }\end{array}$ \\
\hline $\begin{array}{l}\text { 5. The barriers to growth viewed by those who } \\
\text { desire to grow are different than those who do } \\
\text { not wish to grow. }\end{array}$ & $\begin{array}{l}\text { Investigates intention growth } \\
\text { factor }\end{array}$ \\
\hline $\begin{array}{l}\text { 6. The dominant barriers to growth for small } \\
\text { and mid-sized wineries will be access to } \\
\text { capital. }\end{array}$ & $\begin{array}{l}\text { Investigates size and financial } \\
\text { flexibility growth factors }\end{array}$ \\
\hline $\begin{array}{l}\text { 7. Those wineries that use long-term contracts } \\
\text { produce a higher percentage of premium and } \\
\text { super-premium wine with purchased grapes } \\
\text { than wineries that don't use long-term } \\
\text { contracts. }\end{array}$ & $\begin{array}{l}\text { Investigates macro factor of grape } \\
\text { grower/winery acrimony }\end{array}$ \\
\hline $\begin{array}{l}\text { 8. Marketing competency is weaker for craft } \\
\text { and small wineries than for medium and large } \\
\text { wineries. }\end{array}$ & $\begin{array}{l}\text { Investigates if marketing } \\
\text { competency and size are related }\end{array}$ \\
\hline $\begin{array}{l}\text { 9. Wineries that have a weak marketing } \\
\text { competency will score the LCBO higher as a } \\
\text { barrier than wineries with a strong marketing } \\
\text { competency. }\end{array}$ & $\begin{array}{l}\text { Investigates relationship between } \\
\text { macro factor of LCBO and factor } \\
\text { of marketing competency }\end{array}$ \\
\hline
\end{tabular}

Table 2: Summary of winery hypotheses 


\begin{tabular}{|l|l|}
\hline Hypothesis & Area being tested \\
\hline $\begin{array}{l}\text { 1. Grape growers that express a higher satisfaction } \\
\text { score for their buyer relationships are less likely to } \\
\text { express an interest in forward integration }\end{array}$ & $\begin{array}{l}\text { Investigates winery and grape } \\
\text { grower dynamic }\end{array}$ \\
\hline $\begin{array}{l}\text { 2. Barriers to growth are different for those that } \\
\text { intend to grow and those that don't. }\end{array}$ & $\begin{array}{l}\text { Investigates winery and grape } \\
\text { grower dynamic }\end{array}$ \\
\hline $\begin{array}{l}\text { 3. Grape growers that have contracts that have } \\
\text { viticulture specifications express a higher satisfaction } \\
\text { score for their buyer relationships than those grape } \\
\text { growers without such contracts. }\end{array}$ & $\begin{array}{l}\text { Investigates winery and grape } \\
\text { grower dynamic }\end{array}$ \\
\hline $\begin{array}{l}\text { 4. Those grape growers that are paid a premium for } \\
\text { their grapes express a higher satisfaction score for } \\
\text { their buyer relationships than those that are not paid a } \\
\text { premium. }\end{array}$ & $\begin{array}{l}\text { Investigates winery and grape } \\
\text { grower dynamic }\end{array}$ \\
\hline $\begin{array}{l}\text { 5a. Those grape growers which have contracts with } \\
\text { viticulture specifications of duration of greater than } \\
\text { one year perceive different barriers to growth than } \\
\text { those that don't. }\end{array}$ & $\begin{array}{l}\text { Investigates winery and grape } \\
\text { grower dynamic }\end{array}$ \\
\hline $\begin{array}{l}\text { 5b. Those grape growers that are paid a premium for } \\
\text { their grapes perceive different barriers to growth than } \\
\text { those that don't. }\end{array}$ & $\begin{array}{l}\text { Investigates winery and grape } \\
\text { grower dynamic }\end{array}$ \\
\hline
\end{tabular}

Table 3: Summary of grower hypotheses

\begin{tabular}{|l|l|}
\hline Hypothesis & Area being tested \\
\hline $\begin{array}{l}\text { 1. Financial flexibility is a function of intention to } \\
\text { grow, innovation, marketing competency, age of } \\
\text { winery, size of winery, and the macroeconomic factor } \\
\text { of level of satisfaction expressed with the grape } \\
\text { growers. Also tested here is the correlation between } \\
\text { age and size. }\end{array}$ & \\
\hline $\begin{array}{l}\text { 2. Innovation is weakly correlated to intention to } \\
\text { grow and size. }\end{array}$ & \\
\hline $\begin{array}{l}\text { 3. Growth is a function of intention to grow, } \\
\text { innovation, marketing competency, financial } \\
\text { flexibility, and the macroeconomic factor of level of } \\
\text { satisfaction expressed with the grape growers. }\end{array}$ & $\begin{array}{l}\text { Not tested because growth } \\
\text { requires a longitudinal study }\end{array}$ \\
\hline
\end{tabular}

Table 4: Summary of conceptual model hypotheses 


\subsubsection{Hypotheses for Wineries}

Hypothesis 1: Investigates age growth factor

Barriers perceived by old and new wineries will be different. Wineries created after 1993 will be used initially as the cut-off between old and new.

Hypothesis 2: Investigates size growth factor

Barriers will be different based on the size of winery.

Hypothesis 3: Investigates macro factor of grape grower/winery acrimony

Barriers are different for those wineries that grow most of their own grapes than for those wineries that purchase the majority of their grapes.

Hypothesis 4: Investigates macro factor of grape grower/winery acrimony

Those wineries which express a higher satisfaction score for their grape grower relationships will show statistically less interest in growing via backward integration. Backward integration in this context means planting more grapes.

Hypothesis 5: Investigates intention growth factor

The barriers to growth viewed by those who desire to grow are different than those who do not wish to grow.

Hypothesis 6: Investigates size and financial flexibility growth factors

The dominant barriers to growth for small and mid-sized wineries will be access to capital.

Hypothesis 7: Investigates macro factor of grape grower/winery acrimony Those wineries that use long-term contracts (greater than one year) produce a higher percentage of premium and super-premium wine with purchased grapes than wineries that don't use long-term contracts. 
Hypothesis 8: Investigates if marketing competency and size are related (not shown in current conceptual model)

Marketing competency is weaker for craft and small wineries than for medium and large wineries.

Hypothesis 9: Investigates relationship between macro factor of $\mathrm{LCBO}$ and factor of marketing competency

Wineries that have a weak marketing competency will score the LCBO higher as a barrier than wineries with a strong marketing competency.

\subsubsection{Hypotheses for Grape Growers}

The purpose of all grape grower hypotheses is to investigate the dynamics of the grape grower and winery acrimony.

Hypothesis 1:

Grape growers that express a higher satisfaction score for their buyer relationships are less likely to express an interest in forward integration (becoming a winery) than those grape growers that express a lower satisfaction score for their buyer relationships.

Hypothesis 2:

Barriers to growth are different for those that intend to grow and those that don't. Hypothesis 3:

Grape growers that have contracts that have viticulture specifications express a higher satisfaction score for their buyer relationships than those grape growers without such contracts. 
Hypothesis 4:

Those grape growers that are paid a premium for their grapes express a higher satisfaction score for their buyer relationships than those that are not paid a premium.

Hypothesis 5:

a) Those grape growers which have contracts with viticulture specifications of duration of greater than one year perceive different barriers to growth than those that don't.

b) Those grape growers that are paid a premium for their grapes perceive different barriers to growth than those that don't.

\subsubsection{Hypotheses for the Conceptual Model}

Only those variables that are included in the survey instrument are listed here. Therefore the moderating variables management competency and poor intra-cluster communication are not included here.

Hypothesis 1:

Financial flexibility is a function of intention to grow, innovation, marketing competency, age of winery, size of winery, and the macroeconomic factor of level of satisfaction expressed with the grape growers. Also tested here is the correlation between age and size.

Hypothesis 2:

Innovation is weakly correlated to intention to grow and size. Weak correlation means that the variance explained by using a linear regression with the factors is less 
than a factor of two of the variance explained by the other linear regression models.

See Figure 1: Conceptual model for growth on page 44.

Hypothesis 3: (not tested because growth requires a longitudinal study)

Growth is a function of intention to grow, innovation, marketing competency, financial flexibility, and the macroeconomic factor of level of satisfaction expressed with the grape growers.

\subsection{Research Methodology}

\subsection{Introduction}

The research analyzed data collected from wineries and grape growers using a survey instrument. In this section, the instrument development will be explained, followed by descriptions of the sampling frame, sampling procedure, data analysis, and the limitations that were encountered.

\subsection{Instrument Development}

There were two survey instruments used for this study. Due to the distinct nature of grape growers and wineries, a separate instrument was developed for each of them. The survey instruments were based on a combination of a barrier to growth survey and a management competency survey that were developed and used by Orser and Riding (2003). The surveys that were developed by Orser and Riding (2003) were modified to take into account concerns and issues specific to grape growers and wineries. These concerns and issues were learned through a series of one hour structured interviews with seven wineries representing small, medium, and large wineries and three grape growers representing large and small grape growers. The winery and grape grower questionnaires that were used in this research are in Appendix 1. 


\subsection{Sampling Frame}

The sampling frame for the wineries was all the VQA grape wineries in Ontario. There are VQA wineries located on the north shore of Lake Erie (5), in Niagara (53), around Toronto (9) and Prince Edward County (8). As of January 10, 2005, there were a total of 75 VQA wineries in Ontario with more coming on stream every year. All licensed wineries at the beginning of 2005 were targeted since it is a small number and a maximum number of data points are required in order to perform factor analysis and to validate the conceptual model. Since every VQA winery in Ontario was targeted, the sample was a census.

There were 587 grape growers in Ontario who sold grapes in 2004 (data obtained from conversations with GGO). This total number of growers includes both Labrusca and Vinifera growers. According to the GGO, 68\% of the growers grow Vinifera. The plan was to randomly survey 50 Vinifera growers which would give a worst case error of $14 \%$ on the binary questions (yes/no) when the responses split equally ( $50 \%$ yes $/ 50 \%$ no) with a $95 \%$ confidence ratio.

\subsection{Sampling Procedure}

A preliminary version of the survey instruments was tested during the one hour structured interviews that were carried out with the three grape growers and seven wineries. To achieve a sample size of 50 Vinifera grape growers, all grape growers were put in a random ordered list. GGO did not allow access to their list of growers but they did provide identification numbers for all the active growers. An active grower is a grower that sold grapes in 2004. Stamped sealed envelopes were couriered to the GGO and they printed the address labels using the randomly selected grape grower numbers 
that I gave them. The GGO was unable to separate out Vinifera from Labrusca growers, so that questionnaires were mailed to both types of growers. Given that only $68 \%$ of the growers grew Vinifera, on average $32 \%$ of the mail-out went to invalid recipients. The first 100 on the random sorted grape grower list were mailed a questionnaire. After one month, 18 valid responses (i.e. from Vinifera growers) were received. Based on this response rate, another 200 questionnaires were mailed out and resulted in a combined total of 70 valid responses. Given the well known difficulties in getting winery owners to respond to questionnaires of any form, the plan was to phone the winery and determine their preference for doing the survey (email, fax, phone, in person). If after several attempts at getting the winery to respond was unsuccessful, an onsite visit was made. In the end 59 of the 75 wineries responded.

\subsection{Data Analysis}

Data analysis was carried out using a variety of statistical methods available through SPSS which included descriptive statistics, frequencies, independent sample mean t-tests, linear regression, MANOVA and factorial design. The type of statistical methods used varied with the hypothesis being tested and therefore they are included with the discussion of the results of each hypothesis.

\subsection{Limitations}

There are several known limitations with this study. With regards to the winery data, several wineries refused outright to participate in the study citing the necessity of keeping their business plans private. As a generalization (learned from talking to other winery owners), these winery owners tended to be loners within the winery industry whom from a networking perspective are isolated from the general winery community. Therefore the 
data represented by this type of owner is missing from the study. Since only five wineries refused outright to participate in the study, it was felt that this would not unduly affect the overall results considering that 59 wineries did participate. Another limitation of note would be those grape growers and wineries ( 10 plus one owner who had passed away) who never responded. Is there possibly a characteristic(s) that caused these potential respondents not to respond that is being missed from the study and would change the results substantively? Though possible, it was felt that this was unlikely but should still be considered when reading the results.

A further limitation of this study is it is a cross-sectional study. Given that it is a cross-sectional study, it was not possible to fully test out the conceptual model of growth which requires a longitudinal study.

Lastly as with all studies which rely on a questionnaire that is to be answered by a particular person (in this case the owner of the winery) is the issue of key informant. Is the person that answered the questionnaire actually the owner, has the same opinions if there are a group of owners or if it is a delegate, represents the owner's opinions? In the majority of cases, the owner actually answered the questionnaire and in those cases where it was a delegate or one from a group of owners answering the questionnaire, the question was always asked that their opinions were shared by the owners. In all cases the answer was "yes". Using the assumption that the respondents were not misrepresenting the situation, the data obtained should be representative. Nevertheless, the reader should realize that the issue of key informant is still a possibility if this assumption is false. Furthermore, the majority of respondent firms, not to mention firms in the industry, are 
small firms. In such firms, communications are generally much more transparent than in oft-compartmentalized large firms. This also mitigates potential key informant problems.

\subsection{Results}

\subsection{Introduction}

As described earlier, 59 out of a possible 75 wineries participated in the study for a response rate of $79 \%$. This was a highly significant response rate for this industry and a comment to this effect was made by the Wine Council of Ontario. These 59 wineries represent 1.42 million cases of wine, \$242 million in revenues, 427 full-time employees and 379 part-time employees. Of the 59 wineries, 46 were from Niagara, four were from north shore Lake Erie, three from around Toronto and six from Prince Edward County. The participation based on size of winery was 27 craft wineries $(0-5 \mathrm{~K}$ cases), 22 small wineries ( $5 \mathrm{~K}-30 \mathrm{~K}$ cases), 8 medium wineries (30K-100K cases) and 2 large wineries (greater than $100 \mathrm{~K}$ cases). Since only two large wineries participated, it was not meaningful to perform any analysis based on this winery classification.

The 70 grape growers that responded (34\% response rate) represented 3500 acres of grapes. Sixteen of the 70 responses were from wineries which is $23 \%$ of the sample compared to $18 \%$ in the normal population.

Though there were no hypotheses for the wineries or the grape growers made regarding differences based on if their respective businesses were their primary source of income, it is interesting to note that $59 \%$ of the winery owners listed the winery as their primary source of income (in the winery questionnaire) versus $37 \%$ for all grape growers (in the grape grower questionnaire). With respect to data analysis, winery responses (in the winery questionnaire) were not significantly different when compared based on 
source of income. On the other hand, grape grower responses had several significant differences when based on source of income. Winery grape grower responses were not included in this analysis. For example, the average acreage for grape growers for whom it is their primary source of income is 87 acres versus 23 acres $(p=.007)$ for those whom it is not. Additionally the grape growers who make it their primary source of income have been in business 29 years versus 20 years for the part-timers $(p=.048)$. There is also a difference in the expressed satisfaction with the wineries. The full-time grape grower has a lower satisfaction of $3.35 / 5$ versus $3.9 / 5$ for the part-time grower $(p=.045)$. This makes intuitive sense since the relationship has more relative importance to the full-time growers given that it is their primary source of income. Therefore if the full-time grower was unhappy in the relationship, this would be felt more acutely.

The remainder of the results will be presented as follows. The next subsection presents a discussion of Bayesian and classical statistics interpretation of the results. The next subsection gives the results from testing the winery hypotheses, followed by a subsection detailing the results of the grape grower hypotheses, which is followed by the results from testing the conceptual model for growth. The last subsection is devoted to findings derived from investigating the winery-grape grower dynamic.

\subsection{Bayesian versus Classical Statistic Interpretation}

With only 75 VQA wineries in Ontario, this group is considered a small population. Given the small population, it is difficult to get classical statistically significant results even though $59(79 \%)$ of the wineries participated. Classical statistics assumes a large population with generally greater than 59 respondents. The number of respondents required for a given degree of accuracy is dependent on the variance in the responses. In 
classical statistics, as the sample size increases the variance decreases to the point where it is zero in the case of a census. In regards to this research, since it is a virtual census, it is possible to interpret the results without considering their classical statistic significance. This is considered to be a Bayesian approach. The discussion of the results provided with the research follows this Bayesian approach. Realizing that some readers might be uncomfortable with this, classical statistical significances are still provided throughout the thesis allowing the reader to make their own choices.

\subsection{Winery Hypotheses}

There are a total of nine winery hypotheses. Each will be covered in turn.

\subsubsection{Hypothesis 1}

Barriers perceived by old and new wineries will be different. Wineries created after 1993 will be used initially as the cut-off between old and new.

This hypothesis was tested using several different dates for separating the wineries. The original year of 1993 was chosen since all wineries licensed after that date could no longer use imported wine or grapes in their wine. Separating based on 1993, resulted in 12 wineries in the 1993 or earlier group and 41 in the post-1993 group. The number of wineries doesn't add up to 59 since 6 wineries didn't express an interest in growing and therefore did not respond to the questions dealing with obstacles to their growth. See Appendix II for the winery questionnaire.

Having unequal group sizes can pose a statistical issue if their variances are unequal. Since Box's test did not compute (fewer than two non-singular cell covariance matrices), Levene's test for equality of variances was used instead. When Levene's test was significant, the t-test assuming unequal variances was used. Only 4 of the 20 barriers 
under test had significant Levene's test results. Using both a MANOVA and individual ttests, there were no significant differences between the two groups other than the obvious foreign content rule ( $1 / 5$ for 1993 or earlier and $2.46 / 5$ for the post-1993, $\mathrm{p}=.006)$. It is interesting to note that even with the foreign content rule the wineries affected by it rated it quite low in comparison to their main perceived obstacles such as taxation levels $4.25 / 5$, working with the LCBO $4.15 / 5$, government regulations $3.98 / 5$ and government paperwork 3.91/5.

The next test separated the wineries into approximately two equal sized groups while removing the wineries that were licensed after 2002. The reason for removing post-2002 wineries was that they wouldn't have opened or only had just opened the retail part of their business, making their opinions based on expectation rather than experience. This resulted in 1998 being used as the cut-off year. There were 20 wineries in the 1998 and earlier group and 23 wineries in the 1999 to 2002 group. Once again there were no significant findings using MANOVA but using independent $t$-tests resulted in instability of demand being significantly different with a score of $2.50 / 5$ for the older group and a score of $3.22 / 5$ for the younger group ( $\mathrm{p}=.021)$. It is important to note at this point that when looking at $t$-tests of individual variables at the .05 significance level when there are 20 variables, one would expect to find at least one significant finding that would in fact be a statistical artefact. This is true when using a sample of a large population. In the case of this research, the sample is actually a census ( $79 \%$ of the population) such that the variance is virtually zero. Given this, it was felt that the results obtained from independent t-tests were valid and meaningful. With this in mind, the finding that the younger firms perceive instability of demand as a greater issue is not a surprise. Younger 
wineries are smaller wineries. The correlation between size and age was $.57(\mathrm{p}=.000)$. See Table 5 below which shows a breakdown of winery averages based on size. As a generalization, young and small wineries are still trying to establish themselves in the marketplace and are unlikely to have a large variety of different types of customers. Being dependent on a smaller set of customers, leaves the newer winery more open to fluctuations in demand since they don't have as large and varied a customer base as the larger wineries.

\begin{tabular}{|l|l|l|l|l|}
\hline & $\begin{array}{l}\text { Volume } \\
\text { (cases) }\end{array}$ & $\begin{array}{l}\text { Age } \\
\text { (years) }\end{array}$ & $\begin{array}{l}\text { Fulltime } \\
\text { (\#staff) }\end{array}$ & $\begin{array}{c}\text { Part-time } \\
\text { (\#staff) }\end{array}$ \\
\hline craft & $2.9 \mathrm{~K}$ & 5 & 2.1 & 6.1 \\
\hline small & $13.2 \mathrm{~K}$ & 8 & 6.8 & 6.1 \\
\hline medium & $56.8 \mathrm{~K}$ & 16 & 25.1 & 10.3 \\
\hline
\end{tabular}

Table 5: Averages based on size of winery

The last age difference that was investigated was between the wineries created in the 2000 and 2002 period and those in the 2003 and 2005 period. As mentioned above, those wineries created in post 2002 had just opened or have yet to open their retail stores and their perceptions of barriers to growth are more based on expectation rather than experience. The results are shown in Table 6 below. It is very interesting to note how the perceptions of the new wineries change as they get older. Before truly experiencing the retail market they don't consider Ontario's foreign content rules to be much of a problem, but after being in the market the concern rises considerably. The same applies to the stability of demand. Both these findings are consistent with the naïve optimism of new businesses. The importance of finding qualified labour for the new winery is to be expected considering this is the stage they are at. The older winery has overcome this 
hurdle since it is still in business but it is still an issue given it is rated 3/5. From conversations with people in the industry there is a high staff turnover rate due to the low wages that the industry pays.

\begin{tabular}{|c|c|c|c|}
\hline & $\begin{array}{c}\text { Can't use foreign } \\
\text { content }\end{array}$ & $\begin{array}{c}\text { Finding } \\
\text { qualified } \\
\text { Labour }\end{array}$ & $\begin{array}{c}\text { Unstable } \\
\text { demand }\end{array}$ \\
\hline $2000-2002$ & $2.8 / 5$ & $3 / 5$ & $3.3 / 5$ \\
\hline $2003-2005$ & $1.2 / 5$ & $4 / 5$ & $2.4 / 5$ \\
\hline p-value & .011 & .094 & .049 \\
\hline
\end{tabular}

Table 6: Obstacles differences: new and nearly new wineries

With the empirical findings presented above, it has been shown that the perception of obstacles to growth change based on the age of the winery. This is consistent with the empirical literature showing that age is a factor affecting the growth rate of firms.

\subsubsection{Hypothesis 2}

Barriers will be different based on the size of winery.

The analysis of the perceived obstacles facing wineries was carried out using a variety of techniques. This hypothesis was tested using factor analysis, t-tests, and factorial MANOVA with age and size as the two dependent factors. In the discussion of the results for hypothesis 1 , it was shown that there is a strong significant correlation between age and size within Ontario's wine industry. As a winery gets older it gets bigger (see Table 5 above). For this reason, the factorial MANOVA was tried. Though the Hotelling's Trace improved in significance from .566 to .135 by including age with size as a fixed factor in the MANOVA, the result was still not significant. Given the less than dramatic change in the significance by including age as an additional factor, it was not 
considered during the remainder of the analysis. Nevertheless, using the previous argument that the winery data was the result of a census, statistical analysis of the obstacles to growth based on size using t-tests and factor analysis is still considered to be valid.

A factor analysis of the perceived obstacles to growth was successful for both the craft and small winery groups. The results of the factor analysis are shown in Table 7 and Table 8 below. Both factor analyses explain $40 \%$ of the variance which is low.

Nevertheless, interpreting the results it can be seen that the perceived barriers are quite similar for both craft and small wineries with the difference being the ordering of the second and third factor. This most important factor for both (and for medium sized wineries as will be shown next) is government regulations. This was a consistent theme throughout the discussions with the winery owners. The second most important factor for craft wineries is market issues. This makes intuitive sense since a craft winery is still quite small and is trying to establish itself in the market. Though market issues are still important for small wineries they have dropped to third since the small winery has now reached a level of production where operational issues are more important. One has to solve operational issues in order to maintain market share and to continue growing.

\begin{tabular}{|l|l|}
\hline Factor & Obstacles making up factor \\
\hline 1. Regulatory & $\begin{array}{l}\text { Government regulations 4.1/5, Government paperwork 4.1/5, } \\
\text { Taxation levels 4.1/5 }\end{array}$ \\
\hline 2. Market issues & $\begin{array}{l}\text { Marketing 2.4/5, Small market base 3.0/5, Lack of consumer } \\
\text { awareness 3.2/5 }\end{array}$ \\
\hline 3. Operational & $\begin{array}{l}\text { Add or upgrade equipment 2.4/5, Obtain financing 2.5/5, Quality of } \\
\text { grapes 2.4/5 }\end{array}$ \\
\hline
\end{tabular}

Table 7: Factors affecting growth of craft wineries 


\begin{tabular}{|l|l|}
\hline Factor & Obstacles making up factor \\
\hline 1. Regulatory & $\begin{array}{l}\text { Government regulations 4.0/5, Government paperwork 3.8/5, } \\
\text { LCBO 4.6/5, Taxation levels 4.4/5, Low profitability 3.8/5 }\end{array}$ \\
\hline 2. Operational & $\begin{array}{l}\text { Obtaining financing 2.3/5, Management skills 2.0/5, Can't use } \\
\text { foreign content 2.5/5 }\end{array}$ \\
\hline 3. Market issues & Marketing 2.7/5, Lack of consumer awareness 3.7/5 \\
\hline
\end{tabular}

Table 8: Factors affecting growth of small wineries

For medium sized wineries the factor analysis was unsuccessful because the analysis factored on all the obstacles. So instead of using a factor analysis, it was decided to list the top seven obstacles by their average score (shown in Table 9 below) and perform ttests comparing obstacles between craft and medium wineries and small and medium wineries (shown in Table 10 and Table 11 below). As already mentioned, government regulations is a top factor just like it is for craft and small wineries.

\begin{tabular}{|c|l|}
\hline Obstacle & Score \\
\hline 1. Taxation levels & $4.57 / 5$ \\
\hline 2. Working with LCBO & $3.71 / 5$ \\
\hline 3. Government paperwork & $3.71 / 5$ \\
\hline 4. Cost of land & $3.71 / 5$ \\
\hline 5. Government regulations & $3.43 / 5$ \\
\hline 6. Finding qualified labour & $3.43 / 5$ \\
\hline 7. Quality of grapes & $3.14 / 5$ \\
\hline
\end{tabular}

Table 9: Obstacles for medium-sized wineries

\begin{tabular}{|l|l|l|l|}
\hline Obstacle & Craft score & Medium score & Significance \\
\hline Wine Content Act & $2.21 / 5$ & $1.14 / 5$ & $\mathrm{p}=.007$ \\
\hline Cost of land & $2.29 / 5$ & $3.71 / 5$ & $\mathrm{p}=.018$ \\
\hline Management skills & $1.92 / 5$ & $2.86 / 5$ & $\mathrm{p}=.025$ \\
\hline Small market base & $2.96 / 5$ & $2.14 / 5$ & $\mathrm{p}=.089$ \\
\hline Quality of grapes & $2.29 / 5$ & $3.14 / 5$ & $\mathrm{p}=.092$ \\
\hline
\end{tabular}

Table 10: Obstacles comparison craft vs medium wineries 


\begin{tabular}{|l|l|l|l|}
\hline Obstacle & Small score & Medium score & Significance \\
\hline Wine Content Act & $2.50 / 5$ & $1.14 / 5$ & $\mathrm{p}=.005$ \\
\hline Small market base & $3.25 / 5$ & $2.14 / 5$ & $\mathrm{p}=.011$ \\
\hline Consumer awareness & $3.70 / 5$ & $2.71 / 5$ & $\mathrm{p}=.043$ \\
\hline Management skills & $1.95 / 5$ & $2.86 / 5$ & $\mathrm{p}=.044$ \\
\hline LCBO & $4.55 / 5$ & $3.71 / 5$ & $\mathrm{p}=.045$ \\
\hline Low profitability & $3.75 / 5$ & $2.86 / 5$ & $\mathrm{p}=.051$ \\
\hline New equipment & $1.90 / 5$ & $2.86 / 5$ & $\mathrm{p}=.060$ \\
\hline Instable demand & $3.05 / 5$ & $2.29 / 5$ & $\mathrm{p}=.065$ \\
\hline
\end{tabular}

Table 11: Obstacle comparison small vs medium wineries

When comparing craft and medium wineries, the craft wineries are more concerned with small market issues and the wine content rules while the medium sized wineries are more concerned about cost of land, grape quality and management skill issues. These differences make intuitive sense based on the age of the wineries (medium sized wineries are older and not affected by the content rule) and that larger wineries need to source more quality grapes in order to service this growing market and need the management skills to operate a larger business. Craft wineries are still trying to establish themselves and sell what they produce and are more concerned with these issues.

When comparing small and medium wineries, the small wineries are again concerned about small market and the wine content rules but they have several other additional issues (instability of demand, consumer awareness, small market and LCBO). These additional issues reflect their business maturity as their business has reached another size level but they are not yet large enough to have mastered these issues to the same extent as the medium sized winery.

So in addition to the perceived barriers to growth being different based on the age of the winery, they are also different based on the size of the winery again supporting the empirical literature on growth. 


\subsubsection{Hypothesis 3}

Barriers are different for those wineries that grow most of their own grapes than for those wineries that purchase the majority of their grapes.

Independent t-tests were run comparing the perceived obstacles for those wineries that grow over $50 \%$ of the grapes used in their wine versus those wineries which grow less than $50 \%$. The differences are shown in Table 12 below. There are 17 wineries which grow less than $50 \%$ of their own grapes averaging $22 \%$ and there are 42 wineries which grow more than $50 \%$ averaging $80 \%(p<.001)$. In addition to the t-tests shown below, a factorial MANOVA using both winery size and percentage of grapes grown was performed to see if size was a convoluting variable. The results are not shown here since the interaction was not significant (Hotelling's Trace $\mathrm{p}=.239$ ). Furthermore, a MANCOVA was run with winery size as the covariate and this time the covariate was marginally significant (Hotelling's Trace $p=.074$ ) but it didn't meaningfully change any of the marginal means and the results are not shown here.

\begin{tabular}{|l|l|l|l|}
\hline Obstacle & Less than 50\% & More than 50\% & Significance \\
\hline Government paperwork & $3.00 / 5$ & $4.33 / 5$ & $\mathrm{p}=.000$ \\
\hline Own confidence & $1.06 / 5$ & $1.47 / 5$ & $\mathrm{p}=.002$ \\
\hline Marketing & $1.88 / 5$ & $2.78 / 5$ & $\mathrm{p}=.003$ \\
\hline Taxation levels & $3.71 / 5$ & $4.5 / 5$ & $\mathrm{p}=.010$ \\
\hline Availability of grapes & $\mathbf{3 . 0 6 / 5}$ & $\mathbf{2 . 1 4 / 5}$ & $\mathbf{p}=. \mathbf{0 2 1}$ \\
\hline Family demands & $1.53 / 5$ & $2.33 / 5$ & $\mathrm{p}=.024$ \\
\hline Government regulations & $3.35 / 5$ & $4.28 / 5$ & $\mathrm{p}=.030$ \\
\hline Instable demand & $2.41 / 5$ & $2.97 / 5$ & $\mathrm{p}=.068$ \\
\hline
\end{tabular}

Table 12: Differences in perceived obstacles based on growing the majority of own grapes

The above results are interesting in two ways. First, in seven of the eight differences (note that a total of 20 obstacles were measured) the wineries that grow greater than $50 \%$ of their grapes are more passionate about the obstacle. A possible explanation for this is 
likely due to amount of capital invested. Those wineries which grow more grapes have much more capital invested (land $[\sim \$ 60 \mathrm{~K} /$ acre $]$ and grape planting $[\sim \$ 10 \mathrm{~K} /$ acre $]$ ) and have that much more to lose. Generally those that have more "skin in the game" care more. This is why venture capitalists want to see an entrepreneur put some of their own money into the enterprise. The second observation from the data is the one obstacle (highlighted in the table) where the winery which buys more than $50 \%$ of their grapes is more concerned is in the availability of grapes. This makes intuitive sense since they have to buy more grapes (on average $58 \%$ more). Also interesting because of its absence is how they perceive quality of grapes since it does not appreciably differ between the two groups ( 2.5 vs. $2.8 \mathrm{p}=.33$ ). So quality isn't the main issue, it is availability. This will be discussed further in section 5.6 "The Winery and Grape Grower Dynamic" on page 95.

This is the first hypothesis so far which shows that the macro growth factor of a winery and grape grower dynamic likely exists within Ontario's VQA wine industry. It has been shown that supply issues (not quality) have more of an effect on those wineries which buy the majority of their grapes. Later on, it will be shown that there is further evidence of this factor.

\subsubsection{Hypothesis 4}

Those wineries which express a higher satisfaction score for their grape grower relationships will show statistically less interest in growing via backward integration. Backward integration in this context means planting more grapes.

This hypothesis was tested by performing a t-test comparing the grape grower relationship score for those wineries intending to plant more grapes and those which are 
not. To be included in this test a winery had to be purchasing grapes currently as well as intending to grow in some manner. There were a total of 41 wineries that met these criteria with 22 intending to plant grapes and 19 which did not. As predicted, those which were planning on planting more grapes had a lower grape grower satisfaction score (3.91/5) versus those which did not intend to plant more $(4.53 / 5, \mathrm{p}=.01)$. This result is consistent in that the quality of the business relationship is reflected in the likelihood of the winery engaging in backward integration. With respect to the overall objectives of this research, this finding helps in identifying possible causes of the growth intentions of the wineries.

\subsubsection{Hypothesis 5}

The barriers to growth viewed by those who desire to grow are different than those who do not wish to grow.

This was a challenging hypothesis to test for two reasons. The first reason was the unusually large percentage of respondents that expressed a desire to grow (90\% or 53 out of the 59 wineries). Typically expressed desire to grow for new businesses being incorporated (average across mixture of businesses being incorporated) is around $50 \%$. Given the substantially unequal group sizes (53 wanting to grow versus 6 which do not), statistics are somewhat questionable even with the knowledge that it is a virtual census. The second reason that makes testing this hypothesis challenging is the fact that only eight obstacle questions were the same between the two groups. Nevertheless, these eight obstacles where compared using t-tests and are shown in Table 13 below. Also the top four obstacles for each group are shown in Table 14 and Table 15 below. 


\begin{tabular}{|l|l|l|l|}
\hline Obstacle & No Grow & Grow & Significance \\
\hline Taxation levels & $2.50 / 5$ & $4.24 / 5$ & $\mathrm{p}=.048$ \\
\hline Cost of land & $1.50 / 5$ & $2.77 / 5$ & $\mathrm{p}=.052$ \\
\hline LCBO & $3.17 / 5$ & $4.15 / 5$ & $\mathrm{p}=.080$ \\
\hline Quality of grapes & $1.67 / 5$ & $2.58 / 5$ & $\mathrm{p}=.096$ \\
\hline Availability of grapes & $1.67 / 5$ & $2.43 / 5$ & $\mathrm{p}=.206$ \\
\hline Wine Content Act & $1.67 / 5$ & $2.13 / 5$ & $\mathrm{p}=.516$ \\
\hline Obtaining financing & $2.50 / 5$ & $2.36 / 5$ & $\mathrm{p}=.803$ \\
\hline Family obligations & $2.17 / 5$ & $2.08 / 5$ & $\mathrm{p}=.867$ \\
\hline
\end{tabular}

Table 13: Comparison of obstacles/reasons between wineries wanting and not wanting to grow

\begin{tabular}{|l|l|}
\hline Obstacle & No grow \\
\hline LCBO & $3.17 / 5$ \\
\hline Lose control over business & $3.17 / 5$ \\
\hline Content with way things are & $3.00 / 5$ \\
\hline Reluctant to incur debt & $2.83 / 5$ \\
\hline
\end{tabular}

Table 14: Top four reasons for wineries not wanting to grow

\begin{tabular}{|l|l|}
\hline Obstacle & Wants grow \\
\hline Taxation levels & $4.25 / 5$ \\
\hline LCBO & $4.15 / 5$ \\
\hline Government regulations & $3.98 / 5$ \\
\hline Government paperwork & $3.91 / 5$ \\
\hline
\end{tabular}

Table 15: Top four obstacle for wineries wanting to grow

Referring to Table 13 above, for those obstacles which have statistical significant differences between the two groups, the group that intends on growing rates the obstacle higher. It appears that those wanting to grow are more passionate about the obstacles because they need to overcome them in order to achieve their growth objectives. Not surprising for those few wineries not wanting to grow, three of the four top reasons are related to keeping things the way they are which is what would be expected since growth invariably means both risk and change. The only item which both groups have in common is their mutual dislike of the LCBO.

In summary, wineries not wanting grow view obstacles differently than those which want to grow proving the hypothesis. The validating of this hypothesis lends credence to the existence of the factor of intention to grow. 


\subsubsection{Hypothesis 6}

The dominant barriers to growth for small and mid-sized wineries will be access to capital.

Of the 20 obstacles that the survey respondents had to choose from "Obtaining financing" ranked $11^{\text {th }}$ for craft wineries with a score of $2.54 / 5$ and $15^{\text {th }}$ for small wineries with a score of 2.25/5. Given the low ranking for both winery sizes (the lowest score possible was $1 / 5$ ), it can be concluded that access to capital is not a major issue for these wineries. Medium-sized wineries ranked it $14^{\text {th }}(2.14 / 5)$ tied with four other obstacles. Though there are differences in the rating of "obtaining financing" for each size of winery, the differences are small and not statistically significant. Therefore within Ontario's VQA wine industry, it appears based on the data from this survey that if a relationship exists between size and access to capital, it is a very weak one.

\subsubsection{Hypothesis 7}

Those wineries that use long-term contracts (greater than one year) produce a higher percentage of premium and super-premium wine with purchased grapes than wineries that don't use long-term contracts.

Premium and super-premium wines were those wines that cost $\$ 15$ or more. This definition differs from the greater than $\$ 10$ definition that Vincor uses since the biggest volume price point independent of winery size is the $\$ 10$ to $\$ 15$. See Table 16 below which shows the winery size/volume data based on price points. The argument can be made that due to price inflation a truly premium wine is now greater than $\$ 15 \mathrm{CDN}$. 


\begin{tabular}{|l|l|l|l|l|l|}
\hline & $<\$ 10$ & $10-15$ & $15-20$ & $20-30$ & $>\$ 30$ \\
\hline craft & $11 \%$ & $32 \%$ & $22 \%$ & $20 \%$ & $15 \%$ \\
\hline small & $20 \%$ & $33 \%$ & $23 \%$ & $13 \%$ & $11 \%$ \\
\hline medium & $13 \%$ & $55 \%$ & $15 \%$ & $8 \%$ & $9 \%$ \\
\hline
\end{tabular}

Table 16: Price points and volume based on winery size

This hypothesis was tested two different ways. The first way was separating wineries into two groups based on those which use contracts and those which don't. An independent $\mathrm{t}$-test was then performed with the two groups using the percentage volume of wine produced above the $\$ 15$ price point using their own grapes and purchased grapes. The result of the t-test using their total production (which includes their own grapes and those that they purchased) is included for completeness. The second t-test repeats the same tests as the first but this time the two groups are those wineries that use single year contracts and those that use greater than one year contracts. The results are shown in Table 17 below.

\begin{tabular}{|l|l|l|l|l|l|l|}
\cline { 2 - 7 } \multicolumn{1}{c|}{} & \multicolumn{4}{c|}{ Contracts } & \multicolumn{3}{c|}{$>1$ year contracts } \\
\cline { 2 - 7 } \multicolumn{1}{c|}{} & Yes & No & P value & Yes & No & P value \\
\cline { 2 - 7 } \multicolumn{1}{c|}{} & $\mathrm{N}=34$ & $\mathrm{~N}=11$ & & $\mathrm{~N}=26$ & $\mathrm{~N}=8$ & \\
\hline Own grapes $>\$ 15$ & $58 \%$ & $39 \%$ & .127 & $56 \%$ & $63 \%$ & .604 \\
\hline Purchased grapes $>\$ 15$ & $44 \%$ & $26 \%$ & .134 & $40 \%$ & $57 \%$ & .210 \\
\hline Combined production $>\$ 15$ & $49 \%$ & $34 \%$ & .147 & $45 \%$ & $62 \%$ & .174 \\
\hline
\end{tabular}

Table 17: Grape contracts and volume price differences

With regards to using contracts or not using contracts, the results are clear. Those wineries which use contracts make more premium and super premium wine independent of winery size or the percentage of grapes that they purchase. These wineries make more premium wine with their own grapes, purchased grapes and with the combination. Also those wineries that use multi-year contracts make more premium and super premium wine than those wineries that don't use contracts. 
The one seemingly contradictory result is the difference between those wineries that use single year contracts and those that use multi-year contracts. Those wineries that use single year contracts produce more premium and super premium wine than those wineries that use multi-year contracts. In trying to determine the cause of this, t-tests were carried out to determine if these differences could be explained by either the winery owner deriving their primary source of income from the winery or the percentage of grapes that the winery grows themselves. There was no difference based on source of income but for those wineries that used single year contracts, they grew $58 \%$ of their grapes versus $46 \%$ for those that used multi-year contracts but this was not significant with $\mathrm{p}=.312$. Nevertheless, given that the survey was a virtual census there may be something to this finding. Maybe those wineries which grow most of their own grapes don't have the same need for or want the risk of entering into long term contracts. Maybe they only setup contracts when their wines from previous vintages have sold well and they can take on the risk of increasing their inventory. It is interesting to note that the wineries that use only single year contracts produce considerable more (on a percentage volume basis) premium wine than those that use multi-year contracts $(62 \%$ vs $45 \% \mathrm{p}=.174)$. Maybe this in an indication that there is less certainty in selling premium wine than there is in nonpremium wine.

From the viewpoint of the macro factor on how grape growers and wineries interact, it appears that contracts are used to achieve a higher quality wine production. As a side note, it was also found that those wineries which use contracts are twice as likely to state a growth strategy of planting more grapes $(61 \%$ vs $30 \% \mathrm{p}=.088)$ and express a slightly lower grower relationship satisfaction rate $(4.15$ vs $4.45 p=.251)$. Wineries that use 
contracts produce a higher percentage of premium wine but it appears that they are slightly more disappointed in the quality they get from the grower. The unproven assumption here is that grower relationship satisfaction is a proxy for grape quality. Using this assumption, disappointment then leads them to express a much greater desire for backward integrating (i.e. planting more grapes) in order to ensure a stable supply of quality grapes..

\subsubsection{Hypothesis 8}

Marketing competency is weaker for craft and small wineries than for medium and large wineries.

Given that only two large wineries participated in the survey, comparisons were made to medium wineries only. There were five marketing competency questions on the questionnaire. The results were compared two ways. The first way was comparing the means for each of the five questions individually and the second way was comparing an aggregated score. The aggregated score was determined by summing each winery's responses for the five questions and then dividing by five. Partial results are shown in Table 18 below. The results that are not shown are not significant but in absolute terms, the means on all the measures are lower for the craft in comparison to small wineries and both craft and small wineries in comparison to medium sized wineries with one exception. The one exception is for "using market research" between small and medium wineries where small wineries scored $3.45 / 5$ to medium wineries $3.38 / 5(p=.878)$. 


\begin{tabular}{|c|c|c|c|}
\hline & Craft & Medium & Significance \\
\hline $\begin{array}{l}\text { Aggregate marketing } \\
\text { competency score }\end{array}$ & $3.66 / 5$ & $4.2 / 5$ & $p=.097$ \\
\hline Developing relationships & $4.26 / 5$ & 4.88 & $p=.006$ \\
\hline \multirow{2}{*}{$\begin{array}{l}\text { Commercializing a new } \\
\text { product or service }\end{array}$} & $3.7 / 5$ & $4.5 / 5$ & $p=.066$ \\
\hline & Small & Medium & Significance \\
\hline $\begin{array}{l}\text { Aggregate marketing } \\
\text { competency score }\end{array}$ & $3.97 / 5$ & $4.20 / 5$ & $\mathrm{p}=.442$ \\
\hline Developing relationships & $4.41 / 5$ & $4.88 / 5$ & $\mathrm{p}=.021$ \\
\hline
\end{tabular}

Table 18: Marketing competency comparison

As can be seen from the results, craft and small wineries do in fact rate themselves lower on marketing competency measures though the results are less significant for the differences between the small and medium wineries which makes intuitive sense. As the winery gets bigger, it becomes more competent and the skill differences become less acute.

In conversations with the numerous players that make up Ontario's VQA wine production, it became anecdotally apparent that wineries might not be making the best use of market research. As it turns out, of the five marketing competency skills that were measured, "using marketing research" was the weakest with a score of $3.2 / 5$ when averaged for all wineries. This score was significantly different $(p=.006)$ from the next ranked skill which was "promotion and advertising" which had a score of 3.63/5.

The purpose of including this hypothesis in the research was to confirm the findings from the literature review that the skill competencies (in this case marketing competency) of Ontario's wineries do indeed increase as the size of the firm increases.

\subsubsection{Hypothesis 9}

Wineries that have a weak marketing competency will score the LCBO higher as a barrier than wineries with a strong marketing competency. 
The purpose of this hypothesis was to try and determine a possible underlying cause for why smaller wineries have a much higher expressed dissatisfaction with the LCBO in comparison to larger wineries. The idea here was that it could be explained by the smaller wineries' weaker marketing competency and therefore lack of understanding of working with a large retailer.

From hypothesis 8 above it was shown that marketing competency increases as the size of the winery increases. Also from hypothesis 8 , the aggregated marketing competency score was under 4/5 (3.66/5 and 3.97) for both the small and craft wineries and above 4 for the medium wineries (4.20/5). Therefore a score of $4 / 5$ and above was chosen as the cut-off point for the group which was deemed to be marketing competent and those wineries with a score below $4 / 5$ as having a weak marketing competency. One might think that a score of $4 / 5$ is rather high for a cut-off but it should be noted that this competency measurement was a self-assessment. Furthermore, using $4 / 5$ as the cut-off point also divided the group into two almost equal groups (26 and 27 members each).

When the independent t-tests were run using these two groups' rating of the LCBO as an obstacle, the results were virtually identical with score of $4.19 / 5$ for the group with market competency below $4 / 5$ and $4.11 / 5$ for the other group $(p=.811)$. Therefore the hypothesis as proposed is not supported. Marketing competency as measured by a selfassessment is not a predictor of the winery's perception of the LCBO as an obstacle.

For the sake of completeness, Table 19 below shows how each winery size group rates the LCBO. Notice how the highest score is given by small wineries not craft wineries. From conversations with winery owners, this appears to be due to small wineries having no choice but to work with the LCBO since that is one of the major ways 
of growing the business (in addition to exporting and inter-provincial). On the other hand, craft wineries can generally sell all their wine (5000 cases or less) using their retail store and licensee sales and therefore don't have to work with the LCBO. By the time a winery has reached the size of a medium winery (greater than 30,000 cases), they have mastered the skill (risk?) of working with the LCBO.

\begin{tabular}{|l|l|l|}
\hline & LCBO obstacle score & $\begin{array}{l}\text { Significance with medium winery } \\
\text { score (t-test) }\end{array}$ \\
\hline Craft winery & $4.12 / 5$ & $\mathrm{p}=.221$ \\
\hline Small winery & $4.55 / 5$ & $\mathrm{p}=.045$ \\
\hline Medium winery & $3.71 / 5$ & \\
\hline
\end{tabular}

Table 19: $L C B O$ as obstacle by winery size

\subsubsection{Summary of Winery Hypotheses and Findings}

Table 20 below presents a summary of the winery hypotheses and finding which were discussed individually in the previous sections. 


\begin{tabular}{|c|c|c|}
\hline Hypothesis & Area being tested & Finding \\
\hline $\begin{array}{l}\text { 1. Barriers perceived by old } \\
\text { and new wineries will be } \\
\text { different. }\end{array}$ & $\begin{array}{l}\text { Investigates age } \\
\text { growth factor }\end{array}$ & $\begin{array}{l}\text { Yes perceived barriers are } \\
\text { different when wineries are } \\
\text { grouped by their age. }\end{array}$ \\
\hline $\begin{array}{l}\text { 2. Barriers will be different } \\
\text { based on the size of winery. }\end{array}$ & $\begin{array}{l}\text { Investigates size } \\
\text { growth factor }\end{array}$ & $\begin{array}{l}\text { Yes perceived barriers are } \\
\text { different based on size. }\end{array}$ \\
\hline $\begin{array}{l}\text { 3. Barriers are different for } \\
\text { those wineries that grow most } \\
\text { of their own grapes than for } \\
\text { those wineries that purchase } \\
\text { the majority of their grapes. }\end{array}$ & $\begin{array}{l}\text { Investigates } \\
\text { macro factor of } \\
\text { grape } \\
\text { grower/winery } \\
\text { acrimony }\end{array}$ & $\begin{array}{l}\text { Yes perceived barriers are } \\
\text { different for those which buy a } \\
\text { majority of their grapes (supply } \\
\text { issues). }\end{array}$ \\
\hline $\begin{array}{l}\text { 4. Those wineries which } \\
\text { express a higher satisfaction } \\
\text { score for their grape grower } \\
\text { relationships will show } \\
\text { statistically less interest in } \\
\text { growing via backward } \\
\text { integration. }\end{array}$ & $\begin{array}{l}\text { Investigates } \\
\text { macro factor of } \\
\text { grape } \\
\text { grower/winery } \\
\text { acrimony }\end{array}$ & $\begin{array}{l}\text { This hypothesis was found to be } \\
\text { true with a satisfaction } \\
\text { difference of } 3.91 / 5 \mathrm{vs} 4.53 / 5 \\
\mathrm{p}=.01 \text { between those wanting to } \\
\text { plant and those not wanting to } \\
\text { plant respectively. }\end{array}$ \\
\hline $\begin{array}{l}5 . \text { The barriers to growth } \\
\text { viewed by those who desire } \\
\text { to grow are different than } \\
\text { those who do not wish to } \\
\text { grow. }\end{array}$ & $\begin{array}{l}\text { Investigates } \\
\text { intention growth } \\
\text { factor }\end{array}$ & $\begin{array}{l}\text { The perceived barriers were } \\
\text { found to differ depending on if } \\
\text { the winery wanted to grow or } \\
\text { not. }\end{array}$ \\
\hline $\begin{array}{l}\text { 6. The dominant barriers to } \\
\text { growth for small and mid- } \\
\text { sized wineries will be access } \\
\text { to capital. }\end{array}$ & $\begin{array}{l}\text { Investigates size } \\
\text { and financial } \\
\text { flexibility growth } \\
\text { factors }\end{array}$ & $\begin{array}{l}\text { Access to capital was not an } \\
\text { issue for small and mid-sized } \\
\text { wineries. }\end{array}$ \\
\hline $\begin{array}{l}\text { 7. Those wineries that use } \\
\text { long-term contracts produce a } \\
\text { higher percentage of premium } \\
\text { and super-premium wine with } \\
\text { purchased grapes than } \\
\text { wineries that don't use long- } \\
\text { term contracts. }\end{array}$ & $\begin{array}{l}\text { Investigates } \\
\text { macro factor of } \\
\text { grape } \\
\text { grower/winery } \\
\text { acrimony }\end{array}$ & $\begin{array}{l}\text { Yes wineries that use contracts } \\
\text { produce a higher percentage of } \\
\text { premium and super-premium } \\
\text { wine. }\end{array}$ \\
\hline $\begin{array}{l}\text { 8. Marketing competency is } \\
\text { weaker for craft and small } \\
\text { wineries than for medium and } \\
\text { large wineries. }\end{array}$ & $\begin{array}{l}\text { Investigates if } \\
\text { marketing } \\
\text { competency and } \\
\text { size are related }\end{array}$ & $\begin{array}{l}\text { Yes marketing competency was } \\
\text { shown to increase as the size of } \\
\text { the winery increased. }\end{array}$ \\
\hline $\begin{array}{l}\text { 9. Wineries that have a weak } \\
\text { marketing competency will } \\
\text { score the LCBO higher as a } \\
\text { barrier than wineries with a } \\
\text { strong marketing } \\
\text { competency. }\end{array}$ & $\begin{array}{l}\text { Investigates } \\
\text { relationship } \\
\text { between macro } \\
\text { factor of LCBO } \\
\text { and factor of } \\
\text { marketing } \\
\text { competency }\end{array}$ & $\begin{array}{l}\text { The data did not support this } \\
\text { hypothesis. There could be an } \\
\text { issue with the predictor used to } \\
\text { measure marketing competency. }\end{array}$ \\
\hline
\end{tabular}

Table 20: Summary of winery hypotheses findings 


\subsection{Grape Grower Hypotheses}

As mentioned previously, the purpose of all the grape grower hypotheses is to investigate the macro factor of the winery and grape grower acrimony. There are five hypotheses related to the grape growers. Each hypothesis will be discussed in turn.

\subsubsection{Hypothesis 1}

Grape growers that express a higher satisfaction score for their buyer relationships are less likely to express an interest in forward integration (becoming a winery) than those grape growers that express a lower satisfaction score for their buyer relationships.

As will be discussed further in the next hypothesis, there were an almost equal number of grape growers that wanted to grow (31) and that didn't want to grow (34) (don't know $=5$ ). This equal split between those wanting to grow and those that don't want to grow is a more typical growth expectation response in comparison to that of the wineries. Of the 31 that wanted to grow only 19 were not already wineries. Of these 19 remaining grape growers, only four stated becoming a winery as one of their growth objectives. Having only four grape growers wanting to become a winery doesn't make for meaningful statistical analysis. Unlike the winery survey where it was a virtual census, the grape grower survey had responses from $17.5 \%$ of the population. Therefore variance has to be considered. With this in mind those grape growers not wanting to become a winery had a mean winery relationship score of $3.67 / 5$ versus $3.75 / 5$ for those growers which wanted to become a winery $(p=.921)$. These scores are virtually the same, so the hypothesis has not been proven. So it appears that dissatisfaction with the winery relationship is not the factor driving grape growers to become wineries. 


\subsubsection{Hypothesis 2}

Barriers to growth are different for those that intend to grow and those that don't.

In the grape grower questionnaire there are nine reasons/obstacles in common between the list of reasons for not growing and the perceived obstacles of those wanting to grow. Before analysing the differences between the two groups, it was necessary to determine if the different grower types would affect the analysis. As describe earlier, there are in fact three types of grape growers: growers for whom growing grapes is their primary source of income; growers for whom growing grapes is not their primary source of income; and wineries which grow grapes. In order to determine if their responses interact in a significant manner a MANOVA was carried out with the nine common obstacles as the dependent variables and the three fixed factors. The three fixed factors were: if the grower was a winery; if the grower derived its primary source of income from grape growing; and if the grower wanted to grow or not. The last fixed factor is the one that this hypothesis is testing. None of the interactions were significant (Hotelling's traces ranged in significance from $\mathrm{p}=.323$ to $\mathrm{p}=.972$ ) and the results are not reported here. With this finding it was possible to analyse the obstacles based on the factor wanting or not wanting to grow alone.

The Hotelling's trace of the MANOVA with the nine common obstacles as the dependent and wanting to grow as the fixed factor was marginally significant at $p=.059$. For the individual obstacles, the overall significance was set at .15 and with nine obstacles in total the individual obstacle significance is $.15 / 9=.017$. Using this as the criteria, taxes are the only obstacle that is significantly different between the two groups. Since not all growers answered all questions, there were 30 growers not wanting to grow 
and 28 wanting to grow included in the analysis. The results of the MANOVA showing estimated marginal means are shown in Table 21 below.

\begin{tabular}{|l|l|l|l|}
\hline Obstacle & No Grow & Grow & Significance \\
\hline Taxes & $2.43 / 5$ & $3.82 / 5$ & $\mathrm{p}=.001$ \\
\hline Family obligations & $1.97 / 5$ & $2.43 / 5$ & $\mathrm{p}=.180$ \\
\hline Obtaining financing & $3.00 / 5$ & $2.57 / 5$ & $\mathrm{p}=.264$ \\
\hline Cost of land & $3.30 / 5$ & $3.64 / 5$ & $\mathrm{p}=.366$ \\
\hline Agree on viticulture techniques & $1.87 / 5$ & $2.14 / 5$ & $\mathrm{p}=.418$ \\
\hline Which varieties to grow & $2.30 / 5$ & $2.54 / 5$ & $\mathrm{p}=.499$ \\
\hline Wine Content Act & $3.53 / 5$ & $3.25 / 5$ & $\mathrm{p}=.524$ \\
\hline Price of grapes & $3.37 / 5$ & $3.50 / 5$ & $\mathrm{p}=.750$ \\
\hline Getting long-term contracts & $2.67 / 5$ & $2.54 / 5$ & $\mathrm{p}=.762$ \\
\hline
\end{tabular}

Table 21: Comparison of perceived obstacles for those not wanting to grow and wanting to grow

As can be seen from the results above, the differences between those wanting to grow and those not wanting to grow are marginal other than their view on taxes. In order to complete the picture, the top reasons for those growers not wanting to grow and those growers wanting to grow are presented separated into the three grower types below in Table 22 and Table 23 respectively.

\begin{tabular}{|c|c|c|}
\hline Grower type & Reason for not growing & Score \\
\hline \multirow{3}{*}{$\begin{array}{l}\text { Primary source of income } \\
N=9\end{array}$} & Wine Content Act & $4.13 / 5$ \\
\hline & Market not growing & $3.89 / 5$ \\
\hline & Price of grapes & $3.78 / 5$ \\
\hline \multirow{3}{*}{$\begin{array}{l}\text { Secondary source of } \\
\text { income } \\
N=21\end{array}$} & Wine Content Act & $3.61 / 5$ \\
\hline & Risks are too high & $3.57 / 5$ \\
\hline & Content way things are & $3.43 / 5$ \\
\hline \multirow{3}{*}{$\begin{array}{l}\text { Winery } \\
N=4\end{array}$} & Reluctant to incur debt & $4.00 / 5$ \\
\hline & Don't want to lose control & $3.75 / 5$ \\
\hline & Content way things are & $3.50 / 5$ \\
\hline
\end{tabular}

Table 22: Top reasons why growers don't want to grow 


\begin{tabular}{|l|l|l|}
\hline Grower type & Reason for not growing & Score \\
\hline \multirow{3}{*}{$\begin{array}{l}\text { Primary source of income } \\
\text { N=10 }\end{array}$} & Wine Content $A c t$ & $4.40 / 5$ \\
\cline { 2 - 3 } & Price of grapes & $4.20 / 5$ \\
\cline { 2 - 3 } & Cost of land & $4.10 / 5$ \\
\hline \multirow{2}{*}{$\begin{array}{l}\text { Secondary source of } \\
\text { income }\end{array}$} & Low profitability & $3.67 / 5$ \\
\cline { 2 - 3 } $\mathrm{N}=9$ & Price of grapes & $3.56 / 5$ \\
\cline { 2 - 3 } $\begin{array}{l}\text { Winery } \\
\mathrm{N}=12\end{array}$ & Tax levels & $3.33 / 5$ \\
\cline { 2 - 3 } & Tax levels & $4.58 / 5$ \\
\cline { 2 - 3 } & Government regulations & $4.33 / 5$ \\
\cline { 2 - 3 } & Low profitability & $4.00 / 5$ \\
\hline
\end{tabular}

Table 23: Top obstacles for growers wanting to grow

It is interesting to note that the top three reasons for the primary source of income grape growers are very similar for those that want to grow and those that don't. Both have the Wine Content Act as the top reason/obstacle with the price of grapes coming in second and third respectively. Another point of note is how differently the wineries view the issues. Winery grape growers and primary income grape growers see things quite differently. For those winery grape growers that aren't content with the way things are, they don't won't to grow because of the perceived risk to the business in growing. For those winery grape growers that want to grow it is an issue of government issues and profitability. The argument can be made that the Wine Content Act which the primary income grape growers complain about is just another aspect of government regulation. Also how different is the low profitability of the winery grape growers from the issue of low price of grapes of the primary income grape growers? It is different sides of the same coin.

So to answer the question poised by the hypothesis, yes the perceived obstacles are statistically different between those growers who want to grow and those who do not. But the more interesting aspect is in understanding how the different types of growers 
perceive the obstacles, though the results were not statistically significant. This is yet another aspect of the grape grower and winery interaction macro factor.

\subsubsection{Hypothesis 3}

Grape growers that have contracts that have viticulture specifications express a higher satisfaction score for their buyer relationships than those grape growers without such contracts.

This hypothesis was tested without including the winery grape growers since they sell most of their grapes to their own winery. The rest of the grower data was tested using ttests as one group as well as dividing it into two groups representing the primary income grape growers and the non-primary income grape growers. Analysing based on income was motivated by the possibility that those who do not have to earn their livelihood from the business might be different in their outlook and approach. The grape grower questionnaire asked three different questions about contracts. The first question was if contracts were used or not. The second question was if the contracts lasted more than a year and the third question asked if the contracts specified viticulture techniques. When testing as one group there were no statistically significant findings, though in each case the group that answered "no" to the question (i.e. didn't have the contract etc.) had a higher winery relationship score. The data is presented in Table 24 below.

\begin{tabular}{|l|l|l|l|}
\hline & \multicolumn{2}{|c|}{ Winery relationship score } & \\
& Yes & No & Significance \\
\hline Do you have contracts? & $3.57 / 5 \mathrm{~N}=35$ & $3.83 / 5 \mathrm{~N}=18$ & $\mathrm{p}=.362$ \\
\hline Contracts $>1$ year? & $3.52 / 5 \mathrm{~N}=31$ & $3.67 / 5 \mathrm{~N}=3$ & $\mathrm{NA}(\mathrm{N}=3)$ \\
\hline Detailed viticulture techniques? & $3.40 / 5 \mathrm{~N}=20$ & $3.71 / 5 \mathrm{~N}=14$ & $\mathrm{p}=.356$ \\
\hline
\end{tabular}

Table 24: Grower contracts and winery relationship scores

From the above data, it gives the impression that contracts actually hinder the relationship rather than help it. Next the responses to the same questions were analysed 
but this time the data was separated based on if grape growing was a primary source of income or not. The results are shown in Table 25 and Table 26 below. By analysing the data this way it becomes apparent that the negative affect which contracts have on the winery relationship come from the primary income growers for two of the three questions. The only one in which both types of growers agree on (again negatively) is on contracts that specify viticulture techniques. One can hypothesize that viticulture techniques are viewed by all growers as extra work and if it involves thinning the crop, it can reduce their income. But with regards to why primary income grape growers have a lower winery relationship score when they have contracts is hard to explain other than it might be just a statistical anomaly given that there are only four responses.

\begin{tabular}{|l|l|l|l|}
\hline & \multicolumn{2}{|c|}{ Winery relationship score } & \\
\cline { 4 - 5 } & Yes & No & Significance \\
\hline Do you have contracts? & $3.17 / 5 \mathrm{~N}=18$ & $4.25 / 5 \mathrm{~N}=4$ & NA $(\mathrm{N}=4)$ \\
\hline Contracts $>1$ year? & $3.06 / 5 \mathrm{~N}=17$ & $\mathrm{~N}=0$ & \\
\hline Detailed viticulture techniques? & $2.90 / 5 \mathrm{~N}=10$ & $3.29 / 5 \mathrm{~N}=7$ & $\mathrm{p}=.436$ \\
\hline
\end{tabular}

Table 25: Primary income grape grower and contracts

\begin{tabular}{|l|l|l|l|}
\hline & \multicolumn{2}{|c|}{ Winery relationship score } & \\
\cline { 1 - 1 } & Yes & No & Significance \\
\hline Do you have contracts? & $4.00 / 5 \mathrm{~N}=17$ & $3.71 / 5 \mathrm{~N}=14$ & $\mathrm{p}=.401$ \\
\hline Contracts $>1$ year? & $4.07 / 5 \mathrm{~N}=14$ & $3.67 / 5 \mathrm{~N}=3$ & $\mathrm{NA}(\mathrm{N}=3)$ \\
\hline Detailed viticulture techniques? & $3.90 / 5 \mathrm{~N}=10$ & $4.14 / 5 \mathrm{~N}=7$ & $\mathrm{p}=.504$ \\
\hline
\end{tabular}

Table 26: Not primary income grape grower and contracts

In conclusion, primary income grape growers rate the winery relationship much lower in general than non-primary income grape growers and this lowers the overall scores making it appear that contracts lower the winery relationship score for all types of growers. Anomalous and unexplained (other than a possible statistical anomaly with only four responses) is the situation where primary income grape growers that don't have 
contracts are happier with the winery. It appears that all grape growers don't like viticulture techniques specified in the contracts. The hypothesis is partially true (for nonprimary income grape growers) and partially false (contracts specifying viticulture techniques) with one part requiring further data (increasing from only four responses for the one situation).

\subsubsection{Hypothesis 4}

Those grape growers that are paid a premium for their grapes express a higher satisfaction score for their buyer relationships than those that are not paid a premium.

There was an issue in the way the question that was used to answer this hypothesis was placed in the questionnaire. Instead of asking all growers if they were sometimes paid a premium for their grapes, the question was only asked if respondents answered "yes" or "sometimes" in response to if they had contracts that specified viticulture techniques. The answer to this question is interesting but doesn't answer the broader question of premiums in general. So the results presented in Table 27 below answer the question does paying the grape growers a premium for following viticulture techniques in a contract increase the winery relationship score. The results show no difference between the winery relationship scores for those that are paid a premium and those that are not for following viticulture techniques. With the caveat that it is a small sample, it appears that paying a premium for following viticulture techniques doesn't affect the winery relationship score.

\begin{tabular}{|l|l|l|l|}
\hline & \multicolumn{2}{|l|}{ Premium for following viticulture techniques } & \\
\hline & Yes & No & Significance \\
\hline $\begin{array}{l}\text { Winery relationship } \\
\text { score }\end{array}$ & $3.38 / 5 \mathrm{~N}=13$ & $3.40 / 5 \mathrm{~N}=5$ & $\mathrm{P}=.977$ \\
\hline
\end{tabular}

Table 27: Effects of paying a premium for specific viticulture techniques 


\subsubsection{Hypothesis 5}

(a) Those grape growers which have contracts with viticulture specifications of duration of greater than one year perceive different barriers to growth than those that don't.

For this hypothesis, the sample was only those grape growers which had contracts. The purpose of this was in trying to determine if having viticulture techniques specified in the contracts gave these grape growers a different perspective. Only those nine reasons/obstacles that were in common with those not wanting to grow and wanting to grow were analysed. A MANOVA was run with the reasons/obstacles as dependent variables and if they had contracts with viticulture specifications as the fixed factor. There were 12 growers which had contracts without viticulture specifications and 16 growers that did. The Hotelling's trace for the MANOVA had a significance of .403 which is nowhere near the typical .05 level of significance. Therefore the hypothesis is not proven. Out of interest the top three differences are listed in Table 28 below. It is interesting to note that those wineries that don't have viticulture techniques specified are more concerned about the Wine Content Act. This appears to indicate that growers with specified viticulture techniques are confident that their grapes are of better quality and the Wine Content Act doesn't have the same effect on them. Nevertheless they seem to be more worried about getting long-term contracts (or is this more in trying to keep the ones they already have?). Lastly, the MANOVA was run as a MANCOVA with proceeds as the covariate. The MANCOVA was not significant and the means changed negligibly so the results are not reported here. 


\begin{tabular}{|l|l|l|l|}
\hline Reason/Obstacle & $\begin{array}{l}\text { No vit. } \\
\text { specified }\end{array}$ & $\begin{array}{l}\text { Viticulture } \\
\text { specified }\end{array}$ & Significance \\
\hline Taxes & $2.58 / 5$ & $3.50 / 5$ & $\mathrm{p}=.117$ \\
\hline Wine Content Act & $4.17 / 5$ & $3.38 / 5$ & $\mathrm{p}=.152$ \\
\hline Getting long-term contracts & $2.41 / 5$ & $3.19 / 5$ & $\mathrm{p}=.171$ \\
\hline
\end{tabular}

Table 28: Comparison of grower perception of obstacles based on viticulture specifications in contracts

(b) Those grape growers that are paid a premium for their grapes perceive different barriers to growth than those that don't

As already mentioned in the results for hypothesis four, the question regarding premium prices for grapes was asked only in conjunction with the grower following specified viticulture techniques from their contract with the winery. In addition, to be included in this specific analysis the grower could not answer "don't know" to the "are you planning to grow question" since that would mean that they didn't fill in any of the "reason for not growing" questions or "obstacle to growth" questions. As it turned out, three of the growers which weren't paid premiums were in this category. Lastly, one other grower that wasn't paid a premium didn't answer all the questions. This then left 13 growers which were paid premiums and one which wasn't to do the analysis with. Having only one grower in the "did not receive a premium" category made the results of the analysis not useful. So the results are not reported here and this hypothesis remains untested.

\subsubsection{Summary of Grape Grower Hypotheses and Findings}

Table 29 below presents a summary of the winery hypotheses and finding which were discussed individually in the previous sections. 


\begin{tabular}{|l|l|l|}
\hline Hypothesis & Area being tested & Finding \\
\hline $\begin{array}{l}\text { l. Grape growers that express a } \\
\text { higher satisfaction score for their } \\
\text { buyer relationships are less likely to } \\
\text { express an interest in forward } \\
\text { integration }\end{array}$ & $\begin{array}{l}\text { Investigates } \\
\text { winery and grape } \\
\text { grower dynamic }\end{array}$ & $\begin{array}{l}\text { This hypothesis was not } \\
\text { supported by the data. Not } \\
\text { enough grape growers } \\
\text { wanted to become } \\
\text { wineries }\end{array}$ \\
\hline $\begin{array}{l}\text { 2. Barriers to growth are different } \\
\text { for those that intend to grow and } \\
\text { those that don't. }\end{array}$ & $\begin{array}{l}\text { Investigates } \\
\text { winery and grape } \\
\text { grower dynamic }\end{array}$ & $\begin{array}{l}\text { Yes the data supports the } \\
\text { hypothesis. }\end{array}$ \\
\hline $\begin{array}{l}\text { 3. Grape growers that have contracts } \\
\text { that have viticulture specifications } \\
\text { express a higher satisfaction score } \\
\text { for their buyer relationships than } \\
\text { those grape growers without such } \\
\text { contracts. }\end{array}$ & $\begin{array}{l}\text { Investigates } \\
\text { winery and grape } \\
\text { grower dynamic }\end{array}$ & $\begin{array}{l}\text { Hypothesis is not } \\
\text { supported. Growers are } \\
\text { happier not having } \\
\text { viticulture specifications. }\end{array}$ \\
\hline $\begin{array}{l}\text { 4. Those grape growers that are paid } \\
\text { a premium for their grapes express a } \\
\text { higher satisfaction score for their } \\
\text { buyer relationships than those that } \\
\text { are not paid a premium. }\end{array}$ & $\begin{array}{l}\text { Investigates } \\
\text { winery and grape } \\
\text { grower dynamic }\end{array}$ & $\begin{array}{l}\text { This hypothesis was not } \\
\text { supported but there was } \\
\text { minimal data collected } \\
\text { due to an issue with the } \\
\text { questionnaire. }\end{array}$ \\
\hline $\begin{array}{l}\text { 5a. Those grape growers which have } \\
\text { contracts with viticulture } \\
\text { specifications of duration of greater } \\
\text { than one year perceive different } \\
\text { barriers to growth than those that } \\
\text { don't. }\end{array}$ & $\begin{array}{l}\text { Investigates } \\
\text { winery and grape } \\
\text { grower dynamic }\end{array}$ & $\begin{array}{l}\text { This hypothesis was not } \\
\text { supported by the data } \\
\text { with no significant } \\
\text { differences between the } \\
\text { two groups. }\end{array}$ \\
\hline $\begin{array}{l}\text { 5b. Those grape growers that are } \\
\text { paid a premium for their grapes } \\
\text { perceive different barriers to growth } \\
\text { than those that don't. }\end{array}$ & $\begin{array}{l}\text { Investigates } \\
\text { winery and grape } \\
\text { grower dynamic }\end{array}$ & $\begin{array}{l}\text { Due to the same } \\
\text { questionnaire issue that } \\
\text { affected hypothesis 4, it } \\
\text { was not possible to test } \\
\text { this hypothesis. }\end{array}$ \\
\hline
\end{tabular}

Table 29: Summary of grower hypotheses findings

\subsection{Growth Model}

\subsubsection{Hypothesis 1}

Financial flexibility is a function of intention to grow, innovation, marketing competency, age of winery, size of winery, and the macroeconomic factor of level of satisfaction expressed with the grape growers. Also tested here is the correlation between age and size. 
For this research a slightly different definition of financial flexibility was used other than that of have financing coming from multiple sources. It was thought that asking wineries their financial structure would be too personal a question and that it was likely to be met with resistance. In order to circumvent this resistance and obtain the required information, asking each winery their ability to get the financing they needed was used as a proxy.

This hypothesis was tested using backward linear regression (probability of F for removal $>=.10$ ) with financial flexibility as the dependent variable and the other factors as the independent variables. How each of the measures used in the linear regression were calculated will be explained next.

The financial flexibility measure was created for each winery by subtracting the winery's response to either the "lack of growth capital" from the reason not to grow or "obtaining financing" from obstacles to growth from "6" in order to invert the scale. Therefore "1" would now mean that it was significant and " 5 " would mean no problem. Then the winery's response to question D13 (winery able to get money to finance growth) would be added to this and the result divided by "2". This would result in a new " 5 " point scale measure of each winery's ability to get financing with " 1 " signifying inability and " 5 " signify that there is no problem.

Intention to grow was a Boolean with " 0 " meaning not wanting to grow and " 1 " meaning planning on growing.

A winery's innovation was calculated by averaging the responses to questions D14 and D15 (See Appendix II for copy of the winery questionnaire). 
Marketing competency was the same measure as described in section 5.3.8 Hypothesis 8 on page 75 .

The number of years that the winery was in business was used as the age factor. Size of the winery was the four point scale of whether the winery was a craft, small, medium or large winery with "one" representing craft winery.

Grape grower relationship was the wineries response to question B8.

After running the regression, the first thing that was noticed was the significant correlation between age and size (Pearson correlation $=.736, \mathrm{p}<.001)$. Within the wine industry the generalization can be made that you definitely get bigger with age. The resulting unstandardized linear equation resulting from the regression was financial flexibility $=5.12-0.47 *$ Market Competency $+.48 *$ Size with an $\mathrm{R}^{2}$ of .161 and an ANOVA significance of $p=.033$. The coefficient for market competency has a significance of $p=.051$ and size is $p=.033$. In looking at the results, the positive coefficient associated with size lines up quite nicely with the conceptual model. As a winery becomes larger its financial flexibility increases. The negative coefficient for market competency was not predicted by the conceptual model. One would have expected that as market competency increases that this was a sign of a more mature firm and would be reflected in better financial flexibility. One possible explanation for this contrary result is that the measure used for market competency is a selfassessed measure and the respondents have a tendency to overrate their abilities. Another explanation is as a winery develops more marketing expertise they then want to expand faster than their sources of capital are comfortable with. This could be an indication that external sources of capital are sceptical of how quickly wineries can 
grow. Further research is required to determine the source of this response and to see if it is unique to the just the wine industry.

The following is a brief discussion of those factors that didn't make it into the final regression equation. Since age and size were highly correlated, it is not surprising that age didn't make it into the final equation. To explore this, another regression was run and this time the winery's actual volume of production in thousands of cases was used instead of the four point scale for size. In this case volume and age are highly correlated (Pearson correlation $=.579, \mathrm{p}<.001)$ and the final regression has marketing competency and age (rather than volume) with a slightly lower $\mathrm{R}^{2}$ of .132 and a slightly lower ANOVA significance of $\mathrm{p}=.064$. Since this was a weaker result than the previous regression, the resulting linear equation is not reported here.

With regards to "intention" not making it into the final regression, this is not surprising since it is not growth that is being measured here. Even though a company doesn't want to grow, if it is well run, it should be able to achieve the same financial flexibility as those that want to grow.

Innovation not being part of the equation was a bit surprising. Since innovation in other empirical literature is strongly correlated with growth, it was expected that it would have some correlation with financial flexibility. Those companies that have exhibited truly innovative behaviours should have faster growth and one would expect them to find financing easier based on their track record. Innovation in this study was a self-measurement. Possibly some of the respondents overrated themselves such that the measure became useless or maybe innovation truly isn't 
required. In order to answer this question a better measurement for innovativeness needs to be developed.

The macro factor of grape grower relationship not remaining in the linear regression equation is not surprising since the wineries tended to rate their relationship with the grape growers somewhat uniformly $(\mathrm{N}=0$ for $1 / 5, \mathrm{~N}=1$ for $2 / 5$, $\mathrm{N}=6$ for $3 / 5, \mathrm{~N}=20$ for $4 / 5$ and $\mathrm{N}=18$ for $5 / 5$ ). In addition 14 wineries do not buy grapes and therefore do not have a grower relationship to measure. Does this mean that grower-winery relationship is not a factor in Ontario's VQA wine industry? The thought is that the factor is important and that the results can possibly have three explanations (or a combination of them). The three possible explanations for this result are: the factor affects all wineries equally and therefore falls out of the equation; the factor's effect is too small to be detected; or the measurement used in this study was ineffectual for determining the effect.

Lastly, in should be pointed out that since a question asking the winery's ability of getting financing was used as a proxy for truly knowing their financing structure, the results of the linear regression could have been affected by this.

In summary, the linear regression showed that size (age highly correlated with size) is a positive contributor to financial flexibility as predicted by the conceptual model and that marketing competency is negatively related to financial flexibility which is contrary to the conceptual model.

\subsubsection{Hypothesis 2}

Innovation is weakly correlated to intention to grow and size. Weak correlation means that the variance explained by using a linear regression with the factors is less 
than a factor of 2 of the variance explained by the other linear regression models. See

Figure 1: Conceptual model for growth on page 44.

The same measures for intention to grow and innovation as those used in the previous hypothesis were used in testing this hypothesis. Backwards, forwards and stepwise linear regressions (probability of $\mathrm{F}$ for removal $>=.10$, entry $<=.05$ ) were used and none resulted in any of the variables remaining in the model. As described already in the previous hypothesis, the measure of innovation used in this study was a self-assessment and possibly this caused it to not be a useful measure or maybe innovation is not a factor in the wine industry which is a dubious explanation. So this hypothesis remains unproven until a better measure of innovation is used.

\subsubsection{Summary of Conceptual Model Hypotheses and Findings}

Table 30 below presents a summary of the conceptual model hypotheses and finding which were discussed individually in the previous sections.

\begin{tabular}{|l|l|l|}
\hline Hypothesis & $\begin{array}{l}\text { Area being } \\
\text { tested }\end{array}$ & Finding \\
\hline $\begin{array}{l}\text { 1. Financial flexibility is a } \\
\text { function of intention to grow, } \\
\text { innovation, marketing } \\
\text { competency, age of winery, size } \\
\text { of winery, and the } \\
\text { macroeconomic factor of level } \\
\text { of satisfaction expressed with } \\
\text { the grape growers. Also tested } \\
\text { here is the correlation between } \\
\text { age and size. }\end{array}$ & $\begin{array}{l}\text { Conceptual } \\
\text { model }\end{array}$ & $\begin{array}{l}\text { Age and size were strongly } \\
\text { correlated .737 p }<.001 \text {. The } \\
\text { linear regression resulted in } \\
\text { financial flexibility being } \\
\text { positively correlated to size } \\
\text { and negatively correlated to } \\
\text { marketing competency. This } \\
\text { negative correlation could be } \\
\text { due to a problem with the } \\
\text { measurement indicator that } \\
\text { was used. }\end{array}$ \\
\hline $\begin{array}{l}\text { 2. Innovation is weakly } \\
\text { correlated to intention to grow } \\
\text { and size. }\end{array}$ & $\begin{array}{l}\text { The hypothesis was } \\
\text { unsupported by the date, but } \\
\text { this could be due to the } \\
\text { indicator used to measure } \\
\text { innovation. }\end{array}$ \\
\hline
\end{tabular}

Table 30: Summary of conceptual model hypotheses findings 


\subsection{The Winery and Grape Grower Dynamic}

One of the research objectives of this study was to better understand the grape grower and winery dynamic. This section presents some of the additional findings that were not covered in the initial hypotheses of the proposal yet are relevant to this general research objective.

In Table 31 below are listed some comparative statistics for the wineries and grape growers. On personal and financial satisfaction scores they are fairly close though wineries owners score better than the grape growers. Notice that both participants are unhappy with the financial aspects of the business. Now look at how each party views the relationship with the other. Wineries have a more favourable view of their relationship with the growers than the growers have with the wineries. Also notice that a much higher percentage of wineries are planning to grow though a higher percentage of those grape growers that are growing are planning on planting more grapes. Lastly, the wineries and growers that are planning on growing by planting more vines are planting roughly the same percentage.

\begin{tabular}{|l|l|l|l|}
\hline & Wineries & Grape growers & Significance \\
\hline Personal satisfaction & $3.81 / 5$ & $3.53 / 5$ & $\mathrm{p}=.182$ \\
\hline Financial satisfaction & $2.64 / 5$ & $2.35 / 5$ & $\mathrm{p}=.197$ \\
\hline Winery/grower relationship & $4.22 / 5$ & $3.66 / 5$ & $\mathrm{p}=.002$ \\
\hline \% which want to grow & $90 \%$ & $45 \%$ & $\mathrm{p}<.001$ \\
\hline \%of those growing planting grapes & $51 \%$ & $94 \%$ & $\mathrm{p}<.001$ \\
\hline \%increase of vines for those planting & $21 \%$ & $28 \%$ & $\mathrm{p}=.296$ \\
\hline
\end{tabular}

Table 31: Comparing wineries and grape growers

With this information it is now possible to calculate what percentage of vines the growers and wineries are planning on planting. Wineries are planning on increasing vines by $9.6 \%$ and the grape growers are planning on adding $11.8 \%$. A simple average of the two percentages gives the finding that the industry is planning on increasing the vine 
planting by approximately $11 \%$. With the additional information that $87 \%$ of the wineries that are planning on growing are going to increase volume by an average of $52 \%$ results in a planned volume increase of $41 \%$. Taking the numbers at face value means that there is a pending $75 \%$ shortfall in the future production of grapes. As a side note, the above calculations were also carried out taking into account the actual volumes of each winery and each grape grower and the numbers where substantively the same.

What are the reasons causing this shortfall? For the grape growers there is no real motivation to plant more grapes since it is capital intensive, there is a minimum of three to four years before revenue starts to come in, and the price of grapes and the relationship with the wineries acts as a disincentive. The wineries aren't keen to plant grapes for the same capital intensive reasons as that of the growers. This is why wineries are planning to buy the grapes from the growers but the growers won't be there. There is no compelling reason for the visions of the two industry participants to be aligned.

With the knowledge that there is a possible looming shortfall in the supply of grapes, what does this mean for Ontario's VQA wine industry? The answer to this one is more difficult. Grape prices could increase but will Ontario remain competitive in the world market? If the Ontario government allows more grape imports, the price of grapes could actually decrease with the exit of some growers from the industry. Premium and super premium ( $>\$ 15$ wines) producers might start courting the best growers to secure supply. Wineries might be forced to plant more grapes and slow their growth plans. Wineries might start changing the type and quality of wines they produce. A wild card in all of this is the potential for the Ontario government to change the rules of the game. A rule change such as changing the Wine Content Act, or changing the labelling of non-VQA wine 
could change the situation dramatically. No matter what, it appears that something has to change if Ontario's wine industry wants to achieve its growth plans.

\subsection{Conclusions}

The objectives of this research study were listed in Table 1 on page 48 . The primary objective was to answer the research question "What are the barriers to growth for Ontario's wine industry?". The other objectives were to test a conceptual model for growth, obtain two-year industry growth objectives for a potential longitudinal study and finally to explore determinants to, outcomes of and solutions to the grape grower and winery acrimony. This study was motivated by the lack of any previous empirically based business research on Ontario's wine industry. Up until now, all the business research has been done via selected case studies and interviews. Another motivating factor was the desire to help the wine industry and the government regulators in developing policies that would ensure the future success of this economically important industry. A literature survey on the theory of growth and the empirical research supporting the theory was carried out. From a growth perspective the literature survey determined there were eight kinds of barriers which affected growth. A conceptual model and hypotheses based on the determined barriers were then developed. A separate survey instrument was developed and delivered to the wineries and grape growers respectively. Seventy-nine percent of Ontario's VQA wineries participated in the study and $17.5 \%$ of the grape growers.

The data analysis determined that $90 \%$ of the wineries surveyed intend on growing versus $45 \%$ of the grape growers. This unequal growth rate between the wineries and grape growers resulted in a projected shortfall in grape supply to match the wineries' wine volume increase projections ( $41 \%$ increase in volume and only $11 \%$ increase in 
planting). Furthermore, the satisfaction of the grape grower in the winery and grape grower relationship is much lower than that of the wineries making it unlikely that the grape growers are going to increase their production unless their situation improves.

Given that there is this projected shortfall, how did it occur and are the wineries aware of it? The answer to the second question is it is doubtful that the wineries are aware of the pending shortfall. It can be argued that winery owners are poor business planners but minimally they realize that they need grapes to make wine. So the more salient question is the first. How did the industry get into this position and why don't they know about it? The research shows that some wineries have plans to plant more grapes to meet their needs but a large majority intend on buying them. The wineries must assume that the grapes will always be there to meet their needs. The wineries are overestimating the supply. Admittedly there have been short crops due to severe winter weather in the last three years (2003-2005) which has limited the grape supply but owners probably think that in a good year there will be more than enough grapes to go around. This perception results from the grape crops in years prior to 2003. As mentioned earlier, 2002 was a bumper crop year and it took until late into the fall before all the grapes where purchased. The wineries must collectively think that this will be the case when the weather allows the crops to return to their normal levels. The one thing that appears to be missing in their reasoning is that since 2002 both the number of wineries and the market for VQA wine has increased and are continuing to increase. Both of these changes will have increased the need for grapes.

Another factor that most likely contributes to this overestimation of supply is the fact that many wineries sell a portion of their grapes to other wineries. Do the wineries that 
purchase these grapes think that they will always be there? Do the wineries have contingency plans if they are no longer able to buy these grapes? It is unlikely that they do. Their plan most likely is to scramble and try to find an alternate supplier. If this research is accurate, many wineries will be doing the same thing. It is like a game of musical chairs, when the music stops playing some players will be without chairs. In the spring of 2005 a situation like this has already occurred in the industry. A winery in Niagara that sold some of their grapes to another winery for many years was purchased by an owner that would now most likely use all the grapes. It is doubtful that the winery which bought the grapes has a backup plan to replace this source of grapes.

So in summary, the wineries are most likely over estimating the supply of grapes. In looking at the possible reasons for this over estimation that are given above, it appears that the root causes are that the winery owners do not do detailed planning or market research. Detailed planning in this context means that they don't consider the numerous "what if" scenarios in their planning and develop contingency plans. The sense is that their planning beyond the straight forward planning of having the necessary equipment to make wine, hiring staff and planning to buy grapes in the fall is weak. Note that $24 \%$ of the wineries that buy grapes don't use contracts at all and the perception is that wineries that do use contracts only buy a portion of their grapes using contracts. Compounding this whole situation is the acrimonious relationship between the wineries and the grape growers. In general, the wineries don't seem to care about developing relationships with their suppliers even though they rate themselves very high on developing relationships with customers (4.4/5). Developing a healthy relationship of mutual respect and understanding with a firm's key suppliers is very important for any firm that wants to be 
successful. There is nothing to indicate that the wine industry should be different than any other industry in this respect. The data indicating the projected shortfall appears to highlight this point.

So far it appears that the wineries are not aware of the projected shortfall due to an over estimation of supply. This over estimation of supply is likely due to a lack of detailed planning and relationship building with key suppliers (grape growers). Planning and relationship building are both management competencies and it appears that Ontario's VQA wineries are weak in these skills. Furthermore when considering their low self assessment on using and performing market research as well, it calls into question the achievability of their projected growth plans. Lastly, a large proportion of Ontario wineries are owner operated rather than having professional managers. The lack of management competency putting into question their projected growth plans is consistent with the findings of Frick (2004) who found that wineries that are run by professional managers are more profitable as a result of their better management competency. It would be interesting to see in two years how many wineries achieve their growth objectives.

As a footnote to the above discussion, the argument often made by the wineries for not entering into long-term contracts with the grape growers is the financial risk in being obligated to buy grapes when a winery already has too much wine in inventory. Grape growers don't want the risk of planting more grapes without a contract. Neither side wants to take on the risk (Catch 22). A possible solution to this dilemma is a profit sharing arrangement between the grape grower and the winery so that both share in the risk. In order for this to work, the grape grower would have to have faith in the winery 
owner to be a competent manager (probably resulting in the owner opening the financial books) and the winery would have to faith in the grape grower to do all that is possible to deliver quality grapes.

Other findings from the research are the top three obstacles for wineries wanting to grow are taxes, LCBO and government regulations. The top three obstacles for grape growers are the Wine Content Act, price of grapes and the cost of land. Lastly, in testing the conceptual model it was found that the financial flexibility is positively correlated with size of the winery and negatively correlated with marketing competency. Marketing competency being negatively correlated seems contradictory, but it could be a result of the outside capital markets unwillingness to invest in the aggressive growth plans associated with those wineries that have higher levels of market competency. The capital markets may think that there is a maximum rate at which it is possible to grow a winery and it would be foolish to invest beyond this point.

In looking forward, there are numerous areas for further research. Ontario still has a grape marketing board while British Columbia (B.C.) removed theirs (at the request of the grape growers) over five years ago. In addition, the wine content and bottle labelling rules in B.C. are different than in Ontario. Do these differences make a difference? Is B.C.'s wine industry better or worse off than Ontario's? Whose wineries and grape growers are more satisfied personally and financially? Does B.C. have less grape grower/winery acrimony than Ontario? Which system gives the best future growth prospects? With respect to continuing the research started by this thesis, a longitudinal study could be carried out in two years in order to track the outcomes of the winery and grape grower growth plans and to further test the conceptual model of growth. This 
longitudinal study would also give an indication of which growth plans work best within the Ontario wine industry context. Yet another area of research would be to explore the exporting or lack of it for Ontario's wineries. Unreported in the thesis was that $60 \%$ of the wineries don't export with an average export volume for all wineries (including those that don't export) of only $4 \%$. Five percent of the wineries export over $25 \%$ of their production. It appears that some wineries have solved the exporting issue. Can the other wineries learn from their experience? It should be noted that this isn't just ice wine that is being exported. For those wineries that export, they export on average $11 \%$ of their production and they produce $7 \%$ by volume ice wine. Even assuming that they export all their ice wine, there is still $4 \%$ that is other types of wine. Furthermore when including inter-provincial trade and exporting, theses wineries sell $16 \%$ of their volume and only produce $6 \%$ is ice wine. Lastly, $90 \%$ of the wineries want to grow which is an unusually high percentage considering that on average only $50 \%$ of small businesses would like to grow. Investigating why Ontario's VQA wine industry is unique in their desire to grow is yet another avenue of research.

In summary, the objectives of this research have been met. An understanding of the barriers to growth affecting Ontario's VQA wine industry and the macro factor of winery and grape grower acrimony has been achieved. Growth plans for the industry have been captured for the future possibility of carrying out a longitudinal study and a preliminary test of the conceptual model for growth has been performed with mixed results. 


\subsection{References}

Alcohol and Gaming Commission of Ontario. List of current licensed wineries requested from their office at 1-416-326-8700.

Aldrich, H. \& Fiol, M. (1994). Fools Rush In? The Institutional Context of Industry Creation. Academy of Management Review, 19(4): 645-670.

Angulo, A., Gil, J., Gracia, A., \& Sanchez, M. (2000). Hedonic prices for Spanish red quality wine. British Food Journal, 102(7): 481-493.

BC Wine Annual Report 2002-2003, (n.d.). Retrieved on November 12, 2004 from http://www.winebc.com/pdf/BCWI\%20AR\%20Final.pdf

Burton, B. \& Jacobsen, J. (2001). The rate of return on investment in wine. Economic Inquiry, 39(3): 337-350.

Baldwin, J. (1995). Innovation: The Key to Success in Small Firms. Ottawa: Statistics Canada.

Baldwin, J., Gray, T., Johnson, J., Proctor, J., Rafiquzzaman, M., \& Sabourin, D. (1997). Failing Concerns: Business Bankruptcy in Canada. . Ottawa: Statistics Canada.

Baldwin, J., Bian, L., Dupuy, R., \& Gellatly, G. (2000). Failure Rates for New Canadian Firms: New Perspectives on Entry and Exit. Ottawa: Statistics Canada.

Benjamin, B. \& Podolny, J. (1999). Status, Quality, and Social Order in the California Wine Industry. Administrative Science Quarterly, 44(3): 563-589.

Beverland, M. (2004). Brand value, convictions, flexibility, and New Zealand wine. Business Horizons, 47(5): 53-61.

Bramble, L., Cullen, C., Kushner, J., \& Pickering, G. (2004). The Origins, Development and Economic Impact of the Wine Industry in Ontario, Canada. Paper presented at the First International Conference on the Economic History of Wine and Wine Management, University of Avignon France, March 2-4, 2004. Requested from C. Cullen.

Canada's Imports from All Countries. (n.d.). Canadian Vintners Association. Retrieved on September 15, 2004 from http://www.canadianvintners.com/canadianwines/statistics.htm

Canada's Exports to All Countries. (n.d.). Canadian Vintners Association. Retrieved on September 15, 2004 from http://www.canadianvintners.com/canadianwines/statistics.htm 
Combris, P., Lecocq, S. \& Visser, M. (2000). Estimation of a hedonic price equation for Burgundy wine. Applied Economic, 32(8): 961-967.

Corkindale, D. (1991). Establishing Marketing Management in Wine Companies. International Marketing Review, 8(4): 4-7.

Echikson, W. (2004). Noble Rot: A Bordeaux Wine Revolution. New York: W. W. Norton \& Company.

Fickling, D. (2003). Vineyards see red as seven million bottles go to waste. The Guardian Newspaper, December 11, 2003. Retrieved September 15, 2004 from http://www.guardian.co.uk/print/0,3858,4816562-110732,00.html

Frick, B. (2004). Does Ownership Matter? Empirical Evidence from the German Wine Industry. Kyklos, 57(3): 357-386.

Gellatly, G. (1999). Difference in Innovator and Non-innovator Profiles: Small Establishments in Business Services. Ottawa: Statistics Canada.

GGO Annual Report 2002. (n.d.). GGO. Retrieved on September 20, 2004 from http://www.grapegrowersofontario.com/thepress/annual report/index.html

GGO Annual Report 2003. (n.d.). GGO. Retrieved on September 20, 2004 from http://www.grapegrowersofontario.com/thepress/annual report/index.html

GGO Annual Report 2004. (n.d.). GGO. Retrieved on September 20, 2004 from http://www.grapegrowersofontario.com/thepress/annual_report/index.html

Glut sours global wine sales, January 7, 2004. Sydney Morning Herald. Retrieved on September 14, 2004 from http://www.smh.com.au/cgibin/common/popupPrintArticle.pl?path=/articles/2004/01/06/1073268033970.html

Goodhue, R., Heien, D., Lee, H., \& Sumner, D. (2003). Contracts and Quality in the California Winegrape Industry. Review of Industrial Organization, 23: 267-282.

Granovetter, M. (1985). Economic Action and Social Structure: The Problem of Embeddedness. American Journal of Sociology. 91:481-510.

Grove, A. (n.d.). Retrieved on October 15, 2004 from http://www.intel.com/pressromm/kits/bios/grove/paranoid.htm

Hannan, M. \&Freeman, J. (1977). The Population Ecology of Organizations. American Journal of Sociology 82:929-64. 
Hickton, C., \& Padmore, T. (2004). Patterns of Innovation in the Okanagan Wine-making Cluster. Paper presented at Innovation Systems Research Network Annual Meeting, Vancouver, Canada, May 13, 2004. Retrieved July 21, 2004 from http://www.utoronto.ca/isrn/documents/Patterns \%20of\%20innovation\%20Okanagan.doc

Johnson, J., Baldwin, J. \& Hinchley, C. (1997). Successful Entrants: Creating the Capacity for Survival and Growth. Ottawa: Statistics Canada.

Johnson, L., Ringham, L., \& Jurd, K. (1991). Behavioural Segmentation in the Australian Wine Market Using Conjoint Choice Analysis. International Marketing Review, 8(4): 2631 .

Kirchhoff, B. (1994). Entrepreneurship and Dynamic Capitalism. Westport, Conn.: Praeger.

Kirchhoff, B. \& Greene, P. (1995). Response to Renewed Attacks on the Small Business Job Creation Hypothesis. Retrieved July 21, 2004 from http://www.babson.edu/entrep/fer/papers95/kirchof.htm

Kor, Y. \& Mahoney, J. (2004). Edith Penrose's (1959) Contributions to the Resourcebased View of Strategic Management. Journal of Management Studies. 41(1), 183-191.

LCBO Annual Report 2003. (n.d.). Retrieved on September 20, 2004 from http://www.lcbo.com/aboutlcbo/annualreport2003.shtml

LCBO Annual Report 2004. (n.d.). Retrieved on July 20, 2005 from http://www.lcbo.com/aboutlcbo/annualreport2004.shtml

Locket, A. \& Thompson, S. (2004). Edith Penrose's Contributions to the Resource-base View: An alternative Perspective. Journal of Management Studies. 41(1), 193-203.

Lohmann, D. (1998). Strategies of High Growth Firms in Adverse Public Policy and Economic Environments. In Reynolds et al. (Ed.) (1998). Frontiers of Entrepreneurship Research 1998 (pp. 16-29). Babson Park, Massachusetts: Babson College.

Madill, J., Riding, A., \& Haines, G. (2003). "Strategic Dilemmas of a Small Market Player: The Canadian Wine Industry" in Proceedings of the International Colloquium in Wine Marketing. Adelaide, Australia; Wine Marketing Group, University of South Australia.

Mission Hill Winery (n.d.). Retrieved on November 12, 2004 from http://www.missionhillwinery.com/estate_winery/winemaker.html

Morton, F. \& Podolny, J. (2002). Love or Money? The Effects of Owner Motivation in the California Wine Industry. The Journal of Industrial Economics, L(4): 431-456. 
Mytelka, L., \& Goertzen, H. (2004). Learning, Innovation and Cluster Growth: A Study of Two Inherited Organizations in the Niagara Peninsula Wine Cluster. In D. Wolf \& M. Lucas (Ed.) (2004). Clusters in a Cold Climate: Innovation Dynamics in a Diverse Economy (pp. 43-71). Montreal \& Kingston: McGill-Queen's University Press.

Mytelka, L., \& Goertzen, H. (2003). Vision, Innovation and Identity: The Emergence of a Wine Cluster in the Niagara Peninsula. Paper presentation to the Innovation Systems Research Network conference on Innovation and Competitiveness in the New World of Wine, November 12, 2003 in Niagara-on-the-Lake, Ontario. Retrieved on October 15, 2004 from http://www.utoronto.ca/onris/Vision,Innovation_IdentityNov12.doc

Ontario Wine Content and Labelling Act, Retrieved on September 20, 2004 from http://www.e-laws.gov.on.ca/DBLaws/Regs/English/000659_e.htm

Orser, B., \& Hogarth-Scott, S. (2002). Opting for Growth: Gender Dimensions of Choosing Enterprise Development. Canadian Journal of Administrative Sciences, 19(3), 284-300.

Orser, B., \& Riding, A. (2003). Management Competencies and SME Performance Criteria: A Pilot Study. Paper submitted to the Small Business Policy Branch, Industry Canada.

Penrose, E. 1995 (1959). The Theory of the Growth of the Firm. Oxford: Oxford University Press.

Porter, M. (1998). On Competition. Boston: Harvard Business School Publishing.

Prial, F. (2004). Much of Bordeaux Goes Begging. The New York Times, August 11, 2004. Retrieved September 14, 2004 from

http://www.nytimes.com/2004/08/1 1/dining/11BORD.html?ex=1095307200\&en=0ff7d2 634b642ec\&ei $=5070$

Quinton, S. \& Harridge-March, S. (2003). Strategic interactive marketing of wine - a case of evolution. Marketing Intelligence \& Planning, 21(6): 357-362.

Rumball, D. (2000). The Six Stages of Growth in Leading Growth Firms. Research paper written for the Ontario Ministry of Economic Development \& Trade.

Rugman, A. \& Verbeke, A. (2002). Edith Penrose's Contribution to the Resource-based View of Strategic Management. Strategic Management Journal, 23, 769-780.

Rugman, A. \& Verbeke, A. (2004). A Final Word on Edith Penrose. Journal of Management Studies. 41(1), 205-217. 
Sara, C. (1998). Portfolio Entrepreneurship in the Farm Sector: Indigenous Growth in Rural Areas. Entrepreneurship and Regional Development. 10(1), 17-32.

Schumpeter, J. 1954 (1942). Capitalism, Socialism. and Democracy. London: G. Allan \& Unwin.

Shane, S. (1998). New Firm Survival: Institutional Explanations for New Franchisor Mortality. In Reynolds et al. (Ed.) (1998). Frontiers of Entrepreneurship Research 1998 (pp. 1-15). Babson Park, Massachusetts: Babson College.

Spawton, T. (1989). Marketing Planning and Communications for Small Winemakers. International Marketing Review, 6(2): 5-13.

Telfer, D. (2001). Strategic alliances along the Niagara Wine Route. Tourism Management. 22(1), 21-30.

The Canadian Wine Industry. (n.d.). Agriculture and Agri-Food Canada. Retrieved on September 14, 2004 from http://www.agr.gc.ca/misb/fb-ba/index e.php?s1=proctrans\&s2=prof\&page $=$ wine-vin

The Year in Review. (n.d.). Wine Council of Ontario. Retrieved September 20, 2004. from http://www.winesofontario.org/html/strategy.html

Thornhill, S. \& Amit, R. (2003). Learning from failure: Organizational mortality and the resource-based view. Ottawa: Statistics Canada.

Total Wine Sales by Province for 1995 to 2002, Domestic vs. Import (in Litres). (n.d.). Canadian Vintners Association. Retrieved on September 15, 2004 from http://www.canadianvintners.com/canadianwines/statistics.htm

Vincor Annual Report 2004. (n.d.). Vincor International. Retrieved September 20, 2004 from http://www.vincorinternational.com/basemodule/level0.cfm? mainID $=2 \&$ depth $=2 \&$ main Nav $=10$ 


\section{Appendix A Grape Grower Questionnaire}

\section{\begin{tabular}{|l|l|}
\hline SECTION A & Information about the Grape Grower \\
\hline
\end{tabular}}

A1. How many years have you been a grape grower?

A2. How many acres of grapes do you have?

A3. Please allocate on a percentage basis the grape types which you have:

\section{Vinifera:}

Hybrid:

Labrusca:

A4. What is the average age of your vines?

Vinifera:

Hybrid:

A5. How many different varietals do you have in each category?

Vinifera:

Hybrid:

A6. Are you a winery as well? YES NO

A7. If you answered YES to the previous question (A6), what percentage of your grapes do you keep for your winery?

If you answered NO to question A6 or less than $100 \%$ to question $A 7$ and you sell grapes to wineries, continue to Section B, otherwise skip to Section C

\section{\begin{tabular}{|l|l|}
\hline SECTION B & Information about Grape Supply \\
\hline
\end{tabular}}

B1. On average how many different wineries do you sell your grapes to?

B2. Do you have any pre-negotiated contracts with the wineries for your grapes? YES NO

If your answer to question B2 was NO, skip to question B6.

B3. Do the contracts last more than one year? YES NO SOMETIMES 
B4. Do the contracts specify viticulture techniques which you are to follow?

$$
\text { YES NO SOMETIMES }
$$

B5. If YES or SOMETIMES to B4, are you paid a premium (above GGO rates) for following the specified viticulture techniques? YES NO SOMETIMES

B6. In general how successful is your relationship (financial, interpersonal) with the wineries? Please answer on a scale of 1 to 5 where $1=$ not at all successful $5=$ extremely successful:

$$
\begin{array}{lllll}
1 & 2 & 3 & 4 & 5
\end{array}
$$

\section{\begin{tabular}{|l|l|}
\hline SECTION C & Growth \\
\hline
\end{tabular}}

C1. During the next two years, is it your intention to expand your grape growing business? Expand can mean buying/planting more land with grapes, becoming a winery (assuming you are not already a winery), or changing the types of varietals.

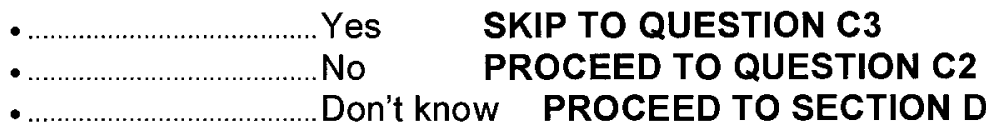

C2. ONLY FOR THOSE WHO RESPOND 'NO' TO C1. How important is each of the following factors as a reason for your intention not to expand? Please answer on a scale of 1 to 5 where $1=$ not at all a reason $5=$ an extremely important reason.

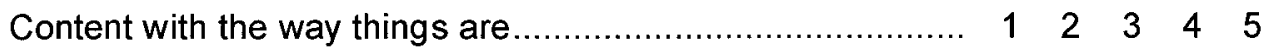

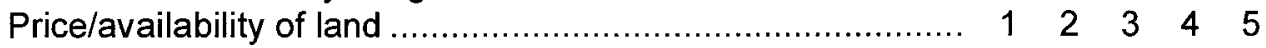

Market not growing .................................................... 1

Price of grapes......................................................... $14 \begin{array}{lllll}2 & 2 & 3 & 4 & 5\end{array}$

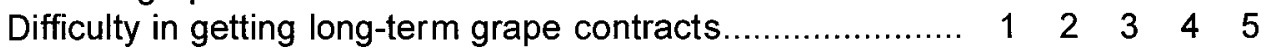

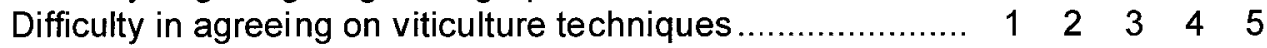

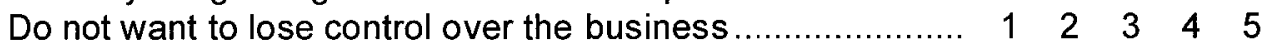

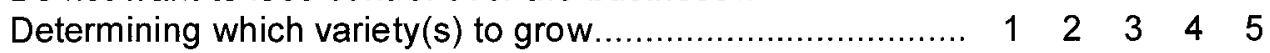

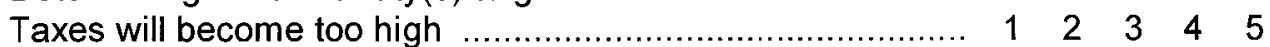

Lack of growth capital ................................................ $14 \begin{array}{lllll}2 & 2 & 3 & 4 & 5\end{array}$

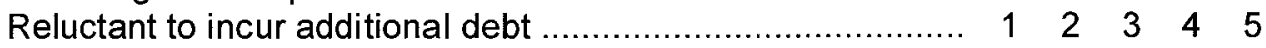

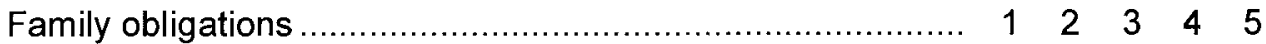

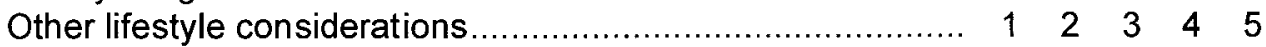

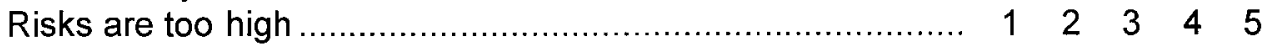

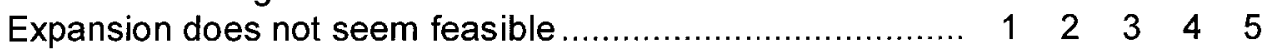

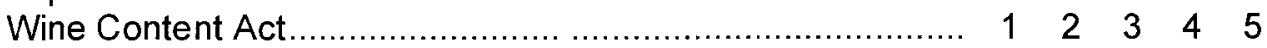

Are there any other significant obstacles to growth that aren't listed here?: 
C3. FOR THOSE WHO RESPONDED 'YES' TO C1. In what respects do you plan to expand your business over the next two years?

\begin{tabular}{|c|c|c|}
\hline Become a winery (if not one already) & 0 & \\
\hline $\begin{array}{l}\text { Increase Assets (equipment, land, } \\
\text { buildings) }\end{array}$ & $\mathrm{O}$ & \\
\hline Plant more grapes & $\mathrm{O}$ & By what \%- \\
\hline Switching grape varieties or clones & $\mathrm{O}$ & \\
\hline Buying other grape growers & $\mathrm{O}$ & \\
\hline Other & $\mathrm{O}$ & \\
\hline
\end{tabular}

If you selected "other", could you please list what other is?

C4. In seeking to expand your business, what would you say are the biggest obstacles to the growth or development? To answer, please rate each of the following potential obstacles on a 5-point scale where $1=$ not at all an obstacle to growth and $5=$ a significant obstacle to growth

Finding qualified labour

$\begin{array}{llll}2 & 3 & 4 & 5\end{array}$

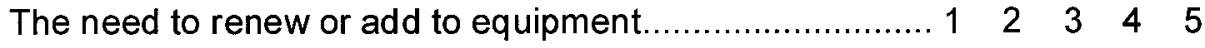

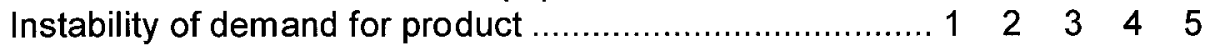

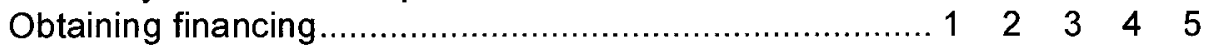

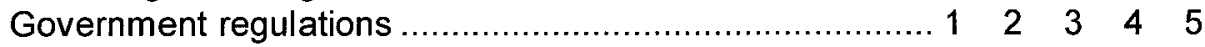

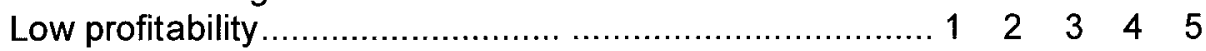

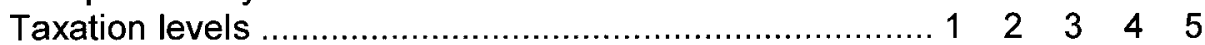

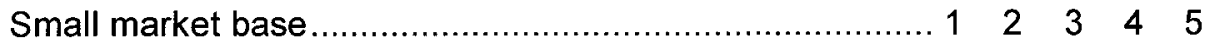

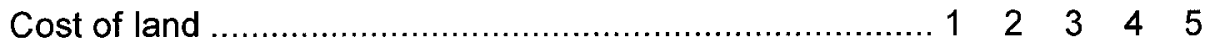

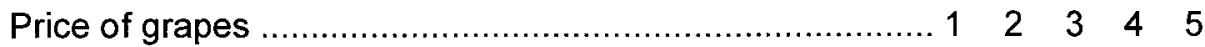

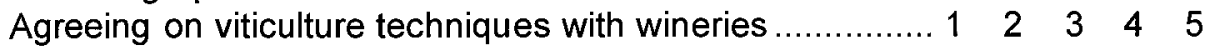

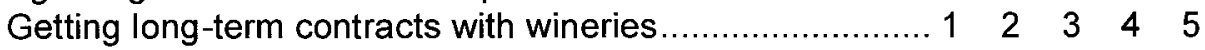

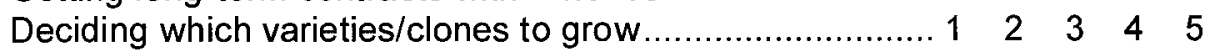

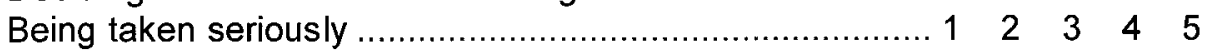

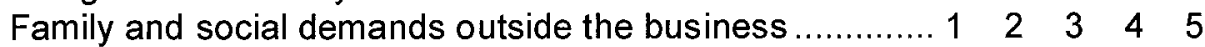

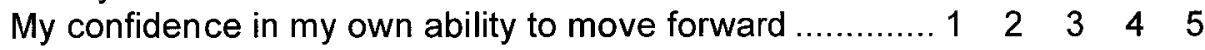

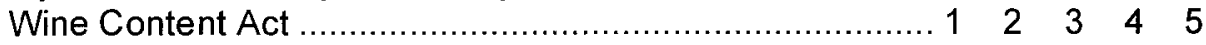

If becoming a winery:

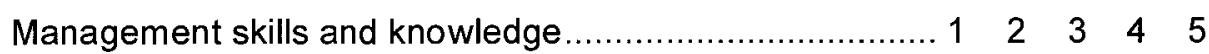

Working with the LCBO ............................................ 1 2 2

Winery license doesn't allow use of foreign content.......... 1 1 $20 \begin{array}{llll}3 & 4 & 5\end{array}$

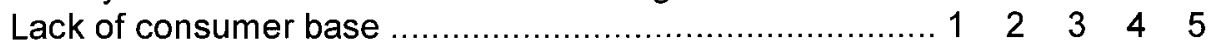

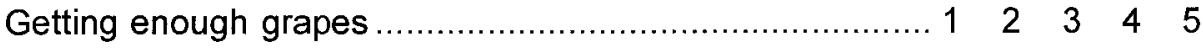


C5. Again using a five-point scale, how important are each of the following as elements in your strategy towards accomplishment of your growth goals $(1=$ not at all important; $5=$ extremely important)?

\begin{tabular}{|c|c|c|c|}
\hline Adding/changing varietals & 2 & & \\
\hline Improving existing quality. & 2 & 3 & 4 \\
\hline Planting more vinifera....... & 2 & 3 & 4 \\
\hline Planting more hybrids... & 2 & 3 & 4 \\
\hline Increasing grapes for icewine production .................... & 2 & 3 & 4 \\
\hline Becoming a winery if not one already ....................... & 2 & 3 & 4 \\
\hline Changing viticulture practises .............. & 2 & 3 & 4 \\
\hline Selling to different/more wineries in Ontario ........... & 2 & 3 & 4 \\
\hline Obtaining longer term contract for the grapes ..... & 2 & 3 & 4 \\
\hline 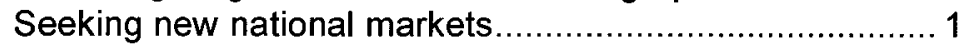 & 2 & 3 & \\
\hline Seeking new international markets & 2 & 3 & 4 \\
\hline 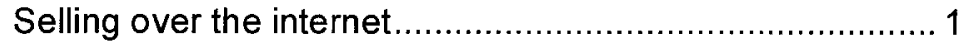 & 2 & 3 & 4 \\
\hline Adding new equipment ...... & 2 & 3 & 4 \\
\hline Upgrading operations ....... & 2 & 3 & 4 \\
\hline ing financing advice & 2 & 3 & 4 \\
\hline Seeking professional advice ................................... 1 & 2 & 3 & 4 \\
\hline 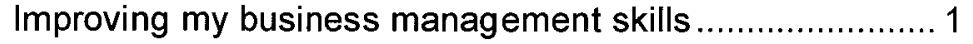 & 2 & 3 & \\
\hline Adding a new viticulture innovation & 2 & 3 & \\
\hline Adding innovative plant stock (clones, rootstock, etc) ....... 1 & 2 & 3 & \\
\hline
\end{tabular}

C6. Are there any other significant obstacles or strategies with respect to your growth objectives that I haven't mentioned?

\begin{tabular}{|l|l|}
\hline SECTION D & Information about the Business \\
\hline
\end{tabular}

D1. Are the proceeds from grape growing your primary source of income? YES NO

D2. What percentage of your crop is mechanically harvested? 
For the following five questions, please answer on a scale of 1 to 5 where $1=$ strongly disagree $5=$ strongly agree:

D3. You're able to get money to finance the growth you seek?

$$
\begin{array}{lllll}
1 & 2 & 3 & 4 & 5
\end{array}
$$

D4. Are your viticulture techniques innovative relative to other grape growers?

$$
\begin{array}{lllll}
1 & 2 & 3 & 4 & 5
\end{array}
$$

D5. Is the plant stock (clones, rootstock, etc.) that you use innovative relative to other grape growers?

$$
\begin{array}{lllll}
1 & 2 & 3 & 4 & 5
\end{array}
$$

D6. In general how satisfied are you personally with grape growing? Please answer on a scale of 1 to 5 where $1=$ not at all satisfied $5=$ extremely satisfied:

$$
\begin{array}{lllll}
1 & 2 & 3 & 4 & 5
\end{array}
$$

D7. In general how satisfied financially are you with grape growing? Please answer on a scale of 1 to 5 where $1=$ not at all satisfied $5=$ extremely satisfied:
$\begin{array}{lllll}1 & 2 & 3 & 4 & 5\end{array}$

Thank-you for completing this survey. 
Would you like to obtain information about our survey results? YES NO

Please fill in the address you would like us to use since we don't have this information.

Mailing Address:

E-mail: @

(To ensure confidentiality, the above information will not be included in the survey data file). 


\section{Appendix B Winery Questionnaire}

\section{\begin{tabular}{l|l}
\hline SECTION A & Information about the Winery
\end{tabular}}

A1. What year did the winery receive its license?

A2. How many cases of wine are you planning to produce for 2004 ?

A3. Is the winery on land affected by the Niagara Escarpment Commission? YES NO

A4. On average, excluding yourself, how many full-time employees worked all year for your winery? Full-time employees are considered those who work 30 hours/week or more.

A5. On average, excluding yourse lf, how many part-time employees (not counting casual farm labour) worked for your winery during the year? Part-time employees are considered those who work less than 30 hours/week.

\section{\begin{tabular}{|l|l|}
\hline SECTION B & Information about Grape Supply \\
\hline
\end{tabular}}

B1. What percentage of wine is produced with winery grown grapes?

\section{If the answer to question B1 was $100 \%$, skip to question B9.}

B2. Please allocate on a percentage basis (based on $750 \mathrm{ml}$ ) how much of the winery grown grapes are used at each of the following price points?

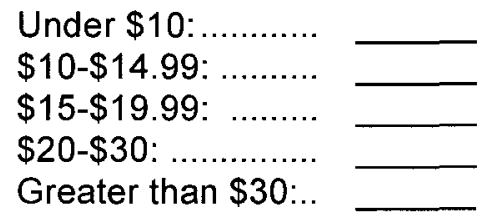

B3. On average, how many different grape growers do you buy your grapes from each year?

B4. Do you have pre-negotiated contracts with your grape growers? YES NO

\section{If your answer to question B4 was NO, skip to question B8.}

B5. Do the contracts last more than one year? YES NO

B6. Do the contracts specify viticulture techniques which the grape growers are to follow? YES NO

B7. If YES to B6, then do you pay a premium (above GGO rates) to the grape growers who follow the specified viticulture techniques? YES NO SOMETIMES 
B8. In general how successful is your relationship (financial, product quality, interpersonal) with your individual grape growers? Please answer on a scale of 1 to 5 where $1=$ not at all successful $5=$ extremely successful:

$$
\begin{array}{lllll}
1 & 2 & 3 & 4 & 5
\end{array}
$$

B9. What percentage of the grapes grown by the winery is sold to other wineries?

\section{\begin{tabular}{|l|l|}
\hline SECTION C & Growth \\
\hline
\end{tabular}}

C1. During the next two years, is it your intention to expand your winery? Expand can mean increasing the number of cases produced, hiring more employees, planting more grapes, buying more equipment, adding/expanding restaurant/accommodation, or increasing the quality of the wine and therefore increasing the price points of the wines produced.

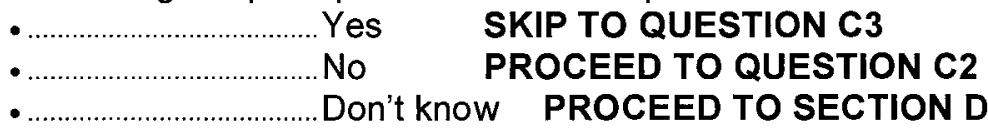

C2. ONLY FOR THOSE WHO RESPOND 'NO' TO C1. How important is each of the following factors as a reason for your intention not to expand? Please answer on a scale of 1 to 5 where $1=$ not at all a reason $5=$ an extremely important reason.

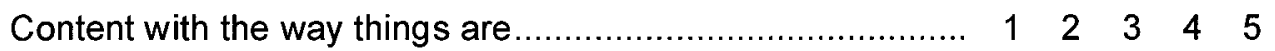

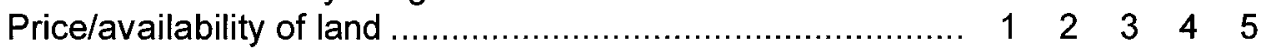

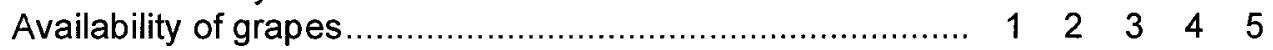

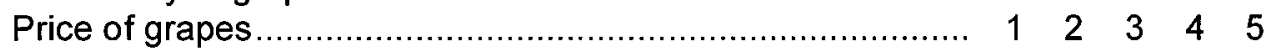

Quality of grapes............................................ $14 \begin{array}{lllll}2 & 3 & 4 & 5\end{array}$

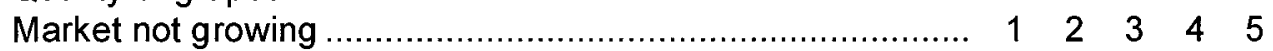

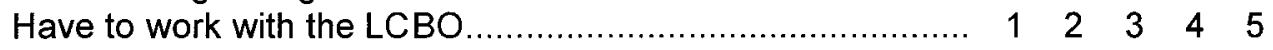

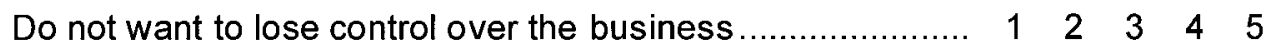

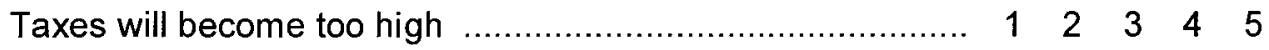

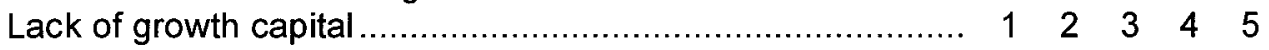

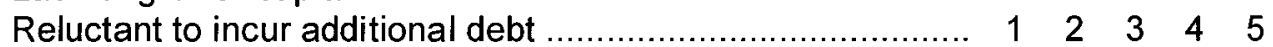

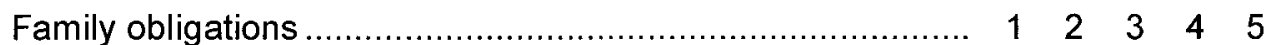

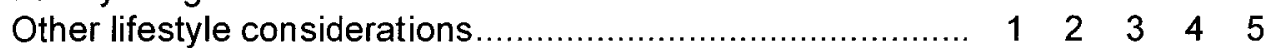

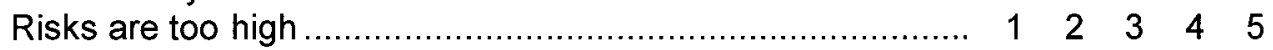

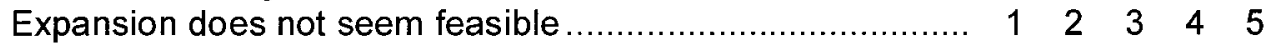

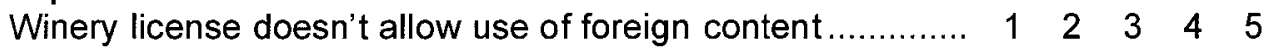

Are there any other significant obstacles to growth that aren't listed here?: 
C3. FOR THOSE WHO RESPONDED 'YES' TO C1. In what respects do you plan to expand your business over the next two years?

\begin{tabular}{|c|c|c|}
\hline Increase \# cases produced & 0 & By what \% \\
\hline Increase Staff & 0 & \\
\hline $\begin{array}{l}\text { Increase Assets (equipment \& } \\
\text { buildings) }\end{array}$ & O & \\
\hline Expand or add restaurant & $\mathrm{O}$ & \\
\hline Expand or add accommodation & $\mathrm{O}$ & \\
\hline Increase quality \& price point of wine & 0 & \\
\hline Plant more grapes & $\mathrm{O}$ & By what \%- \\
\hline Buying other wineries & 0 & \\
\hline Other & $\mathrm{O}$ & \\
\hline
\end{tabular}

If you selected "other", could you please list what other is?

C4. In seeking to expand your winery, what would you say are the biggest obstacles to the growth or development? To answer, please rate each of the following potential obstacles on a 5-point scale where $1=$ not at all an obstacle to growth and $5=$ a significant obstacle to growth

\begin{tabular}{|c|c|c|c|}
\hline inding qualified labour .. & 2 & & \\
\hline The need to renew or add to equipment ............ & 2 & 3 & \\
\hline Instability of demand for product $\ldots \ldots \ldots \ldots \ldots \ldots \ldots \ldots \ldots \ldots \ldots$ & 2 & 3 & 4 \\
\hline Obtaining financing & 2 & 3 & 4 \\
\hline Government regulations .. & 2 & 3 & 4 \\
\hline Government paperwork burden.... & 2 & 3 & \\
\hline Management skills, knowledge, business acumen of the & & & \\
\hline 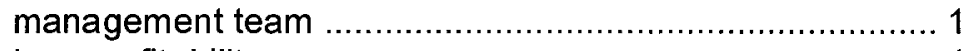 & 2 & 3 & \\
\hline Low profitability & 2 & 3 & \\
\hline Taxation levels .. & 2 & 3 & 4 \\
\hline Lack of consumer awareness.... & 2 & 3 & 4 \\
\hline Small market base ...................... & 2 & 3 & 4 \\
\hline nough grapes ... & 2 & 3 & 4 \\
\hline grapes ............ & 2 & 3 & 4 \\
\hline land ......... & 2 & 3 & 4 \\
\hline Working with the LCBO... & 2 & 3 & \\
\hline Being taken seriously & 2 & 3 & \\
\hline Winery license doesn't allow use of foreign content.......... 1 & 2 & 3 & 4 \\
\hline Family and social demands outside the business ............. 1 & 2 & 3 & \\
\hline My confidence in my own ability to move forward.. & 2 & 3 & \\
\hline arketing ....... & 2 & & \\
\hline
\end{tabular}


C5. Again using a five-point scale, how important are each of the following as elements in your strategy towards accomplishment of your growth goals $(1=$ not at all important; $5=$ extremely important)?

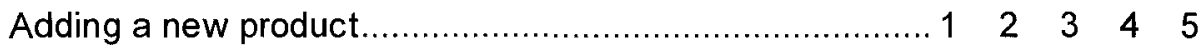

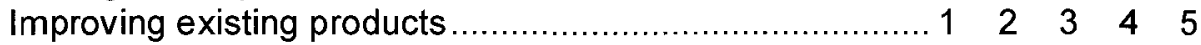

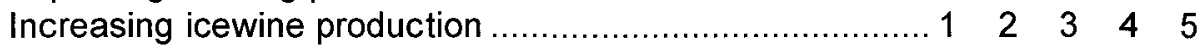

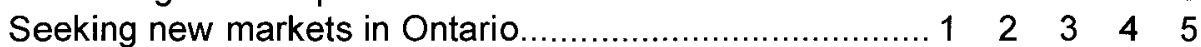

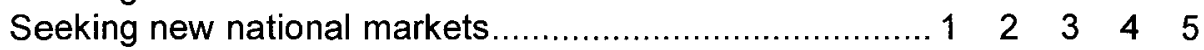

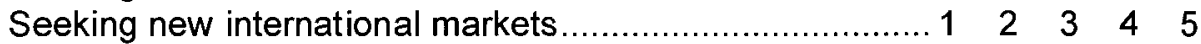

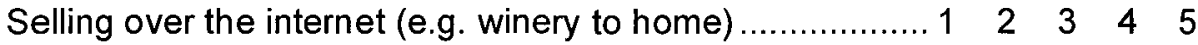

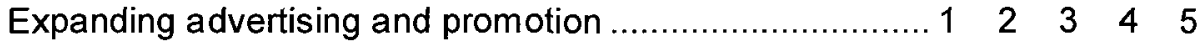

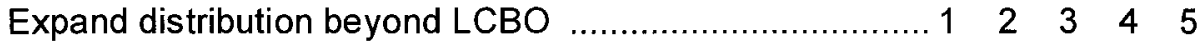

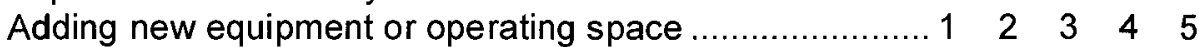

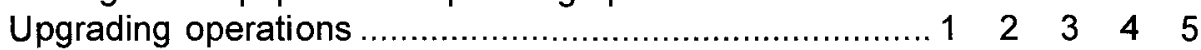

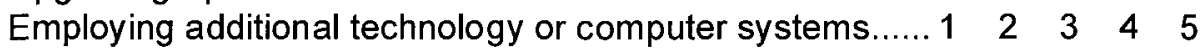

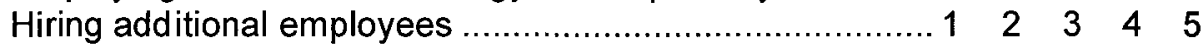

Seeking financing advice.............................................. 1 (2)

Seeking professional advice ............................................. 1 (2)

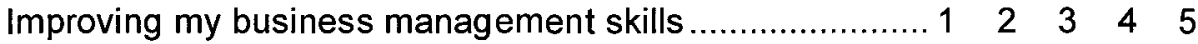

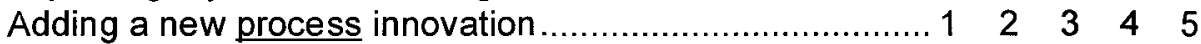

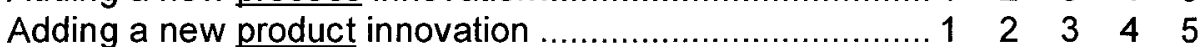

C6. Are there any other significant obstacles or strategies with respect to your growth objectives that I haven't mentioned?

\section{\begin{tabular}{|l|l|}
\hline SECTION D & Information about the Business
\end{tabular}}

D1. Please allocate on a percentage basis (based on $750 \mathrm{ml}$ bottles) how much of your wine retails at each of the following price points:

Under $\$ 10$

$\$ 10-\$ 14.99$

\$15-\$19.99:

$\$ 20-\$ 30$ :

Greater than $\$ 30:$.

D2. Please allocate on a percentage basis (based on volume) how much of your wine is sold through each of the following channels:

Winery retail store:
LCBO: ..................
Licensees: ...........
Winery to home.....
Other:.................
If you selected "other", could you please list what other is?

D3. What percentage of the winery's production by volume is icewine? 
D4. What percentage by volume do you sell in other provinces?

D5. What percentage by volume do you export outside Canada?

The next few questions are about how much experience you have in some aspects of the business. For each question I would like you to indicate your level of experience using a five point scale, where 1 means you have limited or no experience and 5 means you have extensive experience. If any of the experience criteria are "not applicable" to you or the winery, please say so.

Limited or no

Extensive Experience NA

Experience

D6. Pricing goods or services.

$\begin{array}{llllll}1 & 2 & 3 & 4 & 5 & 6 \\ 1 & 2 & 3 & 4 & 5 & 6 \\ 1 & 2 & 3 & 4 & 5 & 6\end{array}$

D8. Developing and commercializing a new product or service idea or concept.

D9. Using market research for competitive analysis, testing new services or products or estimating demand.

D10. Promotion and advertising.

D11. How many years have you been in the wine business?

D12. Are proceeds from the winery your primary source of income? YES NO

For the following five questions, please answer on a scale of 1 to 5 where $1=$ strongly disagree $5=$ strongly agree:

D13. The winery is able to get money to finance the growth it seeks? $\begin{array}{lllll}1 & 2 & 3 & 4\end{array}$ 5

$\begin{array}{llllll}\text { D14. Are your products innovative relative to other Niagara wineries? } & 1 & 2 & 3 & 4\end{array}$ 5

D15. Are your processes innovative relative to other Niagara wineries? $1 \quad \begin{array}{llll}2 & 3 & 4\end{array}$ 5

D16. I am satisfied personally with the winery? $\begin{array}{lllll}1 & 2 & 3 & 4 & 5\end{array}$

D17. I am satisfied financially with the winery?

$\begin{array}{lllll}1 & 2 & 3 & 4 & 5\end{array}$

Thank-you for completing this survey. 
Would you like to obtain information about our survey results?

YES NO

Can we forward this information to your business address?

YES NO

If no, where would you like the survey information sent?

Mailing Address:

E-mail: $@$

(To ensure confidentiality, the above information will not be included in the survey data file). 